Florida International University

FIU Digital Commons

9-25-2019

\title{
The Genetics of Olfactory and Visually Guided Attractive Behaviors in Aedes aegypti Mosquito
}

Joshua Ibukun Raji

jraji001@fiu.edu

Follow this and additional works at: https://digitalcommons.fiu.edu/etd

Part of the Behavioral Neurobiology Commons, Biology Commons, and the Genetics Commons

\section{Recommended Citation}

Raji, Joshua Ibukun, "The Genetics of Olfactory and Visually Guided Attractive Behaviors in Aedes aegypti Mosquito" (2019). FIU Electronic Theses and Dissertations. 4356.

https://digitalcommons.fiu.edu/etd/4356

This work is brought to you for free and open access by the University Graduate School at FIU Digital Commons. It has been accepted for inclusion in FIU Electronic Theses and Dissertations by an authorized administrator of FIU Digital Commons. For more information, please contact dcc@fiu.edu. 


\section{FLORIDA INTERNATIONAL UNIVERSITY}

Miami, Florida

\section{THE GENETICS OF OLFACTORY AND VISUALLY GUIDED ATTRACTIVE BEHAVIORS IN AEDES AEGYPTI MOSQUITO}

A dissertation submitted in partial fulfillment of

the requirements for the degree of

DOCTOR OF PHILOSOPHY

in

BIOLOGY

by

Joshua Ibukun Raji

2019 
To: Dean Michael R. Heithaus

College of Arts, Sciences, and Education

This dissertation, written by Joshua Ibukun Raji, and entitled The Genetics of Olfactory and Visually Guided Attractive Behaviors in Aedes aegypti Mosquito, having been approved in respect to style and intellectual content, is referred to you for judgment.

We have read this dissertation and recommend that it be approved.

Aaron Mattfeld

Fernando G. Noriega

Jamie Theobald

Mauricio Rodriguez-Lanetty

Matthew DeGennaro, Major Professor

Date of Defense: September 25, 2019

The dissertation of Joshua Ibukun Raji is approved.

Dean Michael R. Heithaus

College of Arts, Sciences and Education

Andrés G. Gil

Vice President for Research and Economic Development and Dean of the University Graduate School

Florida International University, 2019 


\section{DEDICATION}

This dissertation is dedicated to my best friend and wife, Esther. Your soothing words of encouragement, inspiration and emotional support got me through the rigor of the doctoral program. I also dedicate this dissertation to my loving parents, Chief and Mrs. Raji. Your prayers and good wishes paid off in my excellence and accomplishments during the program. 


\section{ACKNOWLEDGMENTS}

I owe a debt of gratitude to my major advisor, Dr. Matthew DeGennaro for inspiring me to go farther than I ever thought I could. I appreciate the training and mentorship that brought out the best in me. This dissertation is obviously impossible without you. I am eternally grateful to you for giving me the IR8a project. It is hard to imagine my life if I had a different project. I may be remembered as the first Ph.D. student you graduated, but I will never forget the mentor who placed me on the media spotlight and made me famous. My gratitude goes to all the past and present members of DeGennaro lab who have been very supportive through the journey. Although I may be six thousand miles away from home, I found solace in DeGennaro lab as my second home. I would be remiss if I do not appreciate Dr. Jamie Theobald and his lab members for their immense support while completing my research questions in their lab.

My special appreciation goes to my committee members, Dr. Fernando Noriega, Dr. Jamie Theobald, Dr. Aaron Mattfeld, and Dr. Mauricio Rodriguez-Lanetty for their advice and regular tracking of my progress. I want to thank Dr. Noriega and Dr. Theobald for always available to write me recommendation letters whenever I call on them. I appreciate you all for being so supportive despite your very busy schedule.

Lastly, I am thankful to the funding agencies that supported this study. The National Institutes of Health under Award Number K22AI112585 and CDC Southeastern Center of Excellence in Vector-borne Disease supported this work. I am grateful to FIUUGS for the Dissertation Year Fellowship, and Florida Mosquito Control Association for the T.Wainwright Miller scholarship. 


\section{ABSTRACT OF THE DISSERTATION \\ THE GENETICS OF OLFACTORY AND VISUALLY GUIDED ATTRACTIVE \\ BEHAVIORS IN AEDES AEGYPTI MOSQUITO}

by

Joshua Ibukun Raji

Florida International University, 2019

Miami, Florida

\section{Professor Matthew DeGennaro, Major Professor}

Mosquitoes detect the presence of humans by integrating chemosensory, thermal, and visual cues. Among these, odors are crucial for mosquito host detection. Insects have evolved a diverse repertoire of receptors to detect their plant and animal hosts. Genetic analysis of these receptors in Drosophila has set the stage for similar studies in mosquitoes. The diversity of the cues involved in mosquito host-seeking has made designing behavioral control strategies a challenge. The sensory receptors that are most important for mosquito detection of humans can now be determined using genome editing. In this study, we uncovered the behavioral genetics of the IR8a pathway by disrupting the IR8a co-receptor in Aedes aegypti using CRISPR/Cas9. The Ir8a mutant female mosquitoes are not attracted to lactic acid, a behaviorally active component of human odor, and lack odor-evoked responses to acidic volatiles. The loss of $\operatorname{Ir} 8 a$ reduces mosquito attraction to humans and their odor. We show that the $\mathrm{CO}_{2}$-detection pathway is necessary but not sufficient for IR8a to detect human odor. This study also implicates the IR8a chemosensory pathway in mosquito water seeking behavior. Female Ae. aegypti mutant mosquitoes with disrupted IR8a pathway show increased attraction to standing 
water, a crucial resource for survival. The strong attraction to water is not mediated by a metabolic need or an activity defect. We hypothesized that Ir8a could be part of a neural circuit that represses water sensing. In addition, we also provide evidence that $\mathrm{CO}_{2}$ sensitization is crucial for yellow fever mosquitoes to track a moving object and describe differences in their visual acuity when compared to Drosophila. The $\mathrm{CO}_{2}$-insensitive mutant female mosquitoes exhibit impaired object tracking behavior and cannot associate $\mathrm{CO}_{2}$ with visual cues. Similarly, $\mathrm{CO}_{2}$ elicits increased attention to visual cues in fruit flies. Taken together, this dissertation provides the first comprehensive evidence that the Ae. aegypti IR8a pathway mediates attractive behavior to human hosts. It also suggests that the pathway may indirectly regulate attraction to water sources. The $\mathrm{CO}_{2}$-sensing pathway integrates with the visual system to guide attractive behavior in Ae. aegypti mosquitoes. Understanding the molecular targets that drive attractive behavior will provide insights to generate new behavioral control reagents. 


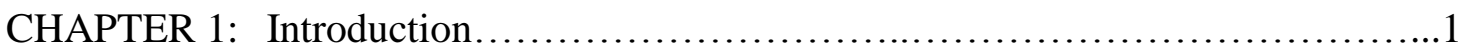

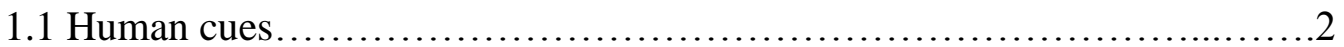

1.2 Multimodal integration of human cues.................................

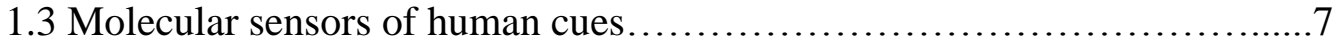

1.4 Behavioral vector control strategies.................................... 8

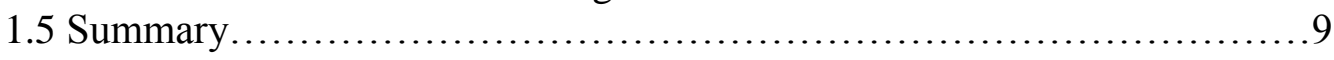

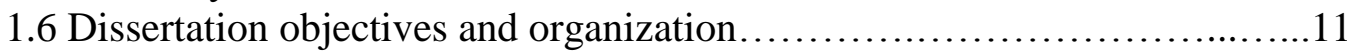

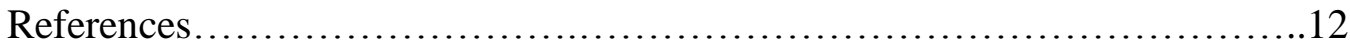

CHAPTER 2: Aedes aegypti mosquitoes detect acidic volatiles found in human odor using the IR8a pathway ........................17

2.1 Abstract.................................................................. 17

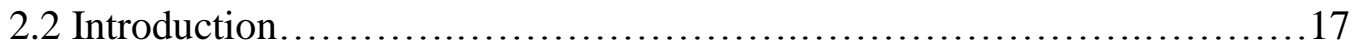

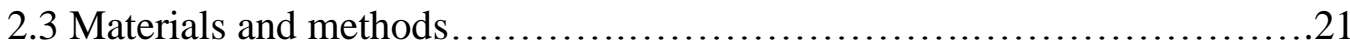

2.3.1 Experimental model and subject details........................21

2.3.2 CRISPR/Cas9 nuclease reagents.............................22

2.3.3. Ir $8 a^{d S R E D}$ and $\operatorname{Ir} 8 a^{\text {attP }}$ mutant allele generation and detection......24

2.3.4 Ir $8 a$ mRNA extraction and treatment.............................27

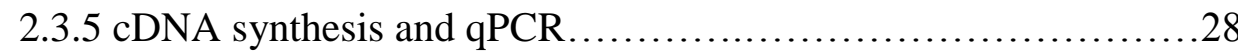

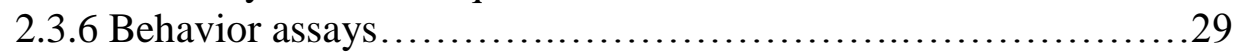

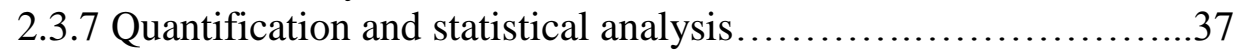

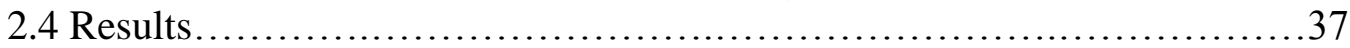

2.4.1 Targeted mutagenesis of Ae. aegypti Ir8a, an antenna specific ionotropic receptor........................... 37

2.4.2 IR8a pathway is required for sensing and responding behaviorally to acidic volatiles......................43

2.4.3. Ae. aegypti IR8a pathway responds to human odor cues during blood-feeding.

2.4.4 Ae. aegypti IR8a pathway is required to detect humans and human odor....................................52

$2.4 .5 \mathrm{CO}_{2}$ differentially modulates the IR8a and Orco pathways.........53

2.4.6 The loss of $G r 3$ enhances the Ir8a-dependent host-seeking defect........................................57

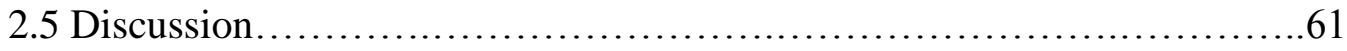

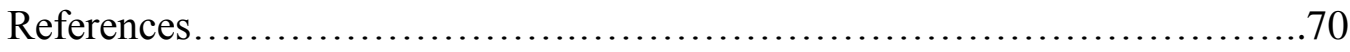


CHAPTER 3: Aedes aegypti Ir8a mutant female mosquitoes show increased attraction to standing water............................ 78

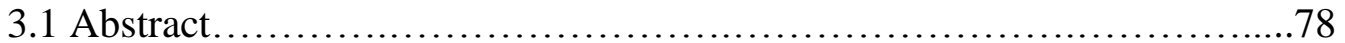

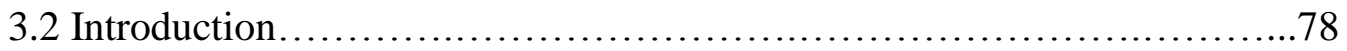

3.3 Methods and Results............................................... 80

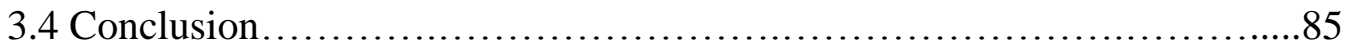

References.......................................................... 86

CHAPTER 4: Carbon dioxide mediates increased visual attention in tethered Aedes aegypti and Drosophila melanogaster.......................86

4.1 Abstract............................................................. 88

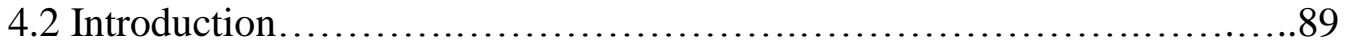

4.3 Materials and Methods................................................. 91

4.4 Results and Discussions.............................................. 94

References.................................................... 102

CHAPTER 5: Conclusions and Future Directions............................... 105

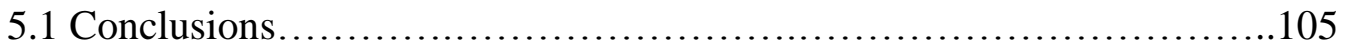

5.2 Genetic pathways for mosquito host seeking....................... 107

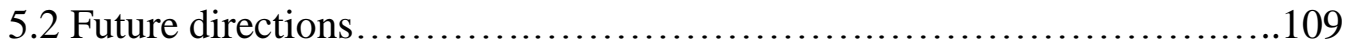

References....................................................... 112

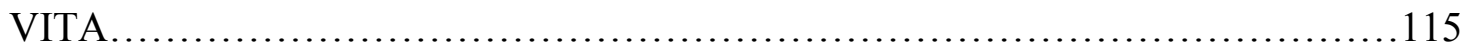




\section{LIST OF FIGURES}

FIGURE

PAGE

1. Olfaction enables mosquitoes to detect human hosts.......................5

2. Designing novel mosquito attractants and repellents ..................... 10

3. Mutagenesis of the Ae. aegypti Ir8a locus, and behavioral phenotypic analysis of $\operatorname{Ir} 8 a$ mutant response to lactic acid.

4. IR8a olfactory receptor pathway is required for sensing acidic volatiles that are component of human odor.

5. Ae. aegypti IR8a pathway responds to human odor cues

during blood-feeding.

6. Ae. aegypti IR8a pathway is required to detect humans and human odor.......55

7. The loss of $G r 3$ enhances the $I r 8 a$-dependent host-seeking defect...........59

8. Material designs for the water trap assay.............................. 81

9. Ir $8 a$ mutant female mosquitoes are more attracted to water. ..................82

10. Ir8a mutant female mosquitoes feed normally on water and sugar, and show normal activity.

11. An arena for simultaneous delivery of visual and olfactory stimuli.

12. Carbon dioxide increases attention to visual cues in Ae. aegypti and D. melanogaster.

13. Carbon dioxide enhances sensitivity to visual contrast in Ae. aegypti and D. melanogaster.

14. Model illustrating the genetic interactions between the olfactory receptor pathways during mosquito host detection. 


\section{LIST OF ABBREVIATIONS AND ACRONYMS}

\begin{tabular}{ll} 
CAFE & Capillary feeder \\
$\mathrm{CO}_{2}$ & Carbon dioxide \\
CRISPR & Clustered Regularly Interspaced Short Palindromic Repeats \\
DEET & N, N-Diethyl-meta-toluamide \\
EAG & Electroantennography \\
Grs & Gustatory Receptors \\
IRs & Ionotropic Receptors \\
LH & Lateral horn \\
MB & Mushroom body \\
OBPs & Odorant-binding proteins \\
ORCO & Olfactory receptor co-receptor \\
ORN & Olfactory receptor neuron \\
ORs & Odorant receptor \\
PNs & Projection neurons \\
qPCR & Quantitative Polymerase Chain Reaction \\
SEZ & Suboesophageal zone \\
ssODN & Single stranded oligo nucleotide \\
TALENs & Transcription Activator-Like Effector Nucleases \\
TRPAl & Transient Receptor Potential Cation Channel Subfamily A \\
WBA & Wing beat amplitude \\
ZFNs & Zinc Finger Nucleases \\
\hline
\end{tabular}




\section{CHAPTER 1: Introduction}

"If you think you are too small to make a difference, try sleeping with a mosquito."

\section{Dalai Lama}

Female mosquitoes use a combination of cues to find their vertebrate hosts and blood-feed. Their feeding behavior not only annoys us but also creates a potent pathway for disease transmission. For example, Aedes aegypti are vectors of viral diseases such as yellow fever, dengue, chikungunya and Zika $[1,2]$. Certain mosquito species like Ae. aegypti and the malaria vector, Anopheles gambiae, have evolved a preference for humans, which makes them efficient vectors for disease transmission [3, 4]. Aedes aegypti mosquitoes have evolved a preference for human hosts (Anthropophily) from an ancestral subspecies that does not prefer humans (Zoophily) [5, 6]. Host discrimination requires olfactory receptor function and has been linked to specific receptors that have increased expression and odor sensitivity in anthropophilic Ae. aegypti [6, 7]. From these studies, it is clear that Ae. aegypti uses olfaction to find their human hosts. Along with olfaction, other sensory pathways are also likely to participate in the detection of humans by mosquitoes. A comprehensive understanding of the cues that attract mosquitoes to humans, the receptors that detect them, and the neural circuits they activate will provide the necessary insight to develop new strategies to disrupt host-seeking behavior. To achieve this goal, genetic tools are now available.

Our ability to understand the molecular basis of mosquito behavior has been enhanced by the recent development of genome editing tools such as CRISPR-Cas9 RNA-guided nucleases, TALE-effector Nucleases (TALENS) and Zinc Finger Nucleases (ZFNs) in Anopheles and Aedes [8]. These approaches can be employed to facilitate 
targeted mutagenesis at any gene of interest to determine their contribution to host detection and blood feeding. These techniques could also be used to integrate genetic tools to map the neural circuits that enable these behaviors. Targeted mutagenesis of the olfactory receptors has been successfully performed in Ae. aegypti and has been linked to a reduction in host attraction [7,9]. These techniques have already identified multiple genetic pathways that mosquitoes employ to detect their hosts, but many questions remain. The current review seeks to survey the progress made in understanding the molecular mechanism of mosquito host detection.

\subsection{Human cues}

Odor is a critical cue that signals the presence of a host to mosquitoes [10]. Human odor is a complex blend of chemicals [11]. Skin microbiota plays a large role in generating volatile compounds that attract mosquitoes [12]. In Ae. aegypti and An. gambiae, odors that elicit both electrophysiological and behavioral responses have been found. Among these compounds are lactic acid, ammonia, ketones, sulfides [13-15], 1octen-3-ol [16], and carboxylic acids [17]. The odors emanating from a host are sensed via olfactory receptors, which can be found on the mosquito antennae, maxillary palps, and proboscis (Figure 1A, [18]). Exposing female mosquitoes to $\mathrm{CO}_{2}$ induces flight takeoff and sustained flight [19]. Carbon dioxide is detected by gustatory receptors that are expressed in the capitate peg sensilla of the maxillary palp [20]. Identifying which components of the diverse set of human odor-ligands are the most salient is a key step in understanding how mosquitoes detect humans. 
Heat attracts mosquitoes to their hosts at close range [21]. Mosquitoes will land on inanimate objects set at human body temperature in the presence of $\mathrm{CO}_{2}[9,22]$. Electrophysiological studies showed that there is an antagonistic pair of thermosensitive neurons within the coeloconic sensilla of the Ae. aegypti antennal tip where one sensillum is tuned to temperature rise and the other is sensitive to cold [23]. The integration of the responses from these two sensilla has been proposed to allow mosquitoes to respond to temperature changes and host thermal cues. The response to thermal cues may depend on the background ambient temperature, which would necessitate that mosquitoes possess a mechanism for sensing thermal contrast. The TRPA1 receptor allows mosquitoes to avoid warm objects that exceed host body temperature aiding the detection of thermal cues [24]. The sensor(s) that allow mosquitoes to detect attractive heat cues are still unknown. Ionotropic Receptors (IRs) that are temperature responsive have been found in Drosophila $[25,26]$. Further studies are needed to identify whether these receptors or others are important for mosquitoes to detect the temperature of their hosts.

Mosquitoes are also guided by visual cues to fly towards their hosts [27]. Adult mosquitoes possess compound eyes that are sensitive to varying light intensity [27]. It has been documented that photoreceptors in night-biting mosquitoes, An. gambiae adjust to varying light intensity by regulating the rhodopsin levels. The photoreceptors could enhance visual sensitivity to a potential host in low light conditions [28]. Unlike Anopheles, visual cues are proposed to be crucial for day-biting mosquitoes including hematophagous Aedes and Culex, but little is known about visual detection of hosts. Visual cues likely play an intermediate role in host detection by integrating long-range odor plume tracking with shorter-range cues [29]. For instance, $\mathrm{CO}_{2}$ or human odor can 
increase the ability of mosquitoes to focus on visual cues by enhancing visual flight navigation to the host $[30,31]$. Understanding the connection between olfactory sensitivity, flight navigation, and visual target selection will help the field identify the behavioral neural circuits that enable mosquito host-seeking.

While female mosquitoes are guided by other cues to fly towards their hosts (Figure 1B), the tastants on the skin likely promote blood feeding once they land. After landing, they soon pierce the skin and draw blood from small blood vessels [31]. The mouthparts of the female mosquito are highly specialized for blood feeding and contain sensory hair cells which help locate blood under the skin [32]. The An. stephensi proboscis does not only respond to taste but also detects thermal cues [22]. The transcriptome of the Ae. aegypti proboscis has been recently identified [33]. Genetically manipulating the chemoreceptors expressed in the proboscis could provide insight into mosquito biting behavior and possibly provide evidence for a role in host detection during flight. The contact cues on human skin and the receptors that sense them remain for the most part elusive. 

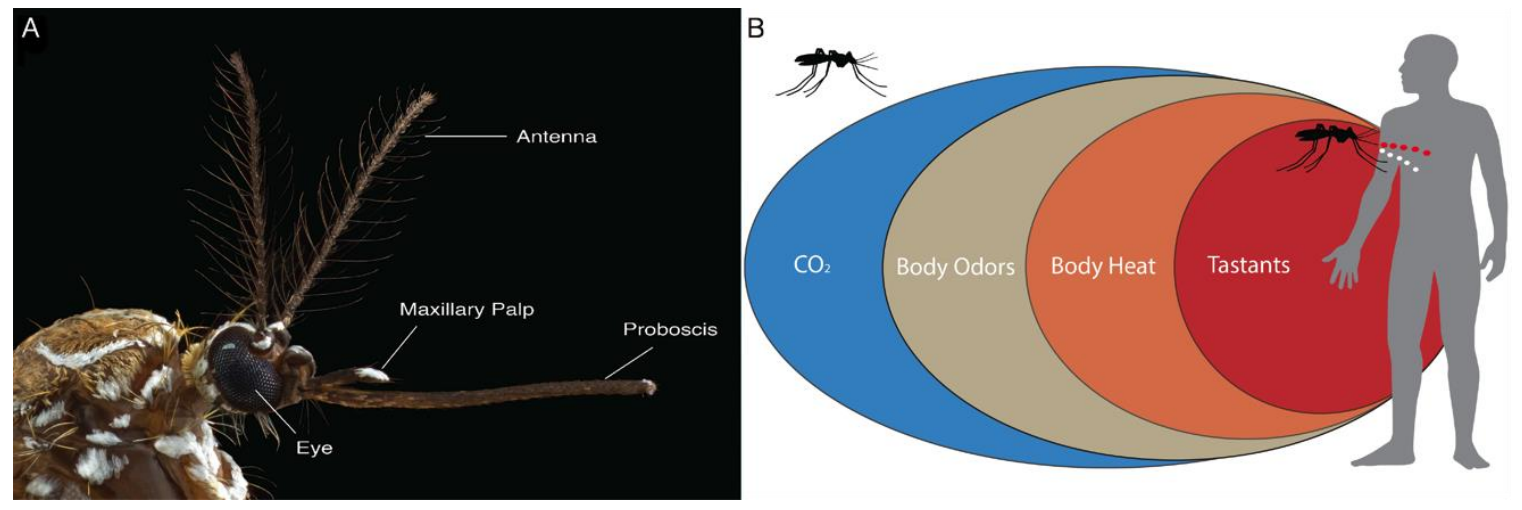

Figure 1. Olfaction enables mosquitoes to detect human hosts.

(A) Image of an Ae. aegypti mosquito showing the sensory organs involved in host detection and blood feeding. The antenna and maxillary palp detect odors emanating from the host. The proboscis detects taste cues and may also perceive odors. The eyes sense visual features in the environment and allow for flight navigation towards the host. (Photograph courtesy of artist Alex Wild) (B) Mosquitoes detect human hosts using combination of cues. At a distance, they sense $\mathrm{CO}_{2}$ exhaled from human's breath. As they move closer, they sense odor and heat that emanate from the host, they land on the skin where they taste with the taste receptors on their legs and mouth parts. When they bite, they can either infect the host with pathogens carried by their saliva (white dots) or become infected with the host's blood (red dots). 


\subsection{Multimodal integration of human cues}

Genetic analysis has demonstrated that mosquitoes integrate multiple stimuli to find their hosts. One of the most striking examples is the gating of multiple cues by $\mathrm{CO}_{2}$ [9]. Aedes aegypti mosquito attraction requires at least two cues. For example, neither thermal cues, nor lactic acid are attractive on their own. If $\mathrm{CO}_{2}$ is combined with either of these cues, mosquito attraction is greatly enhanced. If sensitivity to $\mathrm{CO}_{2}$ is lost, as in $G r 3$ mutants, this synergistic effect of $\mathrm{CO}_{2}$ does not occur. Host odor may also gate mosquito responses to hosts [7]. Mutant mosquitoes lacking the olfactory receptor co-receptor (orco) gene have reduced attraction to human odor, but in the presence of $\mathrm{CO}_{2}$, there was no difference between the wild-type and orco mutant mosquitoes [7]. In addition, both Gr3 and orco mutants respond normally to human arms in olfactometer assays [7, 9]. Taken together, these results demonstrate that mosquitoes have robust and redundant mechanisms to detect human hosts. The disruption of one pathway is unlikely to eliminate mosquito host-seeking. Employing multiple sensory pathways may increase the chance of a mosquito successfully targeting a host.

Mosquitoes may also integrate odor with taste cues in response to hosts. Riabinina et al., [34] recently documented that olfactory receptor neurons (ORN) expressing the orco gene project from the labella on the proboscis to the suboesophageal zone (SEZ) of the brain, and suggests that the SEZ may integrate odor and taste cues during blood feeding. This region of the insect brain has been shown to be critical for taste integration in Drosophila [35]. In Ae. aegypti, in vivo calcium imaging revealed the activation of some ORs by some volatile compounds in the blood and removing the function of the ORs in the stylet impairs blood feeding [31]. Clearly, the ability to integrate host sensory 
cues represents an essential mechanism employed by mosquitoes to guide host detection and blood-feeding behavior.

\subsection{Molecular sensors of human cues}

Insects have evolved complex repertoires of chemosensory receptors to respond to their environment including: odorant receptors (ORs), ionotropic receptors (IRs) and gustatory receptors (GRs) [36]. In Drosophila, the ORs are expressed in the dendrites of ORNs. The sensillar lymph surrounding the ORNs is densely packed with odorantbinding proteins (OBPs) that are hypothesized to be involved in odorant uptake and odor delivery to the ORs, but their role remains unclear [37]. The neural processing of olfactory information has been extensively studied in Drosophila [38, 39]. The axons of the ORNs project to the antennal lobe where they synapse with projection neurons (PN). In turn, PNs convey olfactory information to the mushroom body (MB) and lateral horn (LH) of the brain which subsequently leads to a behavioral response. How mosquitoes process host cue information has not been well established, but the lessons from Drosophila are likely to apply.

In Drosophila, ORs form a heteromeric complex with orco for their targeting to the cell membrane $[40,41]$. The OR pathway plays a critical role in mosquito preference for human hosts and DEET repellency [7, 42]. The ORs from An. gambiae have been comprehensively deorphanized using the Drosophila empty neuron system [43]. These ORs tested seemed to be narrowly tuned to several odor components that emanate from humans such as 1-octen-3-ol (present in human breath), 2,3-butanedione (by-product of metabolized sweat) and indole (human sweat volatile) [43]. The narrow tuning of these ORs may serve to improve cue salience [44]. 
The IRs are expressed in the dendrites of the ORNs innervating the coeloconic sensilla [45]. There are at least two IR co-receptors, $\operatorname{Ir} 8 a$ and $\operatorname{Ir} 25 a$, and possibly a third, $\operatorname{Ir} 76 b[45,46]$. These co-receptors form an odor-responsive ion channel complex with odor-selective IRs. Drosophila IRs respond primarily to amines and acids while ORs respond to esters and alcohols [47]. Beyond olfaction, Drosophila IRs play a role in taste $[48,49]$, moisture and temperature sensing $[25,26]$, and possibly in the auditory system [50]. Although GRs are usually involved in taste [35], specialized GRs have been implicated in other sensory modalities in insects including light sensing [51], warmth sensing [52], and $\mathrm{CO}_{2}$ detection [53]. Excluding the Grs that detect $\mathrm{CO}_{2}$, it remains unknown whether the orthologues of these receptor genes respond to similar stimuli in mosquitoes [9].

\subsection{Behavioral vector control strategies}

Given that olfaction is key for mosquitoes to detect their human hosts, identifying new odors that modulate mosquito olfactory receptor function is a promising approach to combatting mosquito-borne disease $[54,55]$ (Fig. 2). The discovery of novel odors can be accomplished using high-throughput screening assays to identify synthetic and natural compounds that activate receptors associated with repellency or inhibit receptors associated with attraction [56]. This strategy can help develop novel spatial mosquito repellents or create odor baits for traps that reduce mosquito populations. Our current understanding of mosquito host detection makes it likely that effective odor-baited traps would need to include multiple cues such as $\mathrm{CO}_{2}$ and heat to recreate the multimodal sensory experience that drives mosquitoes to their hosts. Next generation mosquito repellents could block multiple chemosensory pathways to render the human host 
"invisible". As an alternative, new repellents that overstimulate a specific chemosensory pathway could cause mosquitoes to avoid humans. To accomplish this important goal, we will need to know the specific receptors that enable mosquito attraction and repellency.

\subsection{Summary}

We have reviewed what is known about the multiple cues that attract mosquitoes to humans and their molecular sensors. Host-seeking is not completely abolished even when either the $\mathrm{CO}_{2}$-sensing or OR pathways were disrupted in Ae. aegypti [7, 9]. The redundancy clearly shows that multiple cues must be considered to understand how mosquitoes find their human hosts. Our current knowledge is not sufficient to develop new behavioral control strategies but sets the stage for further studies. To efficiently develop these new strategies, we need to have a comprehensive understanding of how mosquitoes detect their human hosts from the perception of cues at the periphery, to the integration of the information in the central nervous system, and finally, to the motor circuits that drive the behavior. Genome editing tools such as CRISPR-Cas9 and other genetic manipulations such as using the GAL4-UAS system to mark or manipulate neural circuits could play a significant role in addressing how the mosquito's brain responds to human cues [57]. We have learned so much from the genetic analysis of Drosophila behavior. Using similar approaches to understand mosquito behavior may provide the mechanistic insight to break the cycle of mosquito-borne disease transmission. 
A

Novel odor ligands

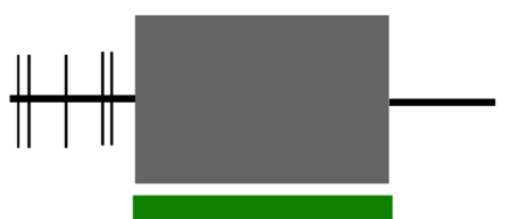

Activators

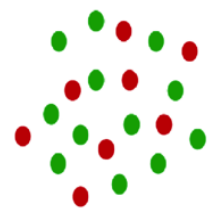

B
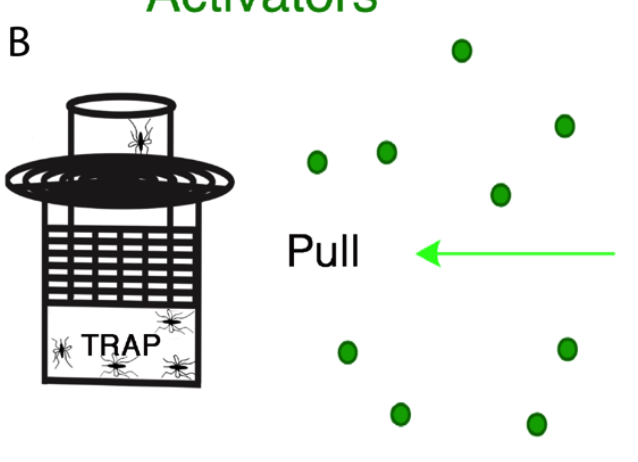
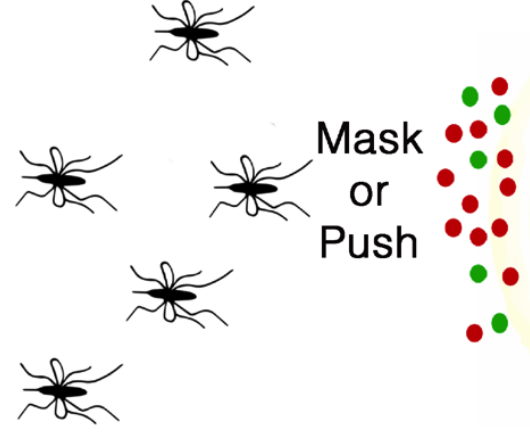

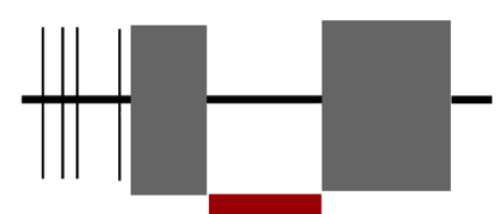

Inhibitors

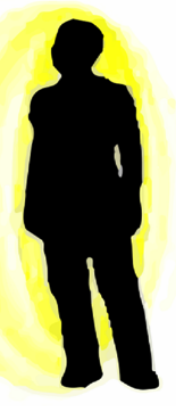

Figure 2. Designing novel mosquito attractants and repellents.

Novel vector control measures can be designed after identifying the salient cues that mosquitoes use to find their hosts and the receptors that perceive them. (A) Cartoons of single sensillum recordings of olfactory receptor neuron (ORN) responses to novel odor ligands. New volatile compounds that activate (green) or inhibit (red) the activity of the ORNs could be used to control mosquito behavior or reduce mosquito populations. (B) Push-pull strategies for mosquito behavioral control. Mosquitoes can be led to a trap containing odors that attract them (pull). Odors that either mask or constitutively activate olfactory receptor function could cause mosquitoes to avoid humans (mask/push). 


\subsection{Dissertation objectives and organization}

Chapter 1 reviews the progress made in understanding the molecular mechanism underlying host detection in mosquitoes. Current understanding of the salient cues that attract mosquitoes, the receptors used to detect these cues were also reviewed. Chapter 1 also suggests ways forward for novel olfaction-based vector control strategies. This chapter is a reprint of a previously published article in Current Opinion in Insect Science.

Chapter 2 is a comprehensive genetic and behavioral analysis of genes crucial for mosquito host detection. Our study is the first to implicate a new family of olfactory receptors, the ionotropic receptors as a key driver for mosquito attraction to human odor. Chapter 2 is also a reprint of the published article in Current Biology.

In Chapter 3, we explored the role of the Iontoropic co-receptor, IR8a, in mosquito water-seeking behavior. On the basis of our data, $\operatorname{Ir} 8 a$ mutants are strongly attracted to water. It is known that water is a crucial resource for mosquitoes to lay their eggs, further examination of the role of the IR8a pathway will provide insight into novel ways of controlling mosquito population. Chapter has been published in Communicative and Integrative Biology. Chapter 4 examines the aspect of mosquito vision and how it integrates with odor cues to enhance host seeking process. The study was carried out on Aedes aegypti mosquitoes and compared to a non-anthropophilic distantly related fruit fly. Chapter 4 manuscript is currently being written up and intended to be published soon. All the chapters are summarized in chapter 5. Future directions and research gaps in the studies are also discussed. 


\section{References}

1. Severson DW, Behura SK: Genome investigations of vector competence in Aedes aegypti to inform novel arbovirus disease control approaches. Insects 2016, 7:58.

2. Petersen LR, Jamieson DJ, Powers AM, Honein MA: Zika virus. $N$ Engl J Med 2016, 374:1552-1563.

3. McBride CS: Genes and odors underlying the recent evolution of mosquito preference for humans. Curr Biol 2016, 26:R41-R46.

4. Takken W, Verhulst NO: Host preferences of blood-feeding mosquitoes. Annu Rev Entomol 2013, 58:433-453.

5. Brown JE, Evans BR, Zheng W, Obas V, Barrera-Martinez L, Egizi A, Zhao H, Caccone A, Powell JR: Human impacts have shaped historical and recent evolution in Aedes aegypti, the dengue and yellow fever mosquito. Evolution 2014, 68:514-525.

6. McBride CS, Baier F, Omondi AB, Spitzer SA, Lutomiah L, Sang R, Ignell R, Vosshall LB: Evolution of mosquito preference for humans linked to an odorant receptor. Nature 2014, 515:222-227.

7. DeGennaro M, McBride CS, Seeholzer L, Nakagawa T, Dennis EJ, Goldman C, Vosshall LB: Orco mutant mosquitoes lose strong preference for humans and are not repelled by volatile DEET. Nature 2013, 498:487-491.

8. Reegan AD, Ceasar SA, Paulraj MG, Ignacimuthu S, Al-Dhabi NA. Current status of genome editing in vector mosquitoes: A review. BioSci Trends 2016, 10:424-432.

9. McMeniman CJ, Corfas RA, Matthews BJ, Ritchie SA, Vosshall LB. Multimodal integration of carbon dioxide and other sensory cues drives mosquito attraction to humans. Cell 2014, 156:1060-1071.

10. Takken W, Knols BG: Odor-mediated behavior of Afrotropical malaria mosquitoes. Annu Rev Entomol 1999, 44:131-157.

11. Bernier UR, Kline DL, Barnard DR, Schreck CE, Yost RA: Analysis of human skin emanations by gas chromatography/mass spectrometry. 2. Identification of volatile compounds that are candidate attractants for the yellow fever mosquito (Aedes aegypti). Anal Chem 2000, 72:747-756.

12. Verhulst NO, Takken W, Dicke M, Schraa G, Smallegange RC: Chemical ecology of interactions between human skin microbiota and mosquitoes. FEMS

Microbiol Ecol 2010, 74:1-9. 
13. Davis EE, Sokolove PG: Lactic acid-sensitive receptors on the antennae of the mosquito, Aedes aegypti. J Comp Physiol 1976, 105:43-54.

14. Braks MA, Meijerink J, Takken W: The response of the malaria mosquito, Anopheles gambiae to two components of human sweat, ammonia and L- lactic acid. Physiol Entomol 2001, 26:142-148.

15. Bernier UR, Kline DL, Posey KH, Booth MM, Yost RA, Barnard DR: Synergistic attraction of Aedes aegypti (L.) to binary blends of L -lactic acid and acetone, dichloromethane, or dimethyl disulfide. J Med Entomol 2003, 40:653-656.

16. Majeed S, Hill SR, Birgersson G, Ignell R: Detection and perception of generic host volatiles by mosquitoes modulate host preference: context dependence of (R)-1- octen-3-ol. $R$ Soc Open Sci 2016, 3:160467.

17. Smallegange RC, Qiu YT, Bukovinszkiné-Kiss G, van Loon JJA, Takken W: The effect of aliphatic carboxylic acids on olfaction-based host-seeking of the malaria mosquito Anopheles gambiae sensu stricto. J Chem Ecol 2016, 35:933-943.

18. Montell C, Zwiebel LJ: Mosquito sensory systems. In Progress in Mosquito Research. Edited by Alexander S. Raikhel. Elsevier Press; 2016:293-328.

19. Dekker T, Carde RT: Moment-to-moment flight manoeuvres of the female yellow fever mosquito (Aedes aegypti L.) in response to plumes of carbon dioxide and human skin odour. J. Exp. Biol. 2011, 214: 3480-3494.

20. Lu T, Qiu YT, Wang G, Kwon J, Rutzler M, Kwon H, Pitts R, van Loon J, Takken W, Carlson J, Zwiebel L: Odor coding in the maxillary palp of the malaria vector mosquito Anopheles gambiae. Curr Biol 2007, 17:1533-1544.

21. Khan AA, Maibach HI, Strauss GW, Fenley WR: Quantification of effect of the several stimuli on the approach of Aedes aegypti. J Econ Entomol 1966, 59:690-694.

22. Maekawa E, Aonuma H, Nelson B, Yoshimura A, Tokunaga F, Fukumoto S, Kanuka H: The role of proboscis of the malaria vector mosquito Anopheles stephensi in host-seeking behavior. Parasit Vectors 2011, 4:10.

23. Gingl E, Hinterwirth A, Tichy H: Sensory representation of temperature in mosquito warm and cold cells. J Neurophysiol 2005, 94:176-185.

24. Corfas AR, Vosshall LB: The cation channel TRPA1 tunes mosquito thermotaxis to host temperatures. eLife 2015, 4:e11750.

25. Enjin A, Zaharieva EE, Frank DD, Mansourian S, Suh GSB, Gallio M, Stensmyr MC: Humidity sensing in Drosophila. Curr Biol 2016, 26:1352-1358. 
26. Knecht ZA, Silbering AF, Ni L, Klein M, Budelli G, Bell R, Abuin L, Ferrer AJ, Samuel AD, Benton R, et al.: Distinct combinations of variant ionotropic glutamate receptors mediate thermosensation and hygrosensation in Drosophila. eLife 2016, 5:e17879.

27. Muir LE, Kay BH, Thorne MJ: Aedes aegypti (Diptera: Culicidae) vision: response to stimuli from the optical environment. J Med Entomol 1992, 29:445-450.

28. Moon YM, Metoxen AJ, Leming MT, Whaley MA, O’Tousa JE: Rhodopsin management during the light-dark cycle of Anopheles gambiae mosquitoes. $J$ Insect Physiol 2014, 70:88-93.

29. van Breugel F, Riffell J, Fairhall A, Dickinson MH: Mosquitoes use vision to associate odor plumes with thermal targets. Curr Biol 2015, 25:2123-2129.

30. Hawkes F, Gibson G: Seeing is believing: the nocturnal malarial mosquito Anopheles coluzzii responds to visual host-cues when odour indicates a host is nearby. Parasit Vectors 2016, 9:320.

31. Krenn HW, Aspöck H: Form, function and evolution of the mouthparts of bloodfeeding arthropoda. Arthropod Struct Dev 2012, 41:101-118.

32. Jung WJ, Baeck SJ, Perumalsamy H, Hansson BS, Ahn YJ, Kwon, HW: A novel olfactory pathway is essential for fast and efficient blood-feeding in mosquitoes. Sci Rep 2015, 5:13444.

33. Matthews BJ, McBride CS, DeGennaro M, Despo O, Vosshall LB: The neurotranscriptome of the Aedes aegypti mosquito. BMC Genomics 2016, $17: 32$.

34. Riabinina O, Task D, Marr E, Lin C-C, Alford R, O'Brochta DA, Potter CJ: Organization of olfactory centres in the malaria mosquito Anopheles gambiae. Nature Communications 2016, 7:13010.

35. Liman ER, Zhang YV, Montell C: Peripheral coding of taste. Neuron 2014, 81:984-1000.

36. Suh E, Bohbot JD, Zwiebel LJ: Peripheral olfactory signaling in insects. Curr Opin Insect Sci 2014, 6:86-92.

37. Pelosi P, Zhou J-J, Ban LP, Calvello M: Soluble proteins in insect chemical communication. Cell Mol Life Sci 2006, 63:1658-1676.

38. Joseph RM, Carlson JR: Drosophila chemoreceptors: A molecular interface between the chemical world and the brain. Trends Genet 2015, 31: 683-695. 
39. Sachse S, Beshel J: The good, the bad, and the hungry: how the central brain codes odor valence to facilitate food approach in Drosophila. Curr Opin Neurobiol 2016, 40:53-58.

40. Larsson MC, Domingos AI, Jones WD, Chiappe ME, Amrein H, Vosshall LB: Or83b encodes a broadly expressed odorant receptor essential for Drosophila olfaction. Neuron 2004, 43:703-714.

41. Benton R, Sachse S, Michnick SW, Vosshall LB: Atypical membrane topology and heteromeric function of Drosophila odorant receptors in vivo. PLoS Biol. 2006, 4:e20.

42. Xu P, Choo Y-M, De La Rosa A, Leal WS: Mosquito odorant receptor for DEET and methyl jasmonate. Proc Natl Acad Sci USA 2014, 111:16592-16597.

43. Carey AF, Wang G, Su CY, Zwiebel LJ, Carlson JR: Odorant reception in the malaria mosquito Anopheles gambiae. Nature 2010, 464:66-71.

44. Bohbot JD, Pitts RJ: The narrowing olfactory landscape of insect odorant receptors. Front Ecol Evol 2015, 3:39.

45. Benton R, Vannice KS, Gomez-Diaz C, Vosshall LB: Variant ionotropic glutamate receptors as chemosensory receptors in Drosophila. Cell 2009, 136:149-162.

46. Abuin L, Bargeton B, Ulbrich MH, Isacoff EY, Kellenberger S, Benton R: Functional architecture of olfactory ionotropic glutamate receptors. Neuron 2011, 69:44-60.

47. Silbering AF, Rytz R, Grosjean Y, Abuin L, Ramdya P, Jefferis GS, Benton R: Complementary function and integrated wiring of the evolutionarily distinct Drosophila olfactory subsystems. J Neurosci 2011, 31:13357-13375.

48. Hussain A, Zhang M, Uçpunar HK, Svensson T, Quillery E, Gompel N, Ignell R, Grunwald Kadow IC: Ionotropic chemosensory receptors mediate the taste and smell of polyamines. PLoS Biol 2016, 14:e1002505.

49. Zhang YV, Ni J, Montell C: The molecular basis for attractive salt-taste coding in Drosophila. Science 2013, 14:1334-1338.

50. Senthilan PR, Piepenbrock D, Ovezmyradov G, Nadrowski B, Bechstedt S, Pauls S, Winkler M, Möbius W, Howard J, Göpfert MC: Drosophila auditory organ genes and genetic hearing defects. Cell 2012, 150:1042-1054.

51. Xiang Y, Yuan Q, Vogt N, Looger LL, Jan LY, Jan YN: Light-avoidancemediating photoreceptors tile the Drosophila larval body wall. Nature 2010, 468:921-926. 
52. Ni L, Bronk, P, Chang EC, Lowell AM, Flam JO, Panzano VC, Theobald DL, Griffith LC, Garrity PA: A gustatory receptor paralog controls rapid warmth avoidance in Drosophila. Nature 2013, 500:580-584.

53. Jones WD, Cayirlioglu P, Kadow IG, Vosshall LB: Two chemosensory receptors together mediate carbon dioxide detection in Drosophila. Nature 2007, 445:86-90.

54. Chen S, Luetje CW: Identification of new agonists and antagonists of the insect odorant receptor co-receptor subunit. PLoS One 2012, 7:e36784.

55. Jones PL, Pask GM, Romaine IM, Taylor RW, Reid PR, Waterson AG, Sulikowski GA, Zwiebel LJ: Allosteric antagonism of insect odorant receptor ion channels. PLoS One 2012, 7:e30304.

56. Rinker DC, Jones PL, Pitts RJ, Rutzler M, Camp G, Sun L, Xu P, Dorset DC, Weaver D, Zwiebel LJ: Novel high-throughput screens of Anopheles gambiae odorant receptors reveal candidate behaviour-modifying chemicals for mosquitoes. Physiol Entomol 2012, 37:33-41.

57. Jones WD: The expanding reach of the GAL4/UAS system into the behavioral neurobiology of Drosophila. BMB Rep 2009, 42:705-712. 
CHAPTER 2: Aedes aegypti mosquitoes detect acidic volatiles found in human odor using the IR8a pathway

"If only mosquitoes sucked fat instead of blood, then we could sit outside and eat burger"

\author{
Anonymous
}

\title{
2.1 Abstract
}

Mosquitoes use olfaction as a primary means of detecting their hosts. Previously, the functional ablation of a family of Aedes aegypti olfactory receptors, the Odorant Receptors (ORs), was not sufficient to reduce host-seeking in the presence of carbon dioxide $\left(\mathrm{CO}_{2}\right)$. This suggests the olfactory receptors that remain, such as the Ionotropic Receptors (IRs), could play a significant role in host detection. To test this, we disrupted the Ir8a co-receptor in Ae. aegypti using CRISPR/Cas9. We found that $\operatorname{Ir} 8 a$ mutant female mosquitoes are not attracted to lactic acid, a behaviorally active component of human sweat, and lack odor-evoked responses to acidic volatiles. The loss of Ir8a reduces mosquito attraction to humans and their odor. We show that the $\mathrm{CO}_{2}$-detection pathway is necessary but not sufficient for IR8a to detect human odor. Our study reveals that the IR8a pathway is crucial for an anthropophilic vector mosquito to effectively seek hosts.

\subsection{Introduction}

Anthropophilic female mosquitoes, such as Aedes aegypti and Anopheles gambiae, have a strong innate drive to find their human hosts and obtain blood meals, which are required for egg production [1]. As has been shown by the recent Zika outbreak, Aedes mosquitoes are efficient vectors for pathogen transmission because of their host-seeking behavior and susceptibility for infection by flaviviruses [2,3]. Female 
mosquitoes, like other haematophagous Diptera, integrate an array of sensory information to find their human hosts including carbon dioxide $\left(\mathrm{CO}_{2}\right)$, body odor, heat, moisture, and visual cues [4-6]. How these different cues are sensed to enable mosquito host-seeking has only begun to be understood [7]. Among these attractive cues, human body odor is a complex blend of volatile chemicals that distinguishes us from other vertebrate hosts [812]. Skin microbiota plays a large role in generating the volatile compounds that attract mosquitoes to human sweat [13-15]. In Ae. aegypti and An. gambiae, human odors that elicit both electrophysiological and behavioral responses have been identified such as ammonia, amines, carboxylic acids, lactic acid, ketones, sulfides, and 1-octen-3-ol [1622]. The odors emanating from a host are sensed via olfactory receptors expressed in the mosquito antennae, maxillary palps, and proboscis [23,24].

Insects respond to volatile chemicals in the environment with a complex repertoire of olfactory receptors that are evolutionarily distinct from vertebrate olfactory receptors [25-27]. Two families of odor-gated ion channels have been identified in insects that respond to a diverse set of molecules, the odorant receptors (ORs) and the ionotropic receptors (IRs) [28-31]. In addition, there are also gustatory receptors (GRs) that are highly sensitive to $\mathrm{CO}_{2}[32-34]$ and whose activity can be altered by other odors $[35,36]$. Odor-tuned ORs rely upon the obligate olfactory co-receptor Orco to form an odor-gated ion channel complex [37-41]. In Ae. aegypti, loss of orco results in a loss of electrophysiological responses to some but not all odorants [42]. In the presence of $\mathrm{CO}_{2}$, attraction to human odor was not significantly different from wild-type controls in female Ae. aegypti orco mutants. However, in the absence of $\mathrm{CO}_{2}$, orco mutants lose strong attraction to human odor. Ae. aegypti mutants lacking $G r 3$, a subunit of the heteromeric 
$\mathrm{CO}_{2}$ receptor complex, show no electrophysiological or behavioral responses to $\mathrm{CO}_{2}$ [43]. Behavioral analysis of $\mathrm{Gr} 3$ mutants showed that $\mathrm{CO}_{2}$ can gate multiple cues that are sensed by mosquitoes including heat and human odor.

Drosophila IRs are expressed in olfactory sensory neurons (OSNs) that are distinct from OR and GR lineages [44]. There are at least two IR co-receptors including IR8a and IR25a, and a putative third, IR76b [30,45]. These co-receptors form an odorresponsive ion channel with other odor-tuned IRs. For example, some Drosophila odortuned IRs require IR8a as a co-receptor, while some other odor-tuned IRs form a functional complex with IR25a and/or IR76b, but not all the three co-receptors. Similarly, some OSNs have been shown to express both IR8a and IR25a protein [45]. There are 30 putative odor-tuned IRs expressed in the Ae. aegypti antennae that could potentially form an odor-responsive ion channel with any of the IR co-receptors [24]. The combinatorial pattern of expression observed in IRs may allow flexibility to respond to more diverse olfactory cues with fewer odor-tuned receptors than the Orco pathway [45], which encompasses at least 117 odor-tuned OR [46].

Insect IRs have been reported to detect amines, aldehydes, ketones, and acids $[22,30,44,47,48]$. As many of these compounds are not represented in the OR chemical space, which includes alcohols and esters, the IR odor-ligands are largely complementary and not overlapping with OR odor-ligands [44,49,50]. In Drosophila, Ir25a and Ir76b are necessary for odor-evoked electrophysiological responses to amines [51], whereas receptor neurons expressing $\operatorname{Ir} 8 a$ are tuned to volatile acids [45]. IR8a forms a functional complex with AgIR75k to elicit odor-evoked inward currents in response to carboxylic acids including heptanoic acid, octanoic acid and nonanoic acid [22]. Lactic acid is 
enriched in human skin emanations compared to other vertebrates and may be one of the cues that signals to the mosquito that the target host is a human [52,53]. How lactic acid is sensed in mosquitoes is unknown, but it is likely to be IR-dependent.

Whereas Drosophila Ir $25 a$ is involved in many functions, including olfaction, taste, hygrosensation, thermosensation, and attraction to $\mathrm{CO}_{2}$ [30,45,51,54-62], Ir8a appears to function exclusively in detecting odors and is not necessary for attractive responses to $\mathrm{CO}_{2}[30,45,47,48,62]$. In Ae. aegypti, Ir8a expression is localized to the antenna and cannot be detected in other chemosensory tissues, whereas $\operatorname{Ir} 25 a$ is broadly expressed in multiple chemosensory tissues and three-fold more abundant in sugar fed female mosquito antennae than $\operatorname{Ir} 8 a$ [24]. Similarly, $\operatorname{Ir} 8 a$ transcript abundance was detected only in the antenna of An. gambiae adults and larvae [23,63,64]. These results make Ir8a a likely candidate receptor for odor detection during mosquito host-seeking behavior. $\operatorname{Ir} 25 a$ and $\operatorname{Ir} 76 b$ have broader expression patterns that are consistent with these receptors being involved in other sensory modalities in addition to olfaction $[24,45,51,54]$.

Since host-seeking is not completely ablated in orco or Gr3 mutants [42,43], we reasoned that the IR olfactory receptors retained in these mutants are crucial for hostseeking. Here, we used the CRISPR/Cas9 system to disrupt Ae. aegypti Ir8a. We test the relative contribution of $\operatorname{Ir} 8 a$ in human odor detection and its genetic interaction with other olfactory receptor pathways that have been previously implicated in Ae. aegypti host-seeking. We find that $\operatorname{Ir} 8 a$ mutants are not attracted to lactic acid, a behaviorally active component of human odor, or able to detect acidic components of human odor. In membrane blood-feeding assays, Ir $8 a$ mutants have reduced responses to human odor, 
but not heat and $\mathrm{CO}_{2}$, when compared to wild-type controls. Ir8a mutants are also less responsive to humans and human odor than wild-type controls in uniport olfactometer assays. The genetic interactions of $\operatorname{Ir} 8 a$ and orco as well as $\operatorname{Ir} 8 a$ and $G r 3$ suggest a crucial role for $\mathrm{CO}_{2}$ to sensitize mosquitoes to human odor and highlights the importance of human acidic volatile detection during mosquito host-seeking.

\subsection{Materials and methods}

\subsubsection{Experimental model and subject details}

All research was conducted in compliance with the NIH guidelines and the Florida International University Environmental Health and Safety guideline. Laboratory practices, facilities and equipment were reviewed and approved by the Florida International University Institutional Biosafety Committee (IBC-18-004) and Institutional Review Board (IRB-16-0388 \& IRB-16-0386-CR02). Informed consent was obtained from human subject volunteers before their participation in this study.

Aedes aegypti mosquitoes were reared and maintained at $25-28^{\circ} \mathrm{C}, 75 \%$ relative humidity under a 14:10 light-dark cycle (lights on at $8 \mathrm{am}$ ). All mosquitoes used in these experiments were generated from the Orlando laboratory strain. Mosquito eggs were hatched in deionized, deoxygenated water containing dissolved tablets of Tetramin tropical fish food (catalog \#16152, Tetra, Melle, Germany), which served as food for the emerged larvae. Adult mosquitoes were given ad libitum access to $10 \%$ sucrose solution. About 1 to 2-week-old adult females were fed on defibrinated sheep blood to generate eggs. Before behavioral assays, 5 to 7 day old sugar-fed mosquitoes were sorted and sexed under hypothermic $\left(4^{\circ} \mathrm{C}\right)$ conditions and fasted for up to 24 hours on water. All mosquitoes were tested only once in the behavioral assays and then sacrificed. 
A total of 18 human subject volunteers participated in the host-seeking experiments (Table S2). However, three subjects were later excluded because they failed either, to complete all the trials or their body odor was not attractive to wild-type mosquitoes. Subject was tested twice to assess their attractiveness to mosquitoes. The volunteers were diverse in age (19 to 41 years), sex (Male $=7$, Female $=8$ ), and race $($ White $=5$, Hispanic $=7$, Asian = 1, Black = 2).

\subsubsection{CRISPR/Cas9 nuclease reagents}

CRISPR short guided RNAs (sgRNA) were designed according to standard protocols [43]. The sgRNAs sequences for the mutagenesis of exon 2 and exon 3 of $\operatorname{Ir} 8 a$ gene were chosen by the presence of protospacer-adjacent motifs (PAMs) with the sequence NGG. Generated sgRNA sequences were checked for potential off-target binding sites using ZiFit (http://zifit.partners.org/ZiFiT/). Double-stranded DNA templates for specific sgRNAs were produced by performing a template-free PCR with two overlapping oligonucleotides. One containing the specific target sequences $\left(\operatorname{Ir} 8 a^{d s R E D}\right.$ exon2: GGGCGGACAAAATGGCGTAT and $\operatorname{Ir} 8 a^{\text {att } P}$ exon 3: GGACATCTGTCGACGATAAC), and the universal CRISPR reverse primer (Table S1). The forward primers used were IR8aExon2CRISPRF and IR8aExon3CRISPRF. The reverse primer used was sgRNArev. Both sgRNAs were produced using MEGAscript T7 Transcription Kit (Catalog \#AM1334, Life Technologies, Carlsbad, CA, USA). Following incubation, sgRNA transcripts were purified using MEGAclear Transcription Clean-Up Kit (Catalog \#AM1908, Life Technologies) and verified on the Agilent bioanalyzer (Agilent, Santa Clara, CA, USA). 
The Cas9 polyadenylated mRNA was made by digesting the MLM3613 plasmid [53] with the PmeI restriction enzyme (New England Biolabs, Ipswich, MA, USA), miniprep purifying the linearized plasmid, and in vitro transcribing the mRNA from the DNA fragment using the mMessage mMachine T7 ultra kit (Catalog \#AM1345, Thermo Fisher Scientific). The mRNA transcript was purified using MEGAclear Transcription Clean-Up Kit (Catalog \#AM1908, Life Technologies) and checked on the Agilent bioanalyzer (Agilent). MLM3613 was a gift from Keith Joung (Addgene plasmid \#42251; http://n2t.net/addgene:42251; RRID: Addgene_42251).

The single stranded oligo nucleotide (ssODN) used to integrate attP recombination site sequences into exon 3 of $\operatorname{Ir} 8 a$ was synthesized by Integrated DNA Technologies (www.idtdna.com) using the 20 nmole ultramer service with standard desalting. The ssODN contains a 50bp attP site flanked by $75 \mathrm{bp}$ of homologous sequences to the target site on both sides:

GATTCTCGGTTCTGGATGCCTGACGGCAGTCGAATGTTACGATACAATTTGAA CGTTTCGATTTGGACATCTGTCCTACGCCCCCAACTGAGAGAACTCAAAGG TTACCCCAGTTGGGGCACTACAACGGGTCTGCTGCAATACACCTTGGGACG ATCGAGAAGGGTGATGTGGTACCGTTCGTGGGTCAGAAGATCAAA

(attP sequence in bold).

To generate the donor DNA to integrate into exon 2 of IR8a, the pSL1180:polyUBdsRED [54] was modified to include homologous sequences surrounding the CRISPR target site. The 796bp left arm and 1005bp right arms were amplified from Orlando strain Ae. aegypti genomic DNA using Novagen KOD polymerase (EMD Millipore, Temecula, CA, USA). 
The following primers were used to amplify the exon: infusionIR8LA_1, infusionIR8LA_2, infusion_IR8RA1, and infusion_IR8RA2 (Table S1).

After the PCR fragments were amplified and purified with Qiaquick PCR purification kit (Catalog \#28106, Qiagen, Hilgen, Germany), pSL 1180:polyUBdsRED was digested with both EcoRI and XhoI (New England Biolabs). The 3253bp fragment (pSL 1180 backbone) and 2321bp fragment (polyubiquitin:dsRED:SV40) were both gel purified. The left homologous arm PCR, polyubiquitin:dsRED fragment, the right homologous arm PCR, and ps11180 backbone were simultaneously assembled using a recombination based method, Infusion HD (Catalog \#638909, Clontech). The resulting DNA was cut with the MluI restriction enzyme (New England Biolabs) and Sanger sequenced to confirm the proper integration of the fragments. The final plasmid DNA, pGT-Ir8a, was purified from E. coli using the Qiagen Endo-free Maxiprep DNA (Catalog \#12362, Qiagen) isolation kit.

\subsection{3. $\operatorname{Ir} 8 a^{d s R E D}$ and $\operatorname{Ir} 8 a^{\text {attP }}$ mutant allele generation and detection}

To generate stable germline mutations, CRISPR-Cas9 reagents were injected into the posterior end of the pre-blastoderm embryos. This stage allows nuclei that will become somatic and germline cells to be exposed to the CRISPR-Cas9 complex since the dividing nuclei have not yet undergone cytokinesis. Microinjection into Ae. aegypti preblastoderm embryos was performed at the Insect Transformation Facility at the University of Maryland. The microinjection mixes were prepared as follows: for $\operatorname{Ir} 8 a^{d s R E D}$, sgRNA $(25 \mathrm{ng} / \mu \mathrm{l})$, Cas9 mRNA (500 $\left.\mathrm{ng} / \mu \mathrm{l}\right)$, and donor plasmid (500 $\left.\mathrm{ng} / \mu \mathrm{l}\right)$

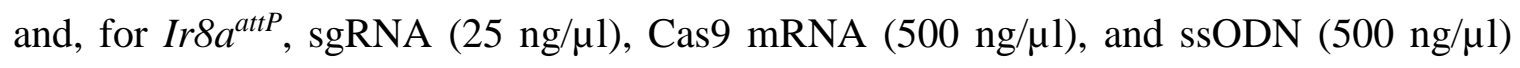
were diluted into nuclease-free $\mathrm{H}_{2} \mathrm{O}$. 
A total of 1,069 and 509 embryos were injected to target exon 2 and exon 3, respectively.

Embryos were hatched 3 days after injection and reared to the adult stage as previously described [42]. A total of $50 \mathrm{G}_{0}$ females were sexed during pupation, allowed to mate freely with wild-type Orlando males, and females were blood-fed to generate $\mathrm{G}_{1}$ progeny. $G_{0}$ females were put into oviposition vials to collect $G_{1}$ eggs. Thereafter, $G_{1}$ eggs were hatched and pupae were screened for $\operatorname{Ir} 8 a^{d s R E D}$ insertion allele using a fluorescent microscope. Fluorescent $\mathrm{G}_{1}$ individuals were sexed and reared to adulthood. Fluorescent females were outcrossed with wild-type animals for 5 generations and homozygosed. The dsRED fluorescent protein gene insertion was detected in the $\operatorname{Ir} 8 a$ locus by PCR. Mosquito genomic DNA was purified using DNeasy Blood \& Tissue kits (Catalog \#69504, Qiagen). PCR amplification was done using the following primers Ir $8 a^{d s R E D}$ ForLA3 and Ir8aexon4rev3 (Table 1).

To further confirm site specific integration of the pGT-Ir8a donor DNA into Ir8a exon 2 and sequence the integration site, a 3483bp PCR product was amplified using Novagen KOD polymerase (Catalog \#71086-5, EMD Millipore) with the forward primer (Ir8a $a^{d s R E D}$ ForLA3) homologous to the first 20bp of $\operatorname{Ir} 8 a$ exon 2, which is also contained in the left arm of the donor plasmid, and the reverse primer (Ir8aexon4rev3) in $\operatorname{Ir} 8 a$ exon 4 outside the boundary of the right arm of the donor plasmid. This PCR product was then purified using NucleoSpin Gel and PCR cleanup kit (Catalog \#740609, Machery-Nagel Inc., Bethlehem, PA, USA), cloned using the NEB PCR cloning kit (Catalog \#E1202S, New England Biolabs) and Sanger sequenced using the SimpleSeq premixed Kit (Eurofins Genomics) with the following primers in Table S1. 
Sequencing showed directed insertion into $\operatorname{Ir} 8 a$ exon 2 with no aberrant insertions or deletions.

Ir $8 a^{a t t P}$ mutant lines were screened for attP insertion and detected by fluorescent size-based genotyping each generation. Pupae were sexed and allowed to eclose in samesex cages. Virgin $\mathrm{G}_{2}$ females were allowed to mate freely with introduced wild-type males 24 hours after eclosion. Mosquitoes were then outcrossed to wild type in this manner for 5 generations. Single-pair crosses of $\mathrm{G}_{5}$ siblings were set up and mosquitoes with the desired mutations were chosen for homozygosing. Females were blood-fed and placed in individual oviposition vials. After eggs were laid, females were sacrificed, and genomic DNA was extracted using the IBI Genomic DNA extraction kit (Catalog \#IB47222, IBI Scientific, Peosta, IA, USA). A fluorescent amplicon was generated using Amplitaq Gold 360 PCR master mix (Catalog \#4398881, Applied Biosystems, Foster City, CA, USA) for each female using the following primers: Ir8aExon3for1 and Ir8aExon3rev2 (Table 1). Samples were sent for capillary electrophoresis to the DNA Core Lab at Florida International University and were then genotyped using Peak Scanner software (v1.0, Applied Biosystems) to determine the fragment length.

To confirm the single stranded donor DNA insertion in the Ir8 $8 a^{\text {attP }}$ allele, PCR products were amplified from mosquitoes that contained the $\operatorname{Ir} 8 a^{\text {att } P}$ allele and were PCR purified using QIAEX II Gel Extraction Kit (Catalog \#20051, Qiagen). After purification, the amplicons were ligated into the pCR2.1 TOPO TA vector (Catalog \#K462040, Invitrogen, Carlsbad, CA, USA) and transformed with One Shot TOP10 chemically competent E. coli cells (Catalog \#C607003, Invitrogen). Thereafter, colonies were picked and prepped using the QIAprep Spin Miniprep Kit (Catalog \#27104, Qiagen). 
The plasmid DNA was sequenced in the DNA Core facility lab at the Florida International University.

In order to determine where $\operatorname{Ir} 8 a$ is expressed in adult female mosquitoes, we dissected five different body parts including the whole body, head without antennae, antennae alone, head alone, and headless body from sugar-fed 7-10 days old wild-type Ae. aegypti of the Orlando strain. A total of 10 mosquitoes were dissected for each body part except for the antennae, where a total of 25 antennal pairs were used for the assay. In addition, we also dissected antennal tissues from $\operatorname{Ir} 8 a^{d s R E D / d s R E D}, \quad \operatorname{Ir} 8 a^{a t t P / d s R E D}$, $\operatorname{Ir} 8 a^{d s R E D} /+, \operatorname{Ir} 8 a^{a t t P} /+$, and wild-type Ae. aegypti Orlando strain to determine if $\operatorname{Ir} 8 a$ mRNA expression was altered by the mutations we made. For this assay, a total of 10 mosquito heads were used for each genotype. Using a pair of forceps, samples were dissected under cold anesthesia into RNAlater stabilization solution (Catalog \#AM7020, Invitrogen) or into a dry ice/ethanol bath. For each genotype or tissue type, at least three biological replicates were used.

\subsubsection{Ir8a mRNA extraction and treatment}

Mosquito tissues were suspended in a $1 \mathrm{ml}$ solution containing $4 \mathrm{M}$ guanidine thiocyanate (CAS: 593-84-0), 0.5\% Sarkosyl (CAS: 137-16-6), Chloroform (CAS 67-663), and 0.1 M of 2-mercapthoethanol (CAS: 60-24-2). Thereafter, tissue samples were manually homogenized using RNase-free disposable pellet pestles (Catalog \#12-141-364, Thermo Fisher Scientific). Phenol-chloroform phase separation was performed to separate the supernatant. This phase extraction process was repeated twice for the supernatant. RNA extraction was performed using the RNAid Kit supplied by MPBio (catalog \#111007200). 
Beads were washed twice using RNA Wash concentrate before eluting in $20 \mu 1$ DEPCtreated water. Sample concentration and quality were determined using NanoDrop 2000c (Thermo Fisher Scientific).

\subsection{5 cDNA synthesis and qPCR}

The RNA extracted was treated with Turbo DNA-free kit (Catalog \#AM1907, Invitrogen) to remove any DNA contamination. RNA was diluted to $50 \mathrm{ng} / \mathrm{ul}$ for each sample. cDNA library was created with reverse transcriptase using the SuperScript II RT reagent kit (Catalog \# 18080-051, Invitrogen) and primed using oligo dT. Each reaction comprises 200ng RNA to make up a final volume of $20 \mu$ l. After cDNA synthesis, samples were treated with RNase cocktail enzyme mix (Catalog \#AM2286, Thermo Fisher Scientific). cDNA samples were amplified using Amplitaq Gold 360 master mix (Catalog \#4398901, Fisher Scientific) and primed by ribosomal protein L32 gene. Genomic contamination and PCR amplification was assessed by running the sample on an agarose gel electrophoresis.

Ae. aegypti Ir8a mRNA expression was quantified using RT-qPCR (Catalog \#4345241, Thermo Fisher Scientific). Quantitative PCR was performed using TaqMan gene expression assay. The reaction consists of two sequence-specific PCR primers with a custom TaqMan probe (Catalog \#4331348, Thermo Fisher Scientific) in 2X universal master mix. The TaqMan assay was performed with three technical replicates for each given biological replicate. The real-time PCR was performed using the TaqMan universal PCR master mix (Catalog \#4324018, Thermo Fisher Scientific). The forward primer sequence (ATCAGTCCGATCGCTATGACAAG) and the reverse primer sequence (GGTTGTCAATACCTTTCGGCTTAC) were used as control primers (Table 1). 
Raw data was analyzed using SDS v1.5.1 software with the detection threshold set at 0.2. Outliers with $\mathrm{Ct}$ values greater by 0.5 from the nearest technical replicate were discarded. The ribosomal protein L32 gene was used as endogenous control to normalize between cDNA samples. Relative fold change was calculated as previously described [55].

\subsubsection{Behavior assays}

Mosquito activity was monitored using Locomotor Activity Monitors (LAM 25; Trikinetics Inc., Waltham, MA, USA). Sugar-fed 5 to 7-day old female mosquitoes were singly aspirated into glass tubes ( $25 \mathrm{~mm}$ diameter, $125 \mathrm{~mm}$ long) directly from the cage without cold anesthesia. The glass tubes were sealed at both ends with cotton plugs. One of the cotton plugs was soaked in water and the other end was left dry. This was done in order to generate more activity in the tube. We hypothesized that mosquitoes would hygrotax to the wet end. The set up was maintained at $25-28^{\circ} \mathrm{C}$ and $75 \%$ relative humidity under a 14:10 light-dark cycle (lights on at $8 \mathrm{am}$ ). The movements of the mosquitoes triggered an infrared beam break. This was set to record at every second and tabulated into 1min bins. Bins with more than 60 beam breaks and trials that exceed 2000 beam breaks per day were excluded from the analysis. Activity count was recorded for 24 hours on the fourth full day of fasting.

The capillary feeder (CAFE) assay was adapted for mosquitoes with slight modifications from the feeding study carried out on fruit flies [45, 46]. Female mosquitoes aged 5 to 7 days were starved from sugar for 24 hours but had unlimited access to water. After fasting, five mosquitoes were transferred into each polystyrene vial (95mm long, $27 \mathrm{~mm}$ wide) and sealed with a cotton plug. Thereafter, two calibrated $5 \mu \mathrm{l}$ capillary tubes (catalog \#1904637, Blaubrand Intramark) were introduced into the vial. 
The capillary tubes were filled with $10 \%$ sucrose to the $5 \mu 1$ mark. The assay lasted for 18 hours and feeding was estimated by recording the change in the sucrose volume. Control vials without mosquitoes were also set up to correct for water loss due to evaporation.

The fasting resistance assay was carried out accordingly as previously described [21]. A total of sixty male and sixty female mosquitoes from each of the five genotypes $\left(\operatorname{Ir} 8 a^{d s R E D / d s R E D}, \operatorname{Ir} 8 a^{a t t P / a t t P}, \operatorname{Ir} 8 a^{d s R E D} /+, \operatorname{Ir} 8 a^{t t P} /+\right.$ and wild-type $)$ were tested for fasting resistance. Prior to the experiment, mosquitoes were fed on $10 \%$ sugar. Thereafter, each mosquito was aspirated into a fly vial (25 mm diameter, $95 \mathrm{~mm}$ long) containing 1 cotton ball soaked in $10 \mathrm{ml}$ of distilled water and plugged with a cellulose acetate fly vial plug (Catalog \# 49-101, Genesee Scientific, San Diego, CA, USA). In order to control for positional effects, vials were randomized for genotype and sex in the racks. Experiments took place in the behavior room at $25-28^{\circ} \mathrm{C}, 75 \%$ relative humidity under a $14: 10$ lightdark cycle (lights on at 8 am). To quantify fasting resistance, visual examination of the vials was carried out each day to observe for any movement. If no movement was noticed, the vial was tapped twice and visually inspected again. If the mosquito failed to move, it was scored as dead.

Electroantennogram (EAG) recordings were made using $\mathrm{Ag}-\mathrm{AgCl}$ electrodes and glass capillaries filled with Ringer solution $\left(8.0 \mathrm{~g} \mathrm{~L}^{-1} \mathrm{NaCl} 0.4 \mathrm{~g} \mathrm{~L}^{-1} \mathrm{CaCl}_{2}\right)$ connected to silver wire, which closed the electric circuit. Non-blood fed female mosquitoes (Ae. aegypti) were recorded at 3-4 days post-eclosion between 8am and 4pm. Mosquitoes were chilled for one minute before their bodies were secured between sticky tape and wax. The glass capillary connected to the indifferent electrode was placed within the eye of the mosquito. 
The glass capillary connected to the recording electrode was connected to the tip of the antennae. The signals were passed through a high impedance amplifier (IDAC-4, Syntech 2004, Hilversum, Netherlands) and analyzed using a customized software package (Syntech EAG-Pro 4.6). Ten microliter aliquots of each chemical compound at a concentration of $1 \times 10^{-3} \mathrm{mg} / \mathrm{mL}$ were added onto a pre-cut filter paper (Whatman No. 1, $20 \mathrm{~mm}$ ), which was inserted into sterilized Pasteur pipette. The stimuli were delivered via an air stream at a flow rate of $1 \mathrm{~L}^{\mathrm{min}}{ }^{-1}$ with a puff ( 2 seconds duration) at 30 second intervals. Solvent control (Hexane) was tested at the beginning and end of each repetition. Each treatment contained 5 replicates.

The odor volatiles tested in the EAG experiment include: Geranylacetone (C.A.S. 689-67-8), 6-methyl-5-hepten-2-one (Sulcatone, C.A.S. 110-93-0), Linalool (C.A.S. 7870-6), Dodecanal (C.A.S. 112-54-9), Lactic acid (C.A.S. 79-33-4) and were obtained from Sigma-Aldrich. Octanoic acid (C.A.S.124-07-2), Heptanoic acid (C.A.S. 111-14-8) and Butyric acid (C.A.S. 107-92-6) were supplied by ICN. Octanal (C.A.S. 124-13-0) and Nonanal (C.A.S. 124-19-6) were obtained from Chemicon:Acros. Limonene (C.A.S. 5989-27-5) and Nonanoic acid (C.A.S. 112-05-0) were supplied by Fluka. 2-ethyl hexanol (C.A.S. 104-76-7) was obtained from Lancaster; while 1-octen-3-ol (C.A.S. 3391-86-4) was supplied by Janssen Chimica.

Membrane-feeding assay was carried out as previously described with slight modifications [22]. A total of four $14 \mathrm{~mm}$ diameter glass-jacketed membrane feeders (\#CG-1835-70, Chemglass) were connected in series using silicone tubing to a digital water bath (VWR international). The membrane feeder was prepared by stretching a thin layer of Parafilm M laboratory film (Catalog \#PM996, Bemis) over the feeders. 
Thereafter, a total of $1000 \mu l$ of defibrinated whole sheep blood without any added ATP (Hemostat Laboratories) was transferred into each feeder. A dimension of $10 \mathrm{~cm}$ by 10 $\mathrm{cm}$ squares of nylon sleeves (Duane Reade), previously worn for 12 hours by a human subject, were perforated and stretched over the Parafilm and tied around the feeder. For each trial, 4 cups of mosquitoes $(n=18-20)$ were set into their feeding positions in a room with regulated temperature $\left(25^{\circ} \mathrm{C}\right)$ and relative humidity $(75 \%)$. The assay was supplemented with $\mathrm{CO}_{2}$ diffusion pads $(8.0 \mathrm{~cm}$ by $11.5 \mathrm{~cm}$; Tritech Research), placed at the edge of the cup, and set to release at a rate of 2500-2700ppm measured by a carbon dioxide monitor (Catalog \# $\mathrm{CO}_{2}-100$, Amprobe, Everett, WA). The blood in the membrane feeder was heated to $37^{\circ} \mathrm{C}$ to mimic human body temperature. For assays without heated blood, the temperature was maintained at room temperature $\left(26^{\circ} \mathrm{C}\right)$. Feeding positions were alternated to control for position effects on the genotypes tested. The assay had duration of 15 minutes. Blood fed mosquitoes were visually scored and any mosquitoes that appeared not to have blood-fed were squashed between paper towels. If blood was found on the paper after squashing, the animal was scored as blood-fed.

A custom-built uniport olfactometer constructed by the Engineering Department at Florida International University was built to assess female mosquito attraction to human host stimuli. The uniport olfactometer is made of a large plexiglass tube $(75 \mathrm{~cm}$ long and $13 \mathrm{~cm}$ wide) attached to a small cylindrical trap $(13 \mathrm{~cm}$ long and diameter is $5 \mathrm{~cm}$ wide) which houses the mosquitoes before the experiment. The other end of the plexiglass tube is a hollow box (length is $25 \mathrm{~cm}$, breadth is $20 \mathrm{~cm}$ and diameter is $13 \mathrm{~cm}$ ) connected to the stimulus chamber. Carbon-filtered, humidified air and $\mathrm{CO}_{2}$ are able to mix with the odorants in the stimulus chamber to attract mosquitoes. 
The $\mathrm{CO}_{2}$ release rate in the stimulus chamber was measured by an acrylic flowmeter Model VFA-4-SSV (Dwyer Instruments Inc., IN, USA) set at 3 SCFH. The final concentration for $\mathrm{CO}_{2}$ in the assay was maintained at 2500-2700ppm by a carbon dioxide monitor (Catalog \# $\mathrm{CO}_{2}-100$, Amprobe). Whereas, air flow rate was set at 21 standard cubic feet per hour by an air flowmeter (King Instruments CA, USA). The sealed design of the uniport, air filtration, and the positive pressure caused by the airflow in the apparatus isolated the assay from potential odors in the surrounding environment.

For each trial, approximately 20 female Ae. aegypti mosquitoes one-week posteclosion were sorted under cold anesthesia $\left(4^{\circ} \mathrm{C}\right)$ and placed in a small cylindrical trap. All females used in the assay had access to their mating partners but had not obtained a blood meal. Females were fasted with access to water for up to 24 hours prior to the assay. Pre-assay fasting and behavior experiments took place at $25^{\circ} \mathrm{C}$ and $70-80 \%$ relative humidity. In our experiments, we tested multiple genotypes including wild-type, heterozygous $\operatorname{Ir} 8 a$ mutant $\left(\operatorname{Ir} 8 a^{d s R E D} /+\right)$, homozygous $\operatorname{Ir} 8 a$ mutant (Ir $\left.8 a^{d s R E D / d s R E D}\right)$, heteroallelic Ir8a mutant (Ir8a $\left.a^{a t t P / d s R E D}\right)$, homozygous orco mutant $\left(\right.$ orco $\left.o^{16 / 16}\right)$, heteroallelic orco mutant $\left(\operatorname{orco}^{5 / 16}\right)$, homozygous $I r 8 a$ and orco double mutants $\left(\operatorname{Ir} 8 a^{d s R E D}, \operatorname{orco}^{16}\right)$, homozygous Gr3 mutant $\left(G r 3^{c f p / c f p}\right)$, heterozygous Gr3 mutant $\left(G r 3^{c f p} /+\right)$, and homozygous $\operatorname{Ir} 8 a$ and $G r 3$ double mutants $\left(\operatorname{Ir} 8 a^{d s R E D}, G r_{3}^{c f p}\right)$. Heteroallelic mutants were tested to control for background mutations that may have occurred independently in each line. Double mutants were tested to assess the epistatic interaction between the two genes. 
To explore the behavior of these mosquito lines, starved mosquitoes were released from the small cylindrical trap and allowed to respond to the stimuli. After 8 mins, the number of mosquitoes attracted by host cues was counted. The 8 mins time point was determined empirically to produce consistently high responses. A blank trial with no odor stimulus was run to ascertain that the set-up was clean. Attraction greater than $20 \%$ indicates the presence of residual odor and the whole set up was cleaned up again with an odorless soap and allowed to air dry. Mosquitoes were scored as attracted if they were able to fly upwind through the tube into the attraction trap within the time frame. Mosquitoes that move out of the cylindrical trap within the assay period were scored as activated.

A total of 15 human subjects were recruited for the uniport assay. Each subject was tested twice to assess his or her attractiveness to mosquitoes in a uniport olfactometer as described above. All subjects were given informed consent before participating in the experiment and approved by the Florida International University Institutional Review Board. The volunteers were diverse in age (19 to 41 years), gender (Male=7, Female=8), and race (White [5], Hispanic [7], Asian [1], Black [2]). All of the human subjects were asked not to wear scented cosmetics, deodorants, or fragrances on the day of the assay. Any subject that did not follow our request was excluded from the study. Human subjects that adhered to this rule were asked to insert their forearm up to the elbow level into the stimulus chamber. The arm was inserted through a tight-fitted glove affixed to the olfactometer to prevent airflow between the assay and the room. Mosquitoes bit none of the human volunteers during the experiment. 
The toe sections of women's knee-high pantyhose (Hanes Brands Inc., NC, USA) were cut off with scissors. A single volunteer subject was used for this assay to control for differential attractiveness. The subject wore the nylon sleeves on the arm and stretched it towards the armpit. This was worn overnight for 12 hours while the subject did not shower or apply any scented products. The nylon sleeves were later retrieved from both arms and immediately tested on the library of mutants already generated, as well as the wild type mosquitoes in the uniport olfactometer. New nylon sleeves perfumed with human odor were used for each day of testing without prior storage. Nylon sleeves that had not been previously worn were used as a negative control.

In order to test the response of wild-type and $\operatorname{Ir} 8 a$ mutant mosquitoes to lactic acid, we used the set up for the uniport olfactometer assay with slight modifications. Approximately 30 mosquitoes were used for each trial. A total of $4 \mathrm{ml} \mathrm{L-(+)-} \mathrm{lactic} \mathrm{acid}$ solution (C.A.S. 79-33-4, catalog number 27714; 88\%-92\%, Sigma-Aldrich) was transferred by a pipette directly into the open lid of a polystyrene Petri dish $(60 \mathrm{~mm}$ diameter, $10 \mathrm{~mm}$ height). The treatment was centrally placed in the stimulus port. For the control, the Petri dish was left blank. The number of mosquitoes attracted was recorded after 10 min. $\mathrm{CO}_{2}$ concentration (2500ppm $\left.-2700 \mathrm{ppm}\right)$ was monitored by a carbon dioxide meter (Catalog \# $\mathrm{CO}_{2}-100$, Amprobe).

Carbon dioxide monitor (Amprobe $\mathrm{CO}_{2}-100$, Everett, WA) was used to measure $\mathrm{CO}_{2}$ release rate in a custom-built uniport olfactometer. In this experiment, air flow rate was maintained at 21 standard cubic feet per hour ( $\mathrm{SCFH})$ as measured by an airflow meter (King Instruments $\mathrm{CA}$, USA). The final $\mathrm{CO}_{2}$ concentration in the assay was measured by placing the $\mathrm{CO}_{2}$ monitor where the trapped mosquitoes were held. 
For the assay with air alone, carbon-filtered humidified air was released into the stimulus port. For the assay with supplemented $\mathrm{CO}_{2}$, an acrylic flowmeter Model VFA-4SSV (Dwyer Instruments Inc., IN, USA) set at $3 \mathrm{SCFH}$ was used to control $\mathrm{CO}_{2}$ release rate into the stimulus chamber of the uniport. For the assay with a human arm, the arm of the subject was inserted through a tight-fitted glove affixed to the olfactometer to prevent airflow between the assay and the room. The sealed design of the uniport and the positive pressure caused by the airflow in the apparatus isolate the assay from potential odors in the surrounding environment. The stimuli (airflow, supplemented $\mathrm{CO}_{2}$ and skin-emanated $\left.\mathrm{CO}_{2}\right)$ traveled from the stimulus port into the large plexiglass tube $(75 \mathrm{~cm}$ long and $13 \mathrm{~cm}$ wide) and exited via the aperture where the mosquitoes were released. The $\mathrm{CO}_{2}$ final concentration was measured via the aperture where the mosquitoes were released.

A total of ten trials were carried out to measure the $\mathrm{CO}_{2}$ release rate from the olfactometer. The device was turned on and allowed to calibrate to ambient $\mathrm{CO}_{2}$ room concentration. For each measurement, the device was placed in the aperture and measurements were recorded when the digital recording was stabilized. The device recording was stable when the beep sound was consistent. After taking the recording, the device was removed from the aperture and allowed to calibrate to ambient room condition. This process was repeated consistently for the ten trials. Carbon dioxide release rates were measured in three different conditions: humidified air, humidified air and $\mathrm{CO}_{2}$, and humidified air supplemented with $\mathrm{CO}_{2}$ and human arm. Data was analyzed using one-way AVOVA. Conditions marked with different letters were significantly different according to post hoc Tukey's HSD test. 


\subsubsection{Quantification and statistical analysis}

Statistical analysis of our behavioral and quantitative PCR data sets was performed using the GraphPad Prism 7 software package (GraphPad Software, San Diego, CA, USA). Statistical analysis of our electrophysiological recordings (EAGs) was performed using GraphPad Prism 8 software package (GraphPad Software, San Diego, CA, USA). All details for statistical analysis including the statistical tests used, number of trials (n), number of animals, and how significance was determined can be found in the figure legends.

\subsection{Results}

\subsubsection{Targeted mutagenesis of Ae. aegypti Ir8a, an antenna specific ionotropic receptor}

Previous analysis of the neurotranscriptome of Ae. aegypti has suggested that Ir $8 a$ is expressed in the antenna and no other chemosensory tissues [24]. To confirm this result, we first asked if Ir $8 a$ expression can be detected in any other body tissues. Using quantitative RT-PCR analysis in wild-type mosquitoes, we compared the expression of the intact female to the head plus antenna, antenna, body minus the head, and head minus antenna. We show that $\operatorname{Ir} 8 a$ mRNA expression is enriched in the antenna and nearly undetectable in other tissues (Figure S1A). Given that olfaction is key for mosquitoes to host seek [6], and $\operatorname{Ir} 8 a$ acts as an obligate olfactory co-receptor that can complex with odor-tuned IRs that detect acids in Drosophila $[45,48]$, we speculated that mutations in Ae. aegypti Ir8a should disrupt a distinct subset of IRs that are responsive to acidic volatiles in human odor. 
To test this hypothesis, we generated targeted null mutations in the Ae. aegypti Ir8a gene using CRISPR/Cas9 RNA-guided gene editing [65]. We integrated two distinct donor DNAs to generate two independent alleles in the $\operatorname{Ir} 8 a$ locus at exon 2 and exon 3 (see methods). These two independent mutant alleles, $\operatorname{Ir} 8 a^{\mathrm{dsRED}}$ (exon 2) and $\operatorname{Ir} 8 a^{\text {attP }}$ (exon 3), are predicted to produce truncated IR8a proteins that would eliminate Ir8a function. The sgRNA was designed to guide the Cas9 endonuclease to exon 2 of $\operatorname{Ir} 8 a$ and enable integration of the polyubiquitin promoter and dsRED fluorescent protein through homology dependent repair by way of a plasmid containing the promoter, fluorescent marker and SV40 terminator flanked by homologous DNA sequences surrounding the predicted cut site (Figure 3A). This insertion visually marked $\operatorname{Ir} 8 a^{\mathrm{d} \text { SRED }}$ mutants with dsRED fluorescence and could be detected in the Ir $8 a$ locus by PCR using a primer that anneals to sequences in the donor construct homologous right arm in $\operatorname{Ir} 8 a$ exon 2 and a second primer that anneals outside the bounds of the donor construct in Ir8a exon 4 (Figure 3B \& C, Table 1).

Sanger sequencing of the PCR amplicon showed site-directed integration of the donor plasmid into the Ir8a locus as expected (Table 1). To generate the Ir8 $a^{\text {attP }}$ allele, an sgRNA, Cas 9 mRNA, and a single stranded DNA oligo containing a 50 bp attP PhiC31 recombination site [66] flanked by 75 bp of homologous sequence surrounding the CRISPR binding site were injected into preblastoderm embryos. However, we observed a 17bp deletion in the CRISPR site and $2 \mathrm{bp}$ deletion in the attP site which may reduce PhiC31-mediated recombination frequency at this site. $\operatorname{Ir} 8 a^{\text {attP }}$ sequencing data suggests that it was a null mutation, as the predicted mRNA from the $\operatorname{Ir} 8 a^{\text {attP }}$ allele would contain 20 stop codons. 
To reduce the possibility of off-target effects, both alleles were outcrossed to the wildtype Orlando laboratory strain for five generations and then homozygosed.

We next investigated if $\operatorname{Ir} 8 a$ mRNA is disrupted in $\operatorname{Ir} 8 a$ mutants. Using quantitative RT-PCR, Ir $8 a$ mRNA in the homozygous $\operatorname{Ir} 8 a^{\text {attP/attP }}$ mutants was nearly undetectable in both sexes (Figure S1B \& C). This suggests that the mRNA is degraded by non-sense mediated decay and that the $\operatorname{Ir} 8 a^{\text {attP/attP }}$ mutant is an RNA null. However, the $\operatorname{Ir} 8 a^{\mathrm{dsRED}}$ allele showed over-expression of $\operatorname{Ir} 8 a$ mRNA in male and female mutants (Figure S1B \& C). The increase in $\operatorname{Ir} 8 a$ transcript levels observed in the $\operatorname{Ir} 8 a^{\mathrm{dsRED}}$ allele is likely the result of the insertion of the polyubiquitin promoter dsRed fluorescent protein expression cassette into the locus. The predicted $\operatorname{Ir} 8 a^{\mathrm{dsRED}}$ transcript cannot produce a full length IR8a protein. No behavioral phenotypic differences were found between the mosquitoes carrying these alleles suggesting that both $\operatorname{Ir} 8 a^{\text {attP }}$ and the $\operatorname{Ir} 8 a^{\mathrm{dsRED}}$ alleles are null. 
A
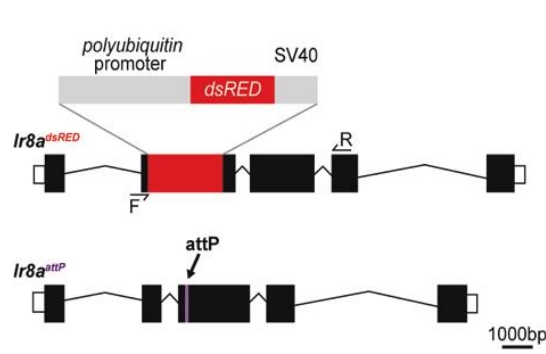

D

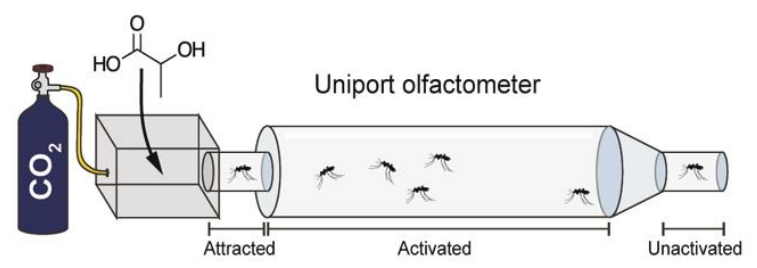

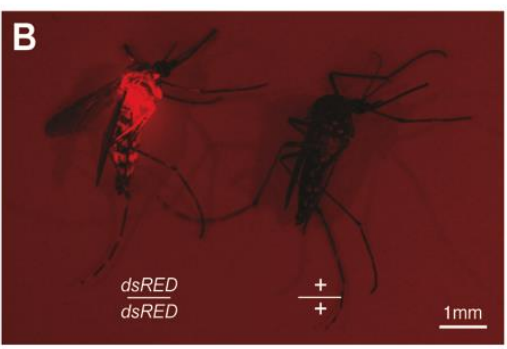
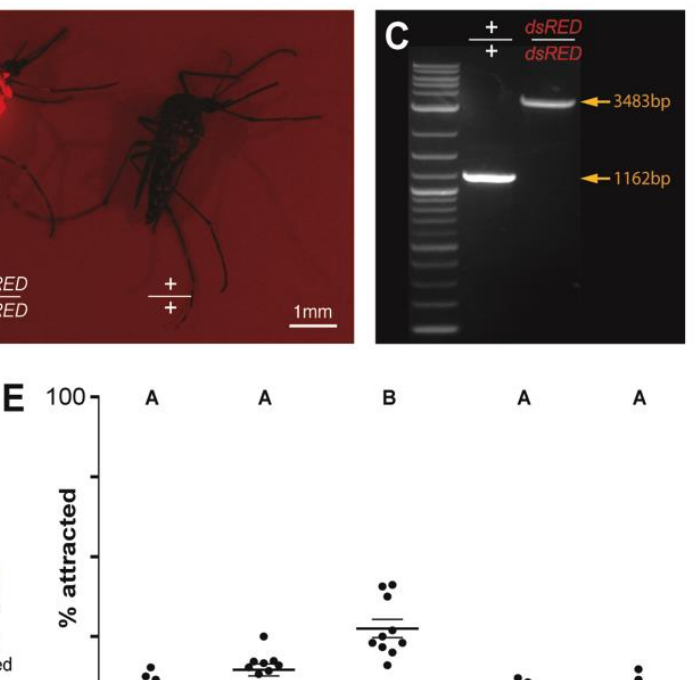

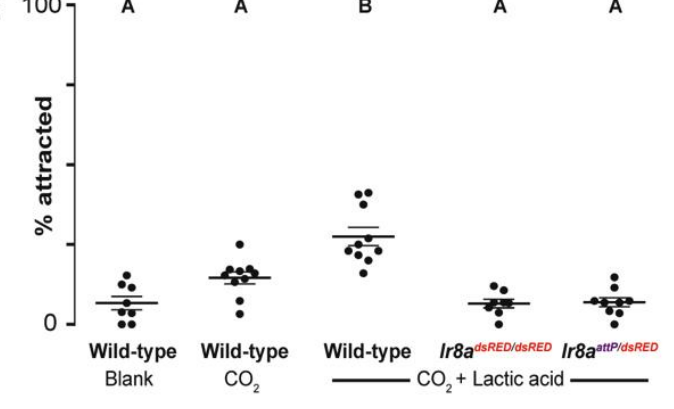

Figure 3. Mutagenesis of the Ae. aegypti Ir8a locus, and behavioral phenotypic analysis of Ir8a mutant response to lactic acid. (A) CRISPR sgRNAs designed to target the Cas9 nuclease to exon 2 and exon 3 of Ir8a. Integration location of the dsRED fluorescent marker and ssODN containing attP site into exon 2 and exon 3 of $\operatorname{Ir} 8 a$ respectively. (B) dsRED fluorescence in the $\operatorname{Ir} 8 a^{d s R E D / d s R E D}$ homozygous mutant (left) and wild-type (right) adult female mosquitoes. (C) PCR amplification from Ir8a exon 2 locus, note $1162 \mathrm{bp}$ amplicon from the wild-type Ir8a locus versus the larger 3483bp amplicon from $\operatorname{Ir} 8 a^{d s R E D / d s R E D}$ homozygous mutant female mosquitoes. (D) Uniport olfactometer assay designed to test behavioral response of $\operatorname{Ir} 8$ a mutants to lactic acid. Mosquitoes that fail to leave the trap during the assay are scored as unactivated, whereas mosquitoes that leave the trap but remain in the main tunnel are scored as activated. Mosquitoes in the trap adjacent to the stimulus chamber are scored as attracted. (E) Percent female mosquitoes attracted to no odor (blank) and $\mathrm{CO}_{2}$ alone $\left(\mathrm{CO}_{2}\right)$ as well as $\mathrm{CO}_{2}$ and lactic acid in a uniport olfactometer. Lactic acid and $\mathrm{CO}_{2}$ were co-presented to wild-type, $\operatorname{Ir} 8 a^{d s R E D / d s R E D}$, and $\operatorname{Ir} 8 a^{a t t P / d s R E D}$ female mosquitoes (right three panels). Trials with different letters are significantly different $(p<0.0001, \mathrm{n}=8-10)$. Analysis was done using One-Way ANOVA with post hoc Tukey's HSD test. See also Figure S1 \& S2, Table S1 

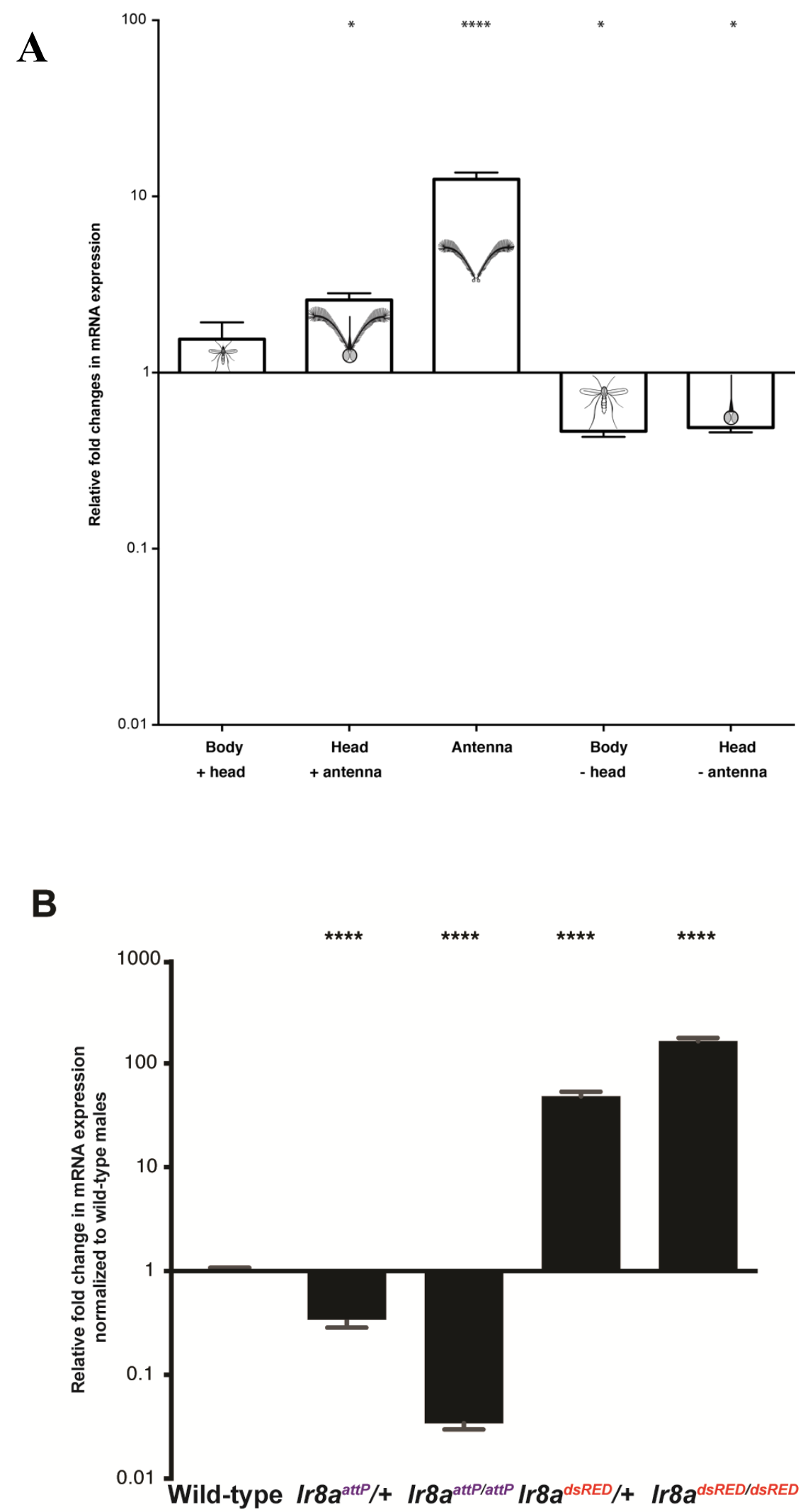


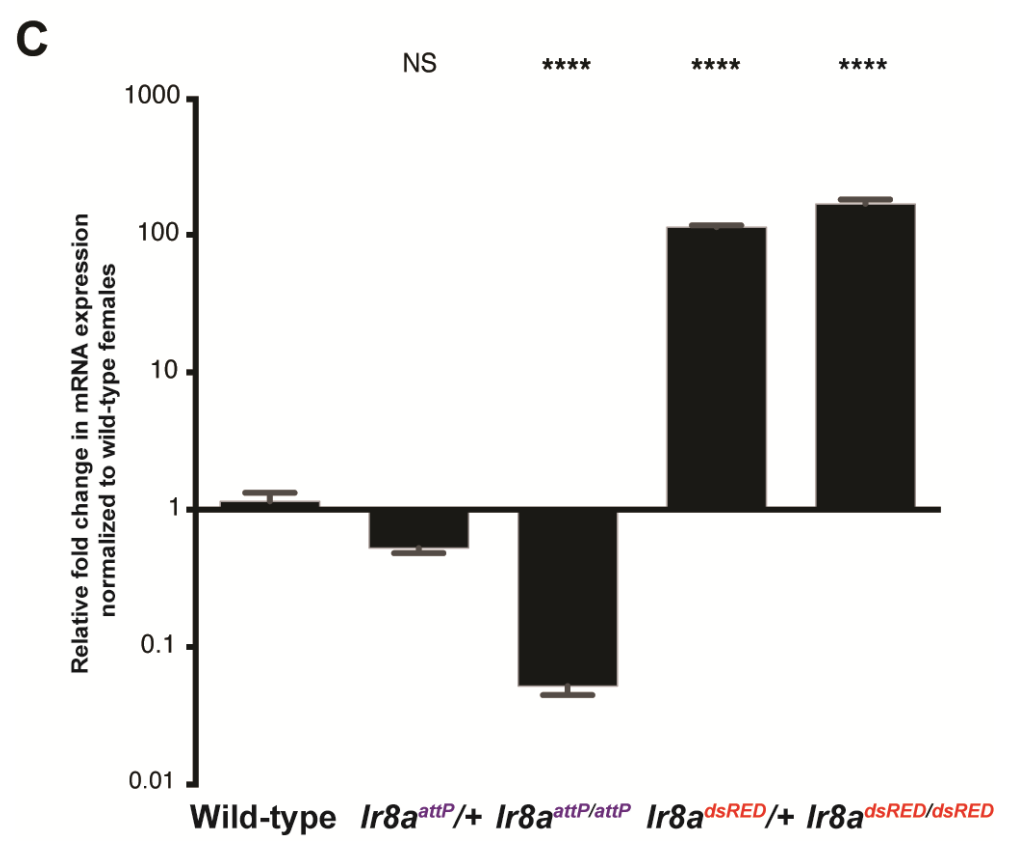

Figure S1: Quantification of Ir8a mRNA expression. Related to Figure 3.

(A) Quantitative RT-PCR analysis of Ir8a mRNA expression in wild-type female mosquito tissues. Bar plots represent the mean and standard error. Samples marked with asterisks are significantly different from an intact female by Mann-Whitney $U$ test $(\mathrm{P}<0.0001)$.(B) Relative fold change in mRNA expression normalized to wild-type males $(\mathrm{p}<0.0001)$ and $(\mathrm{C})$ females Ae. aegypti mosquitoes $(\mathrm{p}<0.0001)$. Bar plots represent the mean and standard error. Data was analyzed by Mann-Whitney U test. Genotypes marked with asterisks are significantly different from wild-type controls. 
A concern with the application of CRISPR/Cas9 mutagenesis is off target mutations which may alter the function of other genes [67]. To rule out non-specific behavioral defects in the Ir8a mutants, we assessed their fitness [42,68,69]. Using a locomotor activity assay, we found no difference in activity in $\operatorname{Ir} 8 a$ mutants when compared to the wild-type and heterozygous controls in the number of times they move past an infrared beam (Figure S2A \& B) [42]. We further investigated if Ir8a mutants may have feeding defects using the capillary feeder assay (CAFE) (Figure S2C) $[68,69]$. In this assay, mosquitoes were allowed to feed through a calibrated capillary tube containing $10 \%$ sucrose solution. We quantified sucrose consumption by recording the change in volume relative to control vials without mosquitoes. We recorded no difference in feeding in Ir8a mutants when compared to the wild-type and heterozygous controls after 18 hours of ad libitum feeding, (Figure S2D). We also evaluated the ability of the Ir $8 a$ mutants to survive fasting. This was tested by sugar-starving mosquitoes with access to water [42]. Our results suggest that our $\operatorname{Ir} 8 a$ mutant males and females can resist starvation as well as wild-type and heterozygous controls. (Figure S2E \& F). Taken together, these studies attest to the fitness of $\operatorname{Ir} 8 a$ mutants as well as their suitability for further behavioral analysis.

\subsubsection{IR8a pathway is required for sensing and responding behaviorally to acidic volatiles}

Lactic acid has been previously identified to be a behaviorally active component of human sweat that has been used to lure mosquitoes into traps or attract mosquitoes in olfactometer assays, but olfactory receptors for the compound have not been identified $[16,19,22,70]$. 
Studies have shown that attraction to lactic acid in Ae. aegypti, An. gambiae, and Culex quinquefasciatus can be enhanced in the presence of $\mathrm{CO}_{2}[43,53,71,72]$. Neither lactic acid nor $\mathrm{CO}_{2}$ is by itself a strong attractant [16]. However, both lactic acid and $\mathrm{CO}_{2}$ can synergize when presented together to elicit attraction in wild-type mosquitoes. Using a uniport olfactometer with carbon-filtered airflow, we tested the responses of wild-type and $\operatorname{Ir} 8 a$ mutant female mosquitoes to filtered air, $\mathrm{CO}_{2}$, as well as lactic acid and $\mathrm{CO}_{2}$ (Figure 3D \& E). In order to control for recessive background mutations that may have occurred in either of the two lines, we tested $\operatorname{Ir} 8 a^{\mathrm{dSRED} / \mathrm{dSRED}}$ and heteroallelic $\operatorname{Ir} 8 a$ mutants $\left(I r 8 a^{\text {attP/dsRED }}\right)$. The responses of $\operatorname{Ir} 8 a^{\mathrm{dsRED} / \mathrm{dsRED}}$ and $\operatorname{Ir} 8 a^{\mathrm{attP} / \mathrm{dsRED}}$ mutants to lactic acid and $\mathrm{CO}_{2}$ were not significantly different from each other or the wild-type responses to $\mathrm{CO}_{2}$ alone or filtered air (blank) (Figure 3E).

To confirm that $\operatorname{Ir} 8 a$ mutants have lost the ability to detect lactic acid, we examined the electrophysiological responses of female mosquitoes to a panel of odors. Unlike Drosophila, the olfactory receptor expression in mosquitoes has not been comprehensively mapped [73,74]. The location of IR8a expressing olfactory receptor neurons in the antenna is unknown making single sensillum recordings difficult to perform. To overcome this limitation, we used electroantennogram (EAG) measurements (Figure 4), which record the average signal output from the entire mosquito antenna for a given odor volatile [75]. 
The wild-type mosquitoes showed robust odor-evoked responses to all the odor panels tested (Figure 4A). However, $\operatorname{Ir} 8 a^{\mathrm{d} S R E D / d \mathrm{dRED}}$ mutants are insensitive to the acidic components of human odor represented in the panel including lactic acid (Figure 4B). We observed a similar lack of olfactory sensitivity in $\operatorname{Ir} 8 a^{\text {attP/dsRED }}$ heteroallelic mutants (Figure 4C). As shown on the representative current traces (Figure 4D), $\operatorname{Ir} 8 a^{\mathrm{d} \text { sRED/dsRED }}$ and $\operatorname{Ir} 8 a^{\text {attP/dsRED }}$ olfactory receptor neurons show weak responses to acidic volatiles similar to the solvent response of wild-type controls.

Our results show that Ir8a mutants have lost their behavioral and electrophysiological responses to lactic acid, and strongly suggests that IR8a is required to detect lactic acid. This was true of both the $\operatorname{Ir} 8 a^{\mathrm{dsRED}}$ allele and the heteroallelic combination of the $\operatorname{Ir} 8 a^{\mathrm{dsRED}}$ allele and the RNA-null $\operatorname{Ir} 8 a^{\text {attP }}$ allele, suggesting that both alleles retain no $\operatorname{Ir} 8 a$ gene function. In our study, $\operatorname{Ir} 8 a$ mutants are still able to detect other human volatile compounds including some alcohols, aldehydes and ketones suggesting that other olfactory pathways are not impaired in these mutants. 
A

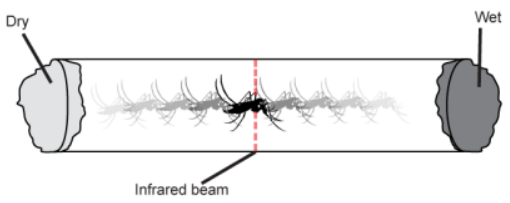

C

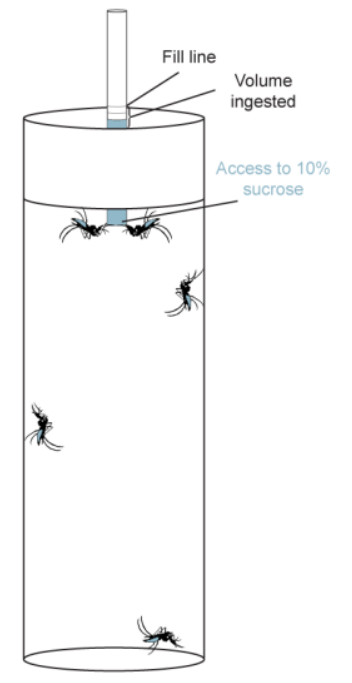

B

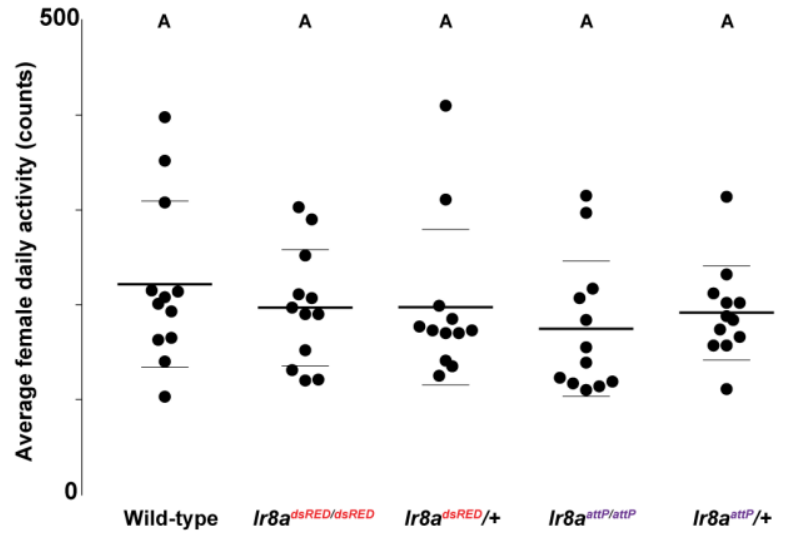

D

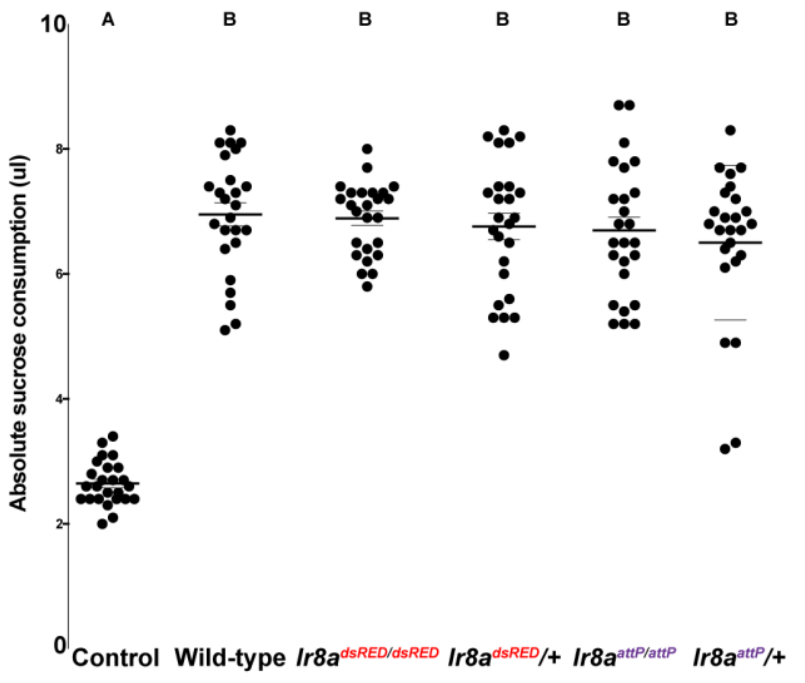




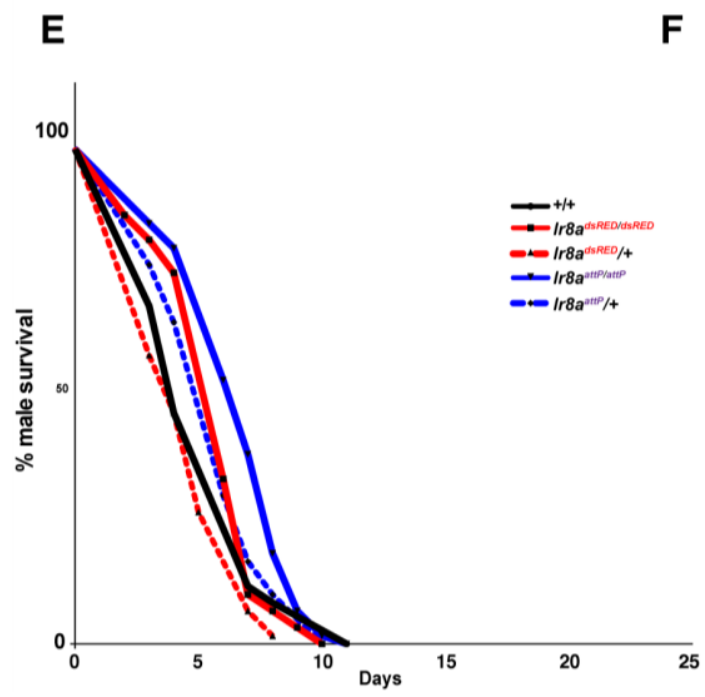

$\mathbf{F}$

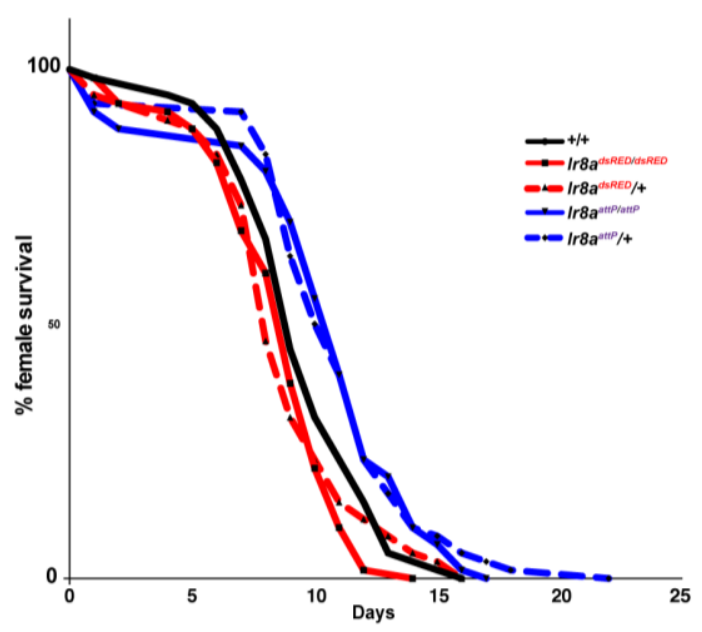

Figure S2. Assessing locomotor activity, survival, and sugar-feeding behavior in Ir $8 a$ mutants. Related to Figure 1.

(A) Diagram of beam break assay to monitor mosquito locomotor activity. (B) Average daily locomotor activity of $\operatorname{Ir} 8 a$ mutants after 4 days of fasting measured by the number of infrared beam breaks (counts). On the dot plot, long lines represent the mean and short lines represent standard error. There were no statistical differences among genotypes $(\mathrm{p}=$ $0.6224, n=12-13$ ). (C) Diagram of Capillary Feeder (CAFÉ) assay to quantify feeding behavior in mosquitoes. (D) Cumulative sucrose consumption after 18 hours of sugar feeding $(\mathrm{p}=0.9411, \mathrm{n}=25)$. On the dot plot, long lines represent the mean and short lines represent standard error. Data was analyzed by one-way ANOVA, and genotypes marked with the same letters are not significantly different by post hoc Tukey's HSD test. (E) Percent survival of 300 females under sugar starvation (F) Survival of 300 males under sugar starvation. Data was analyzed using log rank test and Geahand-Wilcoxon test followed by pairwise log rank comparisons with Bonferroni correction (corrected significance threshold; $\mathrm{p}<0.001)$. Using this test, $\operatorname{Ir} 8 a^{\text {attP/attP }}$ males lived significantly longer than wild-type and $\operatorname{Ir} 8 a^{\mathrm{dsRED}} /+$. Whereas, $\operatorname{Ir} 8 a^{\text {attP/attP }}$ female mosquitoes lived significantly longer than wild-type, $\operatorname{Ir} 8 a^{\mathrm{dsRED}} /+$, and $\operatorname{Ir} 8 a^{\mathrm{dsRED} / \mathrm{dsRED}}$ mosquitoes. There was no difference for any other pair of curves. 

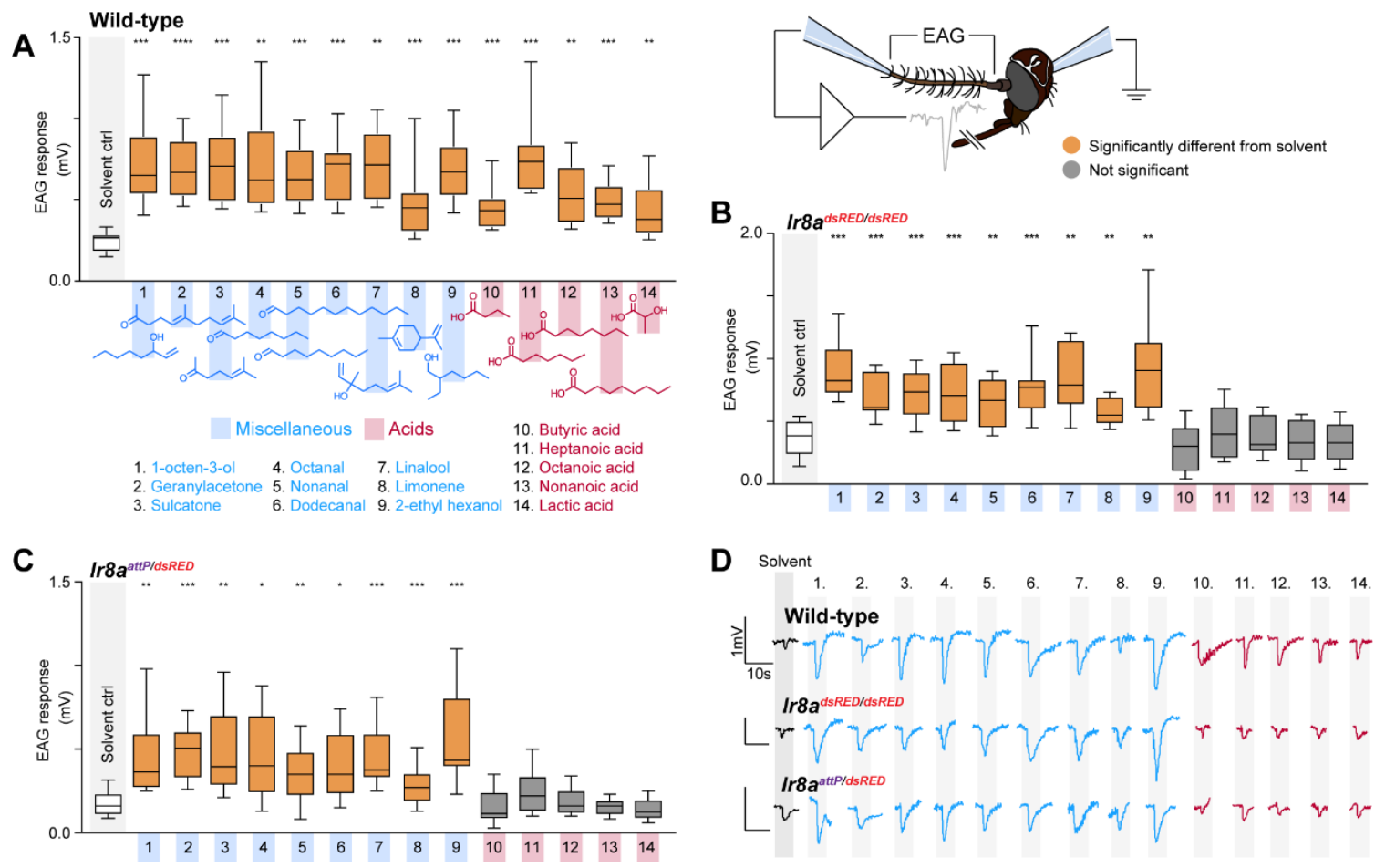

Figure 4. IR8a olfactory receptor pathway is required for sensing acidic volatiles that are component of human odor. (A) Electroantennogram (EAG) responses of wildtype Orlando strain, (B) Ir $8 a^{d s R E D / d s R E D}$ mutants, and (C) heteroallelic Ir $8 a^{d s R E D / a t t P}$ to volatiles that are components of human odor. (D) Representative EAG traces of the wildtype and $\operatorname{Ir} 8 a$ mutant mosquitoes. This figure is represented by a mean-max box and whisker plot. The ends of the box are the upper and lower quartiles. The median is marked by a horizontal line inside the box. The whiskers are the two lines outside the box that extend to the highest and lowest EAG response. The odors marked in red are acidic volatiles while the odors represented in blue include alcohols, ketones, aldehydes, monoterpenoid and alkene. EAG responses represented in orange dots are significantly different from solvent control. Responses labelled in grey are not significantly different from the solvent control. Statistical analysis was done using a mixed-effects model with Dunnet's multiple comparison test. Each column was compared with the mean of the solvent control column. EAG responses marked with asterisks indicate that it is significantly different from response to the control solvent $*^{*}=p<0.01$; $* *=p<0.001$; $* * *=p<0.0001 ; * * * *=p<0.00001)$. 


\subsubsection{Ae. aegypti IR8a pathway responds to human odor cues during blood-feeding}

Using a membrane blood-feeding assay (Figure 5A), we assessed the responses of Ir 8 a mutant and control female mosquitoes to heat, $\mathrm{CO}_{2}$, and human odor cues, by determining the percentage of females that would blood-feed [43]. While $\mathrm{CO}_{2}$ and human odor can activate and elicit mosquito attraction towards a blood source, the temperature of the meal is crucial for feeding to occur [76]. Experiments carried out with wild-type mosquitoes showed a robust feeding response when all cues were present, but feeding was reduced when human odor, $\mathrm{CO}_{2}$, or heat was removed (Figure 5B).

In the presences of all three cues, we found that both the $\operatorname{Ir} 8 a^{\mathrm{dsRED} / \mathrm{dsRED}}$ and the heteroallelic $\operatorname{Ir} 8 a^{\text {attP/dsRED }}$ mutants exhibited reduced blood-feeding when compared to wild-type or heterozygous controls (Figure 5C). We attempted to determine the individual contributions of human odor, $\mathrm{CO}_{2}$, and heat cues in the assay to the $\operatorname{Ir} 8 a$ mutant phenotype by eliminating one cue at a time. When only heated blood and $\mathrm{CO}_{2}$ were used as attractants there was no significant difference among genotypes (Figure 5D). This suggests that $\operatorname{Ir} 8 a$ mutant females can respond similarly to these cues as wildtype females. When the $\mathrm{CO}_{2}$ source was removed from the assay, the rate of bloodfeeding was very low across all the genotypes (Figure 5E). Similarly, when the temperature of the blood was shifted from body temperature $\left(37^{\circ} \mathrm{C}\right)$ to ambient temperature $\left(26^{\circ} \mathrm{C}\right)$, the absence of the heat cue nearly eliminated blood-feeding across all genotypes (Figure 5F). The level of blood-feeding was very low in the absence of heated blood or $\mathrm{CO}_{2}$, so it is difficult to discern genotypic differences. By comparing the results from assays that contain heated blood and $\mathrm{CO}_{2}$ (Figure 5C \& D), one can hypothesize that the defect found in $\operatorname{Ir} 8 a$ mutants is due to human odor detection. 
A

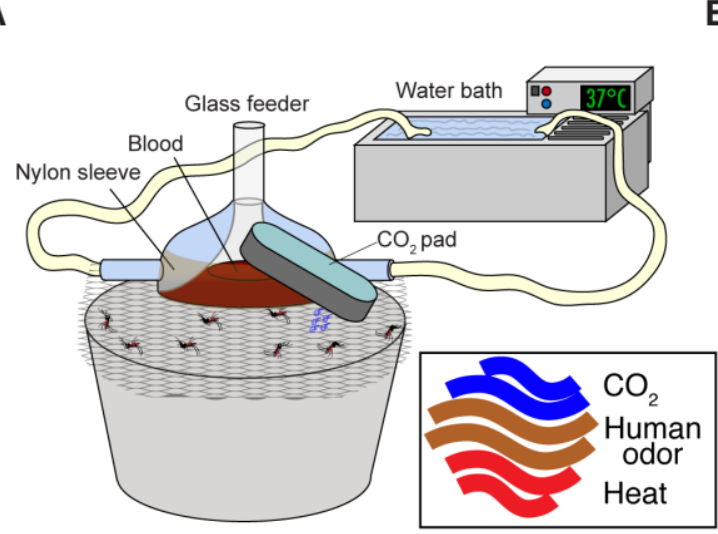

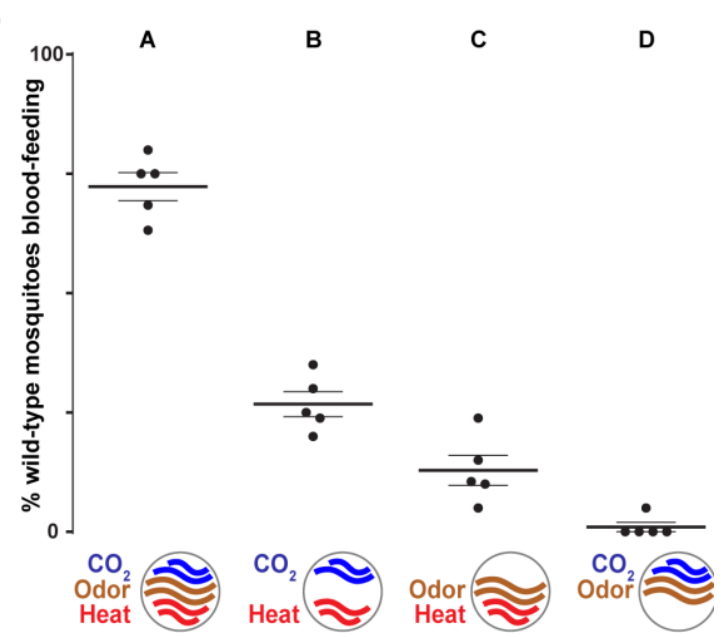

C

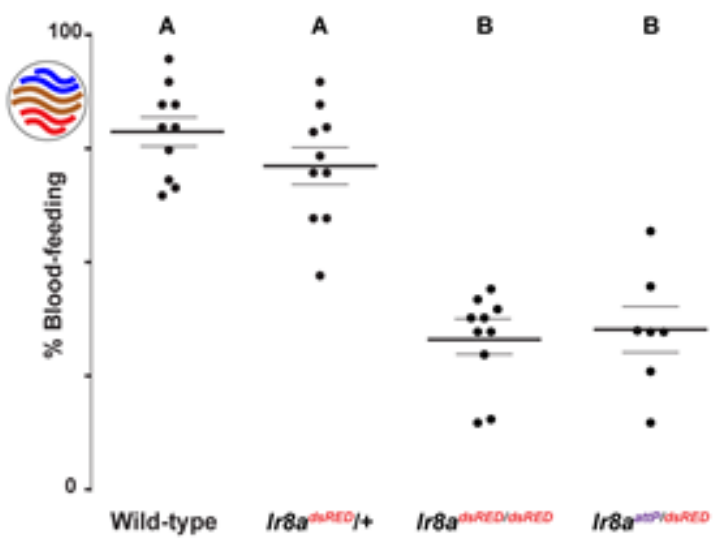

D

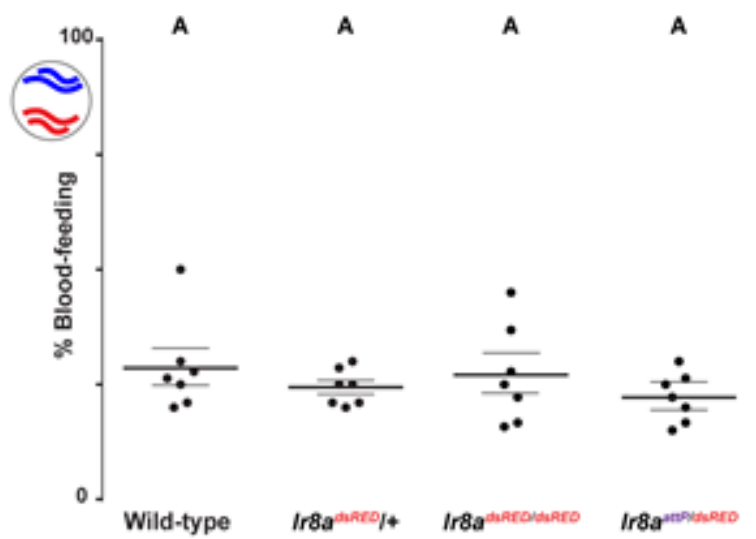




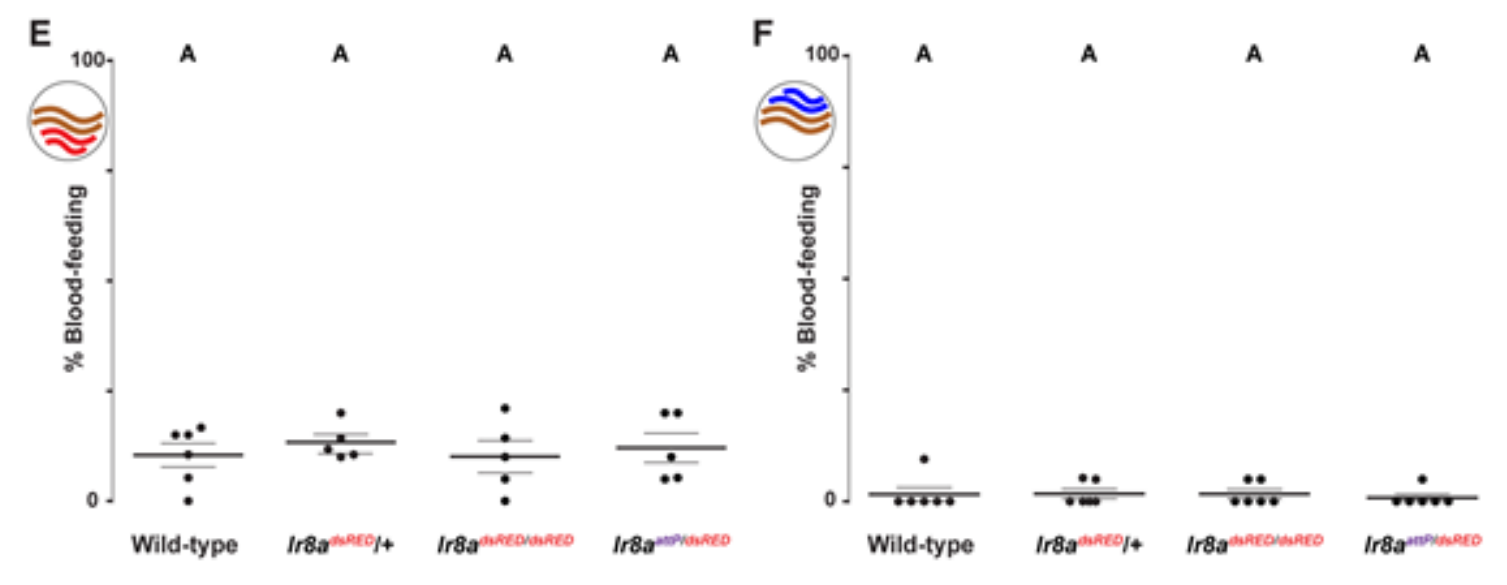

Figure 5. Ae. aegypti IR8a pathway responds to human odor cues during bloodfeeding (A) Illustration showing the membrane feeding assay to simulate female mosquito blood-feeding behavior. (B) Percent wild-type female mosquitoes responding to varying sensory cues $(\mathrm{n}=5 ; p<0.0001)$. (C) Percent female mosquitoes of indicated genotypes blood-feeding in the presences of $\mathrm{CO}_{2}$, human odor and heat cues $(p<0.0001$; $\mathrm{n}=7-10$ ). (D) Percent female mosquitoes of indicated genotypes blood-feeding in the presences of $\mathrm{CO}_{2}$ and heat cues, without human odor $(\mathrm{n}=7 ; p=0.468)$. (E) Percent female mosquitoes of indicated genotypes blood-feeding in the presences of human odor and heat cues, without added $\mathrm{CO}_{2}(\mathrm{n}=5-6 ; p=0.855)$. (F) Percent female mosquitoes of indicated genotypes blood-feeding in the presences of human odor and $\mathrm{CO}_{2}$ cues, without heat cue $(n=6 ; p=0.944)$. For the dot plots in $\mathrm{B}-\mathrm{F}$, long lines represent the mean and short lines represent standard error. Statistical analysis was done using OneWay ANOVA with post hoc Tukey's HSD test. Genotypes marked with different letters are significantly different. Human odor was collected from subject 1. See Table 2. 


\subsubsection{Ae. aegypti IR8a pathway is required to detect humans and human odor}

We subsequently investigated if the electrophysiological and behavioral defects recorded in $\operatorname{Ir} 8 a$ mutants could translate into impaired responses to human hosts. Using a uniport olfactometer with carbon-filtered airflow and added $\mathrm{CO}_{2}$, we examined the attraction rate of olfactory receptor mutants to 15 different human subjects (Figure 6A, Table 1). Each subject was tested twice with wild-type $(+/+)$, heterozygous $\left(\operatorname{Ir} 8 a^{\mathrm{dsRED}} /+\right)$, Ir $8 a$ mutant (Ir $\left.8 a^{\mathrm{dsRED} / \mathrm{dsRED}}\right)$, heteroallelic $\operatorname{Ir} 8 a$ mutant (Ir $\left.8 a^{\mathrm{attP} / \mathrm{dsRED}}\right)$, orco mutant $\left(\right.$ orco $\left.^{16 / 16}\right)$, heteroallelic orco mutant $\left(\operatorname{orco}^{5 / 16}\right)$ and double mutant (Ir8 $a^{d s R E D / d s R E D}$, orco $^{16 / 16}$ ) female mosquitoes. In these assays, wild-type mosquitoes and orco mutants showed robust attraction. In contrast, attraction to humans was significantly impaired in Ir8a mutants (Figure 6B). Differences in attraction were significant for both genotype and the 15 human subjects tested (two-way ANOVA, $\mathrm{P}<0.0001$ for genotype and $\mathrm{P}=$ 0.0095 for subject). The statistical difference in mosquito attraction to individual human subjects reflects the differences in attractive cues that emanate from each subject. Surprisingly, the additional loss of orco in the double mutants did not significantly enhance the $\operatorname{Ir} 8 a$ human detection defect in this assay (Figure 6B). This suggests the existence of other olfactory receptors that can respond to human odor since the double mutant still retains some attraction.

We next asked if the loss of attraction was dependent on olfactory cues from human hosts or on other cues emanating from live humans such as body heat, moisture, or visual cues. To test this, we excluded these other cues by trapping human odor on nylon sleeves previously worn on a human subject for 12 hours and exposing the scented sleeves to mosquitoes in our uniport assay (Figure 6D). In order to ascertain how long the 
scented sleeves could continue to elicit attraction, we tested the responses of wild-type mosquitoes. Even after 7 trials, which take approximately 85 minutes to perform, we found no significant difference in attraction rate (Figure S3). Thus, a given scented nylon sleeve was never used for more than 7 consecutive trials. Nevertheless, we randomly tested all genotypes to control for any potential bias linked to when human odor was presented.

Robust attraction was recorded in the wild-type, heterozygous controls, and orco mutants when the human-scented sleeve was simultaneously presented with $\mathrm{CO}_{2}$. Consistent with the study carried out with human subjects, $\operatorname{Ir} 8 a$ mutants show deficits in detecting nylon sleeves perfumed with human odor in these assays (Figure 6E). The weak attraction in the mutants cannot be explained by a defect in locomotion or overall fitness of the Ir8a mutants (Figure S2A-F). This suggests that impairment in sensitivity to Ir8adependent odor-ligands presented by humans is responsible for the behavioral defect seen in the uniport olfactometer assays with human subjects.

\subsection{5 $\mathrm{CO}_{2}$ differentially modulates the IR8a and Orco pathways}

Several studies have shown that $\mathrm{CO}_{2}$ can activate mosquito flight activity and facilitate host detection [77-81]. We asked if $\mathrm{CO}_{2}$ activation could modulate the attraction rate of Ir $8 a$ mutants by testing the attraction of the mutants to a human subject without including added $\mathrm{CO}_{2}$ in the assay. In contrast to uniport assays that included $\mathrm{CO}_{2}$ (Figure $6 \mathrm{~B} \& \mathrm{E})$, we recorded a host-seeking deficit in orco mutants in the absence of added $\mathrm{CO}_{2}$ that was not statistically different than Ir8a mutants (Figure 6C \& F). This supports an earlier study which reported that $\mathrm{CO}_{2}$ synergizes with human odor to rescue host-seeking defects in orco mutants [42]. Similar to what was observed with a human host when $\mathrm{CO}_{2}$ 
is not included in the assay, both Ir8a and orco single mutants lose strong attraction to nylon sleeves perfumed with human odor compared to wild-type controls (Figure 6C \& F). In contrast to orco mutants, $\operatorname{Ir} 8 a$ mutants' response to human odor was not changed by the presence or absence of $\mathrm{CO}_{2}$ (Figure $\mathrm{S} 4 \mathrm{~A}$ ). We found no difference in $\mathrm{CO}_{2}$ levels in the uniport when airflow is co-presented with a human arm or not (Figure S4B). Passing airflow over a human arm in the presence of $\mathrm{CO}_{2}$ did not increase $\mathrm{CO}_{2}$ levels versus airflow and $\mathrm{CO}_{2}$ alone (Figure $\mathrm{S} 4 \mathrm{~B}$ ).

Similar to what was observed in figure $\mathrm{C}$, attraction to human scented nylon sleeves is impaired in $I r 8 a^{\mathrm{dSRED}}$, orco ${ }^{16}$ double mutants when $\mathrm{CO}_{2}$ is absent (Figure 6F). As the genetic interaction between $\operatorname{Ir} 8 a$ and orco is dependent on $\mathrm{CO}_{2}$ sensation, we hypothesize that $\mathrm{CO}_{2}$ can activate additional olfactory receptor pathways to integrate the response to host odor cues in the absence of the OR pathway. Unlike in orco mutants, the response of $\operatorname{Ir} 8 a$ mutants to human odor is not modulated by $\mathrm{CO}_{2}$ (Figure $6 \mathrm{C} \& \mathrm{~S} 4 \mathrm{~A}$ ). This suggests that $\mathrm{CO}_{2}$ sensitization and host odor detection by other olfactory receptor pathways is not sufficient to rescue the Ir $8 a$ host-seeking defect. To explore this difference, we tested the genetic interaction between $\operatorname{Ir} 8 a$ and $G r 3$ mutants. 

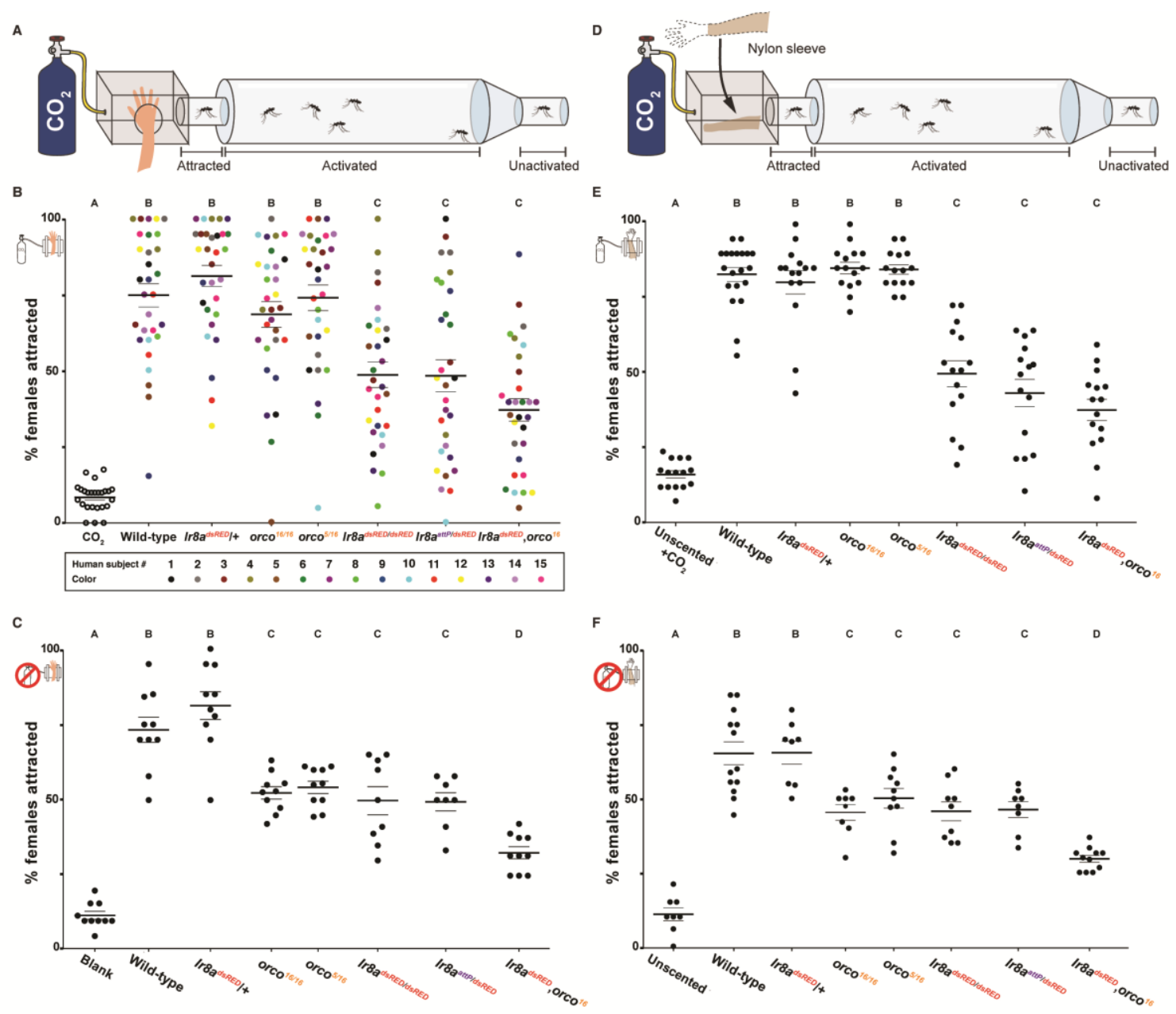

Figure 6. Ae. aegypti IR8a pathway is required to detect humans and human odor. (A) Illustration showing mosquito attraction to a human arm in a uniport olfactometer. (B) Dot plot of percent female mosquitoes of indicated genotypes attracted to 15 human subjects in the presence of $\mathrm{CO}_{2}$. Each subject was tested twice. An analysis was done using two-way ANOVA to compare the mean difference in attraction between subjects ( $\mathrm{n}$ $=30, p<0.0001)$ and genotypes $(\mathrm{n}=30, p<0.0095)$. Human subjects $(1-15)$ were differentiated on the plots by dot color in this figure (bottom panel). (C) Percent female mosquitoes of indicated genotypes attracted to a human arm in the absence of $\mathrm{CO}_{2}(p<$ $0.0001 ; \mathrm{n}=8$-10) (D) Illustration showing mosquito attraction to a human scented nylon sleeve in a uniport olfactometer. (E) Percent female mosquitoes of indicated genotypes attracted to human odor trapped on nylon sleeve in the presence of $\mathrm{CO}_{2}$. Data was analyzed using one-way ANOVA $(\mathrm{n}=15, p=0.0001)$. (F) Percent female mosquitoes of indicated genotypes attracted to human odor trapped on nylon sleeve in the absence of $\mathrm{CO}_{2}(p=0.0001 ; \mathrm{n}=15)$. For the dot plots, long lines represent the mean and short lines represent standard error. All data above was analyzed using One-Way ANOVA. Genotypes marked with different letters are significantly different by post hoc Tukey's HSD test. Human subject 1 was used in the experiments in panels C, E, \& F. See also Figure S3 \& S4 as well as Table S2. 


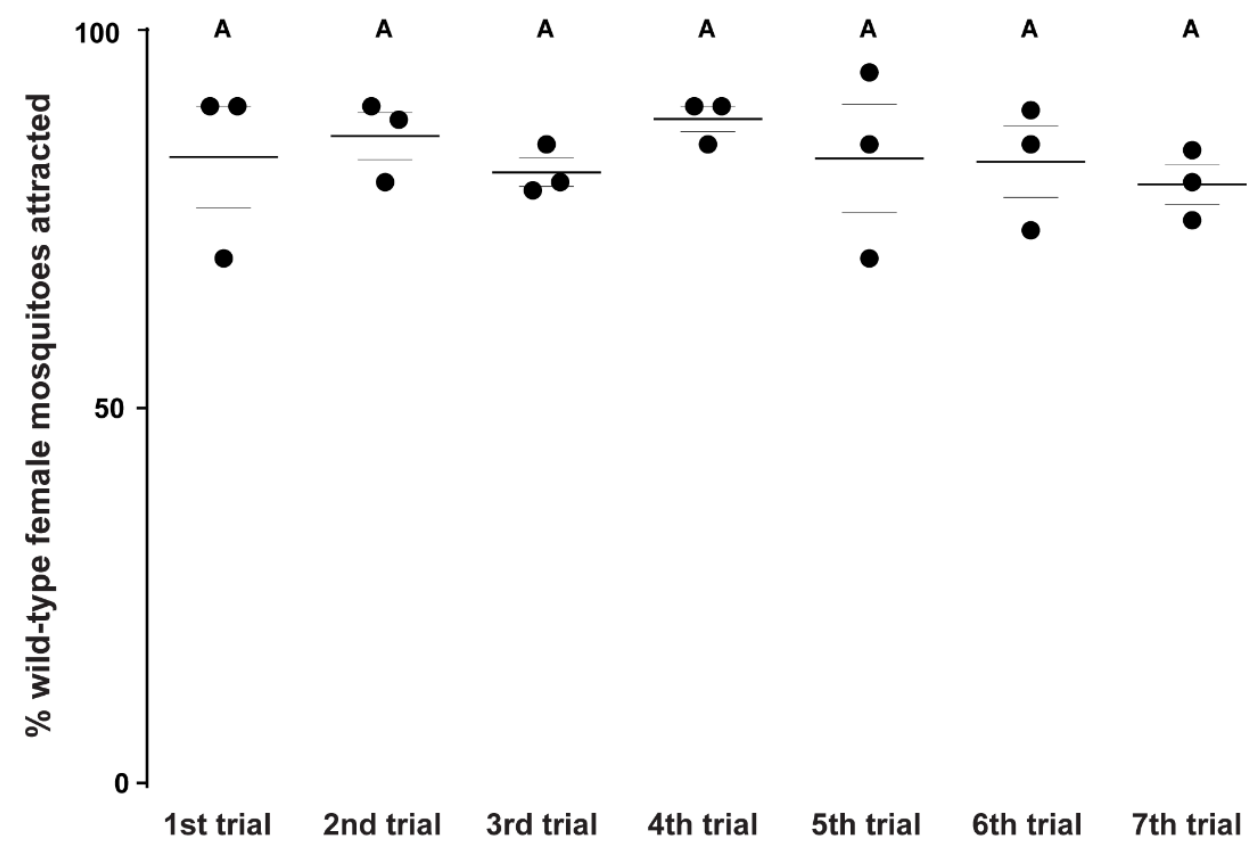

Figure S3: Time course experiment showing mosquito attraction to human-scented nylon sleeves. Related to Figure 4 \& 5 .

Percent wild-type mosquitoes attracted to human odor trapped on nylon sleeves (one-way ANOVA, $n=3$ ). The dot plot represents the mean and standard error. Genotypes marked with the same letters are not significantly different $(\mathrm{P}=0.8576)$ by post hoc Tukey's HSD test. 


\subsubsection{The loss of $G r 3$ enhances the Ir8a-dependent host-seeking defect}

The integration of host cues requires $\mathrm{CO}_{2}$ and is dependent on Gr3 in Ae. aegypti [43]. Similarly, Drosophila Gr63a, an orthologue of $G r 3$ has been shown to mediate $\mathrm{CO}_{2}$ detection as well as neurons that express Gr21a, which is co-expressed with Gr63a, are required for $\mathrm{CO}_{2}$ detection to facilitate $\mathrm{CO}_{2}$-dependent avoidance behavior [32,82-84]. The cpA neuron which expresses $G r 3$ has been reported to respond to human odors beyond $\mathrm{CO}_{2}$, but whether this requires $G r 3$ in Ae. aegypti is unknown $[35,36]$.We investigated if $\operatorname{Ir} 8 a$ and $G r 3$ act together to drive host attraction. Using our uniport assay with a human host and added $\mathrm{CO}_{2}$, we found that host-seeking behavior is also impaired not only in the Ir8a mutants but also in the Gr3 mutants (Figure 7A).

The loss of Gr3 function causes a stronger reduction in host-seeking behavior than the loss of $\operatorname{Ir} 8 a$ function (Figure 7A \& B). The loss of both $\operatorname{Ir} 8 a$ and $G r 3$ causes a host-seeking defect similar to the loss of Gr3 alone (Figure 7A \& B). This suggests that Gr3 may be necessary for Ir8a function. Unlike orco mutants or wild-type controls, the attraction rate of $\operatorname{Ir} 8 a$ mutants were not modified when $\mathrm{CO}_{2}$ was excluded from olfactometer assays with human odor (Figure 7C \& $\mathrm{S} 4 \mathrm{~A}$ ). Therefore, $\mathrm{CO}_{2}$ activation is not sufficient to rescue the $\operatorname{Ir} 8 a$ host-seeking phenotype. This suggests that detection of Ir $8 a$-dependent ligands unlike orco-dependent ligands is a non-redundant component of mosquito host detection. 

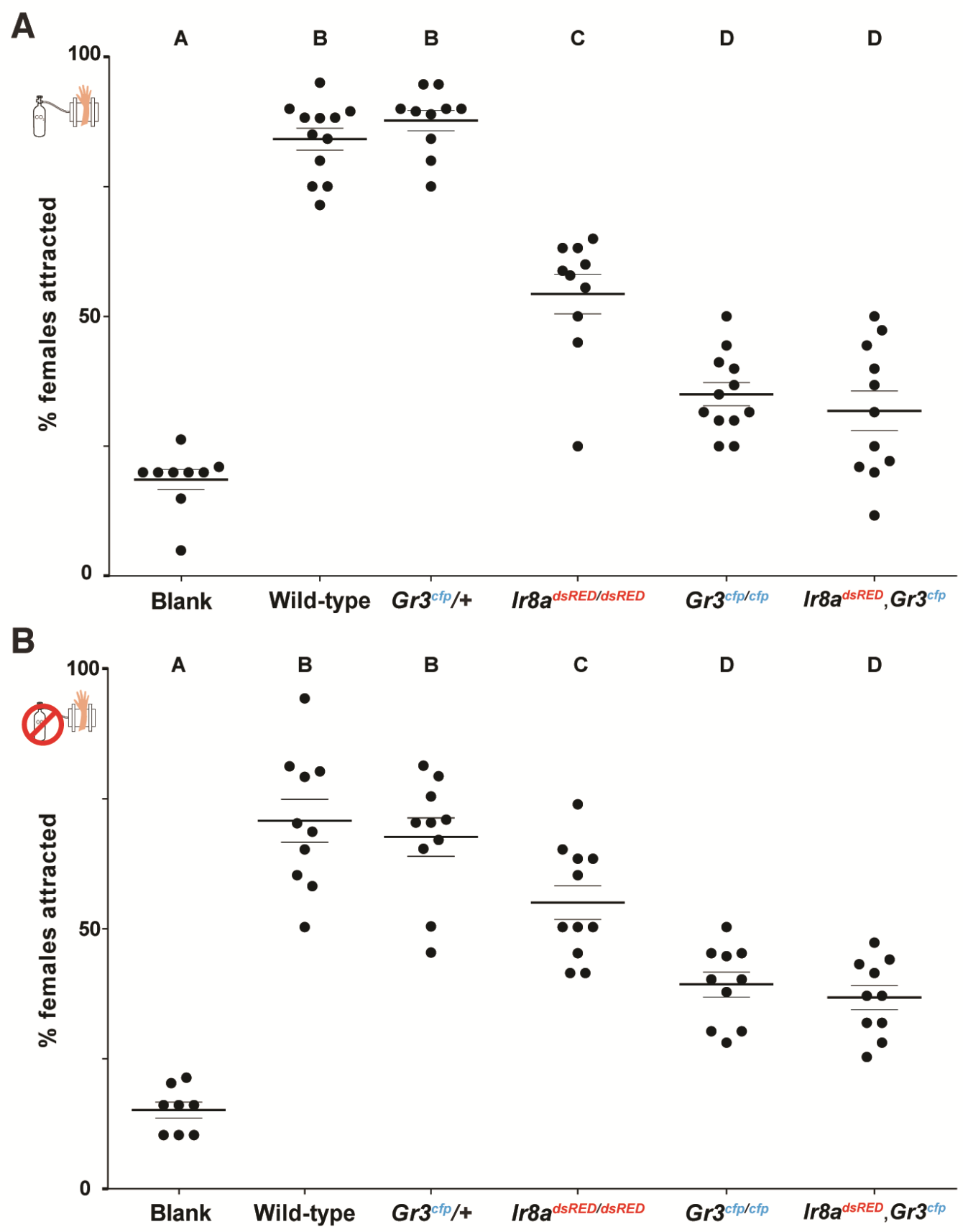


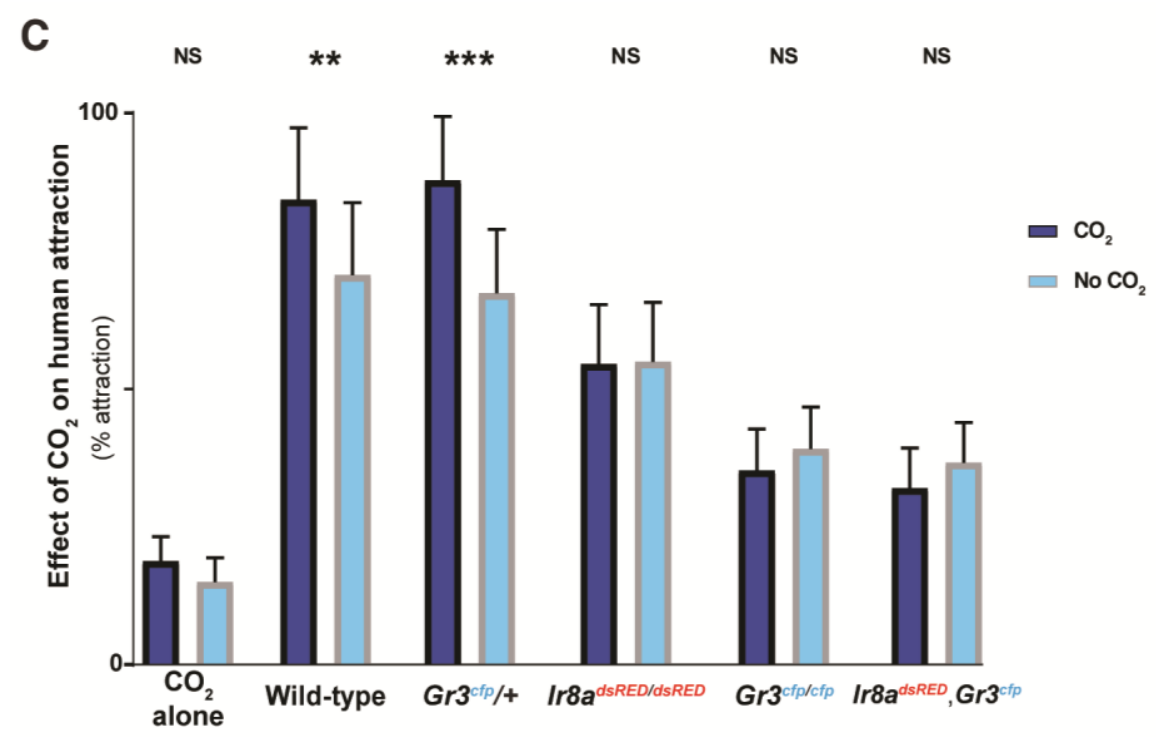

Figure 7. The loss of $\boldsymbol{G r} 3$ enhances the Ir8a-dependent host-seeking defect. (A) Percent female mosquitoes of indicated genotypes attracted to a human arm in the presence of $\mathrm{CO}_{2}(p<0.0001 ; \mathrm{n}=10-12)$. (B) Percent female mosquitoes of indicated genotypes attracted to a human arm in the absence of $\mathrm{CO}_{2}(p<0.0001 ; \mathrm{n}=9-11)$. Analysis was done using one-way ANOVA by comparing mean attraction across all genotypes. Genotypes marked with different letters are significantly different by post hoc Tukey's HSD test. For the dot plots in A and B, long lines represent the mean and short lines represent standard error. (C) Percentage response of mosquitoes attracted to human in the presence and absence of $\mathrm{CO}_{2}$ represented on a bar plot showing mean and standard error. Data compared in $\mathrm{C}$ is from figures $5 \mathrm{~A}$ and $5 \mathrm{~B}$ and analyzed by Two-Way ANOVA, grouped column statistics comparing $\operatorname{Ir} 8 a$ and $G r 3$ mutants $(p<0.001)$. Genotypes marked with asterisks are significantly different. Human subject 1 was used in the experiments in this figure. See also Figure S4 and Table S2. 
A

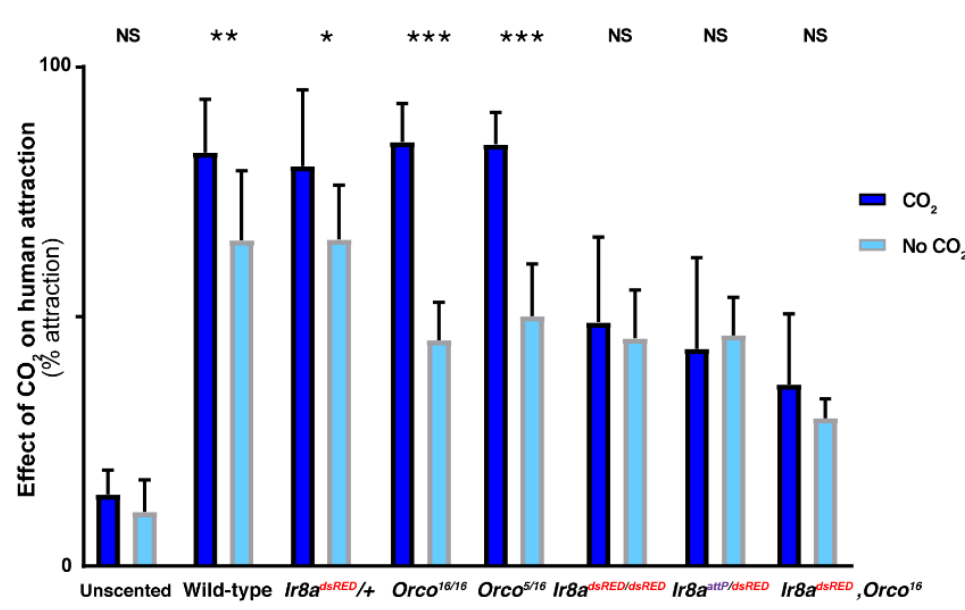

B

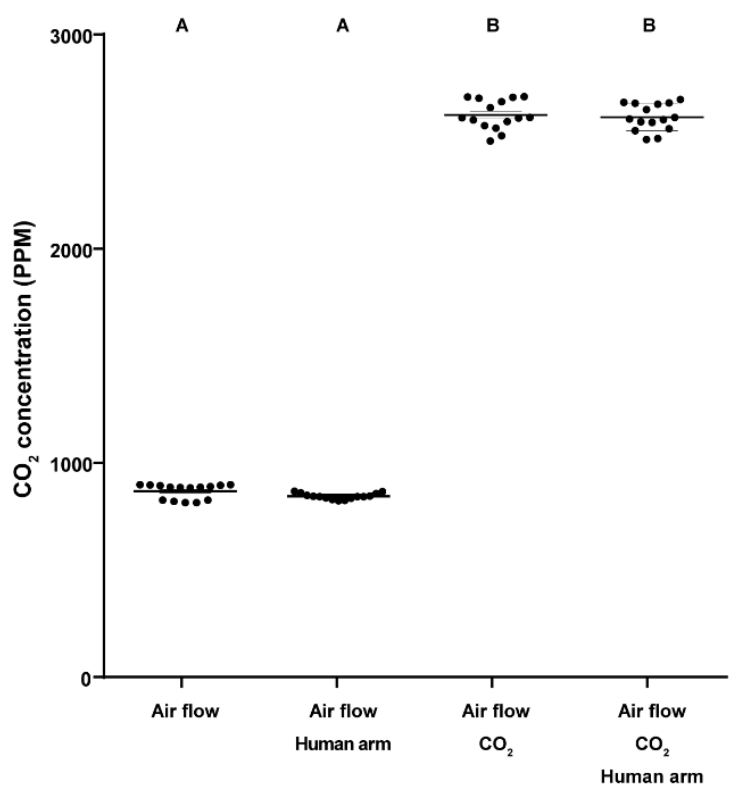

Figure S4: The attraction of Ir8a mutants to human odor is not modulated by the presence of $\mathrm{CO}_{2}$. Related to Figure 6 \& 7 .

(A) Comparison of female mosquitoes attracted to human odor scented nylon sleeve in the presence and absence of $\mathrm{CO}_{2}$. The bar plot represents the mean and standard error. Data compared is from figures $4 \mathrm{C}$ and $4 \mathrm{~F}$ and analyzed by Two-way ANOVA, grouped column statistics comparing Ir8a and orco mutants. Genotypes marked with asterisk are significantly different $(\mathrm{P}<0.001)$.

(B) Measurement of Carbon dioxide concentration in the uniport olfactometer at different conditions with amprobe-100. The presence of a human arm in the assay did not significantly increase the concentration of $\mathrm{CO}_{2}$. The addition of $\mathrm{CO}_{2}$ to the assay significantly increase the amount of $\mathrm{CO}_{2}$ concentration detected. Data was analyzed by one-way ANOVA followed by Tukey's multiple comparison test $(\mathrm{P}<0.0001, \mathrm{n}=15)$. 


\subsection{Discussion}

Here we present evidence that strongly suggests that $\operatorname{Ir} 8 a$ is a crucial mediator of Ae. aegypti mosquito attraction to humans and human odor. Ir8a is necessary for the electrophysiological response of the mosquito antenna to acidic volatiles found in human odor including lactic acid. We present evidence that the Ae. aegypti IR8a pathway responds to human odor cues during blood-feeding as well as enables mosquito attraction to humans, human odor, and lactic acid. By varying $\mathrm{CO}_{2}$ in our behavioral assays and testing the genetic interactions between $\operatorname{Ir} 8 a$ and orco as well as $\operatorname{Ir} 8 a$ and $G r 3$, we have connected the Ir 8 a pathway to the overall integration of host cues by mosquitoes. Taken together, our evidence supports the conclusion that the $\operatorname{Ir} 8 a$ pathway is a key participant in the multimodal integration of host odor cues by Ae. aegypti mosquitoes whose absence cannot be compensated for by other olfactory receptors.

Lactic acid and carboxylic acids are a major component of human sweat and may distinguish humans from other vertebrate hosts [52,53,85]. Lactic acid acts synergistically with certain volatile compounds to increase the attractiveness of either odor blends or human odor to mosquito vectors $[52,53,70,72,86]$. Our results support the conclusion that the detection of lactic acid and carboxylic acids by mosquitoes is necessary for robust attraction to humans. Further study will be required to determine if Ir $8 a$ mediates the decision to target human or other vertebrate hosts. In addition, the identification of IR8a as a co-receptor required for lactic acid detection allows for the recognition of the odor-tuned receptor(s) that are necessary to sense this important kairomone. 
Our results have implications not only for IRs, but also for how sensory information from the $\mathrm{OR}$ and the $\mathrm{CO}_{2}$-sensing $\mathrm{GR}$ pathways are integrated during mosquito host detection. Our experiments reveal that $\operatorname{Ir} 8 a$ and $G r 3$ are both required for human host detection, but the genetic interaction of the two genes is non-additive. It could have been possible that the loss of both genes could eliminate mosquito host detection, but this was not the case. Double mutants lacking $\operatorname{Ir} 8 a$ and Gr3 show a significant reduction in host detection when compared to $\operatorname{Ir} 8 a$ mutants alone (Figure 7A $\&$ B). However, the defects in the double mutant are not enhanced when compared to Gr3 mutants with an intact $\operatorname{Ir} 8 a$ gene (Figure 7A \& B). In addition, the phenotype of $\operatorname{Ir} 8 a$ mutants is not rescued by the presence of $\mathrm{CO}_{2}$ (Figure $\left.7 \mathrm{C}, \mathrm{S} 4 \mathrm{~A}\right)$. This suggests that Gr3 activation is necessary but not sufficient to promote Ir8a-dependent host attraction. Gr3 activation by $\mathrm{CO}_{2}$ or a select group of other odors $[35,36]$ may make acidic volatiles in human odor salient to the mosquito, but $\operatorname{Ir} 8 a$ is still required to detect these odors.

Our evidence suggests that Gr3 activation gates the responses of both the OR pathway and the IR8a pathway to promote host seeking, but how this interaction is achieved is not the same. Based on our results, the loss of $\operatorname{Ir} 8 a$ cannot be compensated for by using other olfactory receptors as in orco mutants. Our genetic interaction experiments support the conclusion that Gr3 activation is required for IR8a pathway function, and $\mathrm{CO}_{2}$-dependent gating of additional $\operatorname{Ir} 8 a$-independent receptors can compensate for the loss of orco function. The identification of these receptors is imperative to understand how mosquitoes find their human hosts. 
In this study, we presented the functional characterization of an ionotropic chemoreceptor family member in Ae. aegypti and provide insight into how olfactory receptor pathways can interact to mediate the detection of humans and their odor by mosquitoes. However, the understanding of how these sensory responses are integrated to facilitate host detection is far from complete. Determining if the integration of cues occurs within the antennal lobe or in higher olfactory processing centers in the brain will help reveal the dynamics of the innate neural circuits that enable mosquito host detection. Further study is necessary to uncover how mosquitoes sense their human hosts starting from the peripheral perception of cues, to the integration and processing of the information in the central nervous system, and finally, the motor circuit outputs that drive host-seeking behavior. 


\begin{tabular}{|l|l|}
\hline Primer name & Sequence \\
\hline CRISPRF & $\begin{array}{l}\text { GAAATTAATACGACTCACTATAGGGCGGACAAAAT } \\
\text { GGCGTATGTTTTAGAGCTAGAAATAGC }\end{array}$ \\
\hline IR8aExon3 & $\begin{array}{l}\text { GAAATTAATACGACTCACTATAGGACATCTGTCGA } \\
\text { CGATAACGTTTTAGAGCTAGAAATAGC }\end{array}$ \\
\hline sgRNArev & AAAAGCACCGACTCGGTGCCACTTTTTCAAGTTGAT \\
AACGGACTAGCCTTATTTTAACTTGCTATTTCTAGCT \\
CTAAAAC \\
\hline infusionIR8LA_1 & $\begin{array}{l}\text { CCATGATTACGAATTCCGGGTGTTTGGTTCTCCAGA } \\
\text { TTTG }\end{array}$ \\
\hline infusionIR8LA_2 & ATGGCCATTCGAATTCATAGCATGCGATGTAAGTGC \\
infusion_IR8RA2 & AGGTAC \\
\hline infusion_IR8RA1 & ATGTACAGAGCTCGAGCGGTATTCGACTACTACATT \\
GTCTAC
\end{tabular}




\begin{tabular}{|l|l|}
\hline Ir8adsRedForLA1 & GAACGTGAACAACCGGAAGTACCT \\
\hline Ir8a_polyU_For & GCGGCCCAAGTAAGCAGTG \\
\hline v2 & \\
\hline Ir8a_afterRA_rev & AACCTCGGTAGTTCCAACGCG \\
\hline SV40For1 & CTGCATTCTAGTTGTGGTTTGTCC \\
\hline Ir8aExon3for1 & $\begin{array}{l}\text { 6-FAM } \\
\text { CGGATTCTCGGTTCTGGATG }\end{array}$ \\
\hline Ir8aExon3rev2 & CTCGGTAGTTCCAAGGCGAAAGTA \\
\hline $\begin{array}{l}\text { TaqMan Universal } \\
\text { forward primer }\end{array}$ & ATCAGTCCGATCGCTATGACAAG \\
\hline $\begin{array}{l}\text { TaqMan Universal } \\
\text { reverse primer }\end{array}$ & GGTTGTCAATACCTTTCGGCTTAC \\
\hline
\end{tabular}

Table 1: Table for oligonucleotides. Table showing the primers and their corresponding oligonucleotide sequences used in the experiments. 


\begin{tabular}{|l|l|l|l|}
\hline Individual ID & Age & Race/Ethnicity & Sex \\
\hline Subject 1 & 28 & Black/African & M \\
\hline Subject 2 & 22 & Black & M \\
\hline Subject 3 & 22 & White/Hispanic & F \\
\hline Subject 4 & 28 & White & M \\
\hline Subject 5 & 23 & Hispanic & M \\
\hline Subject 6 & 22 & White/Hispanic & F \\
\hline Subject 7 & 26 & Hispanic & F \\
\hline Subject 8 & 25 & White & M \\
\hline Subject 9 & 21 & Hispanic & F \\
\hline Subject 10 & 21 & White & F \\
\hline Subject 11 & 41 & White/Hispanic & M \\
\hline Subject 12 & 20 & Asian & F \\
\hline Subject 13 & 24 & Hispanic & M \\
\hline Subject 14 & 19 & White & F \\
\hline Subject 15 & 21 & White & F \\
\hline *Subject 16 & 24 & White/Hispanic & M \\
\hline *Subject 17 & 22 & White/Hispanic & M \\
\hline *Subject 18 & 41 & White & M \\
\hline
\end{tabular}

Table 2: Subject details used for the uniport olfactometer assay. Table showing the profile of the subjects used in the uniport olfactometer assay. Attraction to subject number 1 to 15 is shown in figure $4 \mathrm{~A}$. Subject number 1 was used for the remaining experiment with uniport assay to control for individual differences that exists in mosquito host attraction. Subject number 16 to 18 marked in asterisks did not complete the experiment or excluded due to attraction lower than $20 \%$. 
Table 3: $\quad$ Key resources table

\begin{tabular}{|c|c|c|}
\hline REAGENT or RESOURCE & SOURCE & IDENTIFIER \\
\hline \multicolumn{3}{|l|}{ Chemicals } \\
\hline Geranylacetone & Sigma-Aldrich & C.A.S. $689-67-8$ \\
\hline Methyl-5-hepten-2-one & Sigma-Aldrich & C.A.S. $110-93-0$ \\
\hline Dodecanal & Sigma-Aldrich & C.A.S. $112-54-9$ \\
\hline L-Lactic acid & Sigma-Aldrich & C.A.S. $79-33-4$ \\
\hline Octanoic acid & ICN & C.A.S. 124-07-2 \\
\hline Heptanoic acid & ICN & C.A.S. 111-14-8 \\
\hline Butyric acid & ICN & C.A.S. 107-92-6 \\
\hline Octanal & $\begin{array}{l}\text { Chemicon: } \\
\text { Acros }\end{array}$ & C.A.S. 124-13-0 \\
\hline Nonanal & $\begin{array}{l}\text { Chemicon: } \\
\text { Acros }\end{array}$ & C.A.S. 124-19-6 \\
\hline Limonene & Fluka & C.A.S. 5989-27-5 \\
\hline Nonanoic acid & Fluka & C.A.S. $112-05-0$ \\
\hline 2-ethyl hexanol & Lancaster & C.A.S. 104-76-7 \\
\hline 1-octen-3-ol & $\begin{array}{l}\text { Janssen } \\
\text { Chimica }\end{array}$ & C.A.S. 3391-86-4 \\
\hline Guanidine thiocyanate & Sigma-Aldrich & C.A.S. 593-84-0 \\
\hline Sarkosyl & $\begin{array}{l}\text { Fisher } \\
\text { Scientific }\end{array}$ & C.A.S. 137-16-6 \\
\hline Chloroform & $\begin{array}{l}\text { Fisher } \\
\text { Scientific }\end{array}$ & C.A.S. $67-66-3$ \\
\hline Linalool & Sigma-Aldrich & C.A.S. $78-70-6$ \\
\hline 2-mercapthoethanol & Sigma-Aldrich & C.A.S: $60-24-2$ \\
\hline \multicolumn{3}{|l|}{ Restriction enzymes } \\
\hline PmeI & $\begin{array}{l}\text { New England } \\
\text { Biolabs }\end{array}$ & Catalog \# R0560S \\
\hline EcoRI & $\begin{array}{l}\text { New England } \\
\text { Biolabs }\end{array}$ & Catalog \# R0101S \\
\hline XhoI & $\begin{array}{l}\text { New England } \\
\text { Biolabs }\end{array}$ & Catalog \# R0146S \\
\hline MluI & $\begin{array}{l}\text { New England } \\
\text { Biolabs }\end{array}$ & Catalog \# R1089S \\
\hline \multicolumn{3}{|l|}{ Recombinant DNA } \\
\hline pGT-Ir8a (used for donor plasmid) & This study & N/A \\
\hline pMLM3613 (used for Cas9 MRNA) & [53] & Addgene \# 42251 \\
\hline pSL1 180:polyUBdsRED (donor plasmid) & [54] & Addgene \# 49327 \\
\hline Oligonucleotides (primers) & $\begin{array}{l}\text { Integrated DNA } \\
\text { Technologies }\end{array}$ & See Table S1 \\
\hline
\end{tabular}




\begin{tabular}{|c|c|c|}
\hline \multicolumn{3}{|l|}{ Commercial Assays } \\
\hline MEGAscript T7 Transcription Kit & $\begin{array}{l}\text { Life } \\
\text { Technologies }\end{array}$ & Catalog \# AM1334 \\
\hline MEGAclear transcription clean-up kit & $\begin{array}{l}\text { Life } \\
\text { Technologies }\end{array}$ & Catalog \# AM1908 \\
\hline mMachine mMachine T7 ultra kit & $\begin{array}{l}\text { Thermo-Fisher } \\
\text { Scientific }\end{array}$ & Catalog \# AM1345 \\
\hline DNeasy blood \& tissue kits & $\begin{array}{l}\text { QIAGEN } \\
\text { GmbH }\end{array}$ & Catalog \# 69504 \\
\hline NucleoSpin gel and PCR cleanup kit & $\begin{array}{l}\text { Machery-Nagel } \\
\text { Inc. }\end{array}$ & Catalog \# 740609 \\
\hline NEB PCR cloning kit & $\begin{array}{l}\text { New England } \\
\text { Biolabs }\end{array}$ & Catalog \# E1202S \\
\hline RNAlater stablization solution & Invitrogen & Catalog \# AM7020 \\
\hline RNAid Kit & MPBio & $\begin{array}{l}\text { Catalog \# } \\
111007200\end{array}$ \\
\hline TURBO DNA-free kit & Invitrogen & Catalog \# AM1907 \\
\hline KOD polymerase & EMD Millipore & Catalog \# 71086 \\
\hline Qiaquick PCR purification kit & Qiagen & Catalog \# 28106 \\
\hline Infusion HD cloning kit & Clontech & Catalog \# 638909 \\
\hline Qiagen Endo-free Maxiprep kit & Qiagen & Catalog \#12362 \\
\hline SimpleSeq premixed kit & Eurofins & N/A \\
\hline IBI Genomic DNA extraction kit & IBI scientific & Catalog \# IB47222 \\
\hline Amplitaq Gold 360 PCR master mix & $\begin{array}{l}\text { Applied } \\
\text { Biosystems }\end{array}$ & Catalog \# 4398881 \\
\hline QIAEX II Gel extraction kit & $\begin{array}{l}\text { QIAGEN } \\
\text { GmbH }\end{array}$ & Catalog \# 20051 \\
\hline pCR2.1 TOPO TA vector & Invitrogen & Catalog \# K462040 \\
\hline One Shot TOP10 cells & Invitrogen & Catalog \# C607003 \\
\hline QIAprep Spin Miniprep kit & $\begin{array}{l}\text { QIAGEN } \\
\text { GmbH }\end{array}$ & Catalog \# 27104 \\
\hline SuperScript II RT reagent kit & Invitrogen & $\begin{array}{l}\text { Catalog \# 18080- } \\
051\end{array}$ \\
\hline RNase cocktail enzyme mix & $\begin{array}{l}\text { Thermo-Fisher } \\
\text { Scientific }\end{array}$ & Catalog \# AM2286 \\
\hline TaqMan 2X universal master mix & $\begin{array}{l}\text { Thermo-Fisher } \\
\text { Scientific }\end{array}$ & Catalog \# 4324018 \\
\hline Custom TaqMan Ir8a probe & $\begin{array}{l}\text { ThermoFisher } \\
\text { Scientific }\end{array}$ & Catalog \# 4331348 \\
\hline \multicolumn{3}{|c|}{ Experimental Models: Organisms/Strains } \\
\hline Ae. aegypti: Orlando & Leslie Vosshall & N/A \\
\hline Ae. aegypti: $\operatorname{Ir} 8 a^{d s R E D}$ & This study & N/A \\
\hline Ae. aegypti: $\operatorname{Ir} 8 a^{a t t P}$ & This study & N/A \\
\hline Ae. aegypti: Orco ${ }^{5}$ & BEI resources & NR-44377 \\
\hline Ae. aegypti: Orco ${ }^{16}$ & BEI resources & NR-44378 \\
\hline
\end{tabular}




\begin{tabular}{|l|l|l|}
\hline Ae. aegypti: Gr3 ${ }^{c f p}$ & BEI resources & NR-48760 \\
\hline Computer, Software and algorithms & \multicolumn{2}{|l|}{} \\
\hline Syntech EAG-Pro 4.6 & Custom-made & N/A \\
\hline Peak Scanner software & $\begin{array}{l}\text { Applied } \\
\text { Biosystems }\end{array}$ & v1.0 \\
\hline Impedance amplifier & $\begin{array}{l}\text { Syntech } \\
\text { https://zifit. } \\
\text { partners.org } \\
\text { ZiFit/ }\end{array}$ & IDAC-4 \\
\hline ZiFit & $\begin{array}{l}\text { Applied } \\
\text { Biosystems }\end{array}$ & 7500 \\
\hline Real time PCR system & Trikinetics Inc. & LAM 25 \\
\hline Locomotor activity monitor & SnapGene & N/A \\
\hline SnapGene \& SnapGene Viewer & $\begin{array}{l}\text { Applied } \\
\text { Biosystems }\end{array}$ & v1.4.1 \\
\hline SDS software & GraphPad & Prism v7 \& v8 \\
\hline GraphPad Prism & Tetra & Catalog \# 16152 \\
\hline Others & $\begin{array}{l}\text { Blaubrand } \\
\text { Intramark }\end{array}$ & Catalog \# 1904637 \\
\hline Tetramin tropical fish food & $\begin{array}{l}\text { Genesee } \\
\text { Scientific }\end{array}$ & Catalog \# 49-101 \\
\hline Capillary tubes & $\begin{array}{l}\text { Tritech } \\
\text { Research }\end{array}$ & $\begin{array}{l}\text { Model \# MINJ- } \\
\text { DROS-FP }\end{array}$ \\
\hline Cellulose acetate fly vial plug & Chemglass & $\begin{array}{l}\text { Catalog \# CG- } \\
1835-70\end{array}$ \\
\hline CO diffusion pad & Custom-made & N/A \\
\hline Membrane feeders & Amprobe & Catalog \# CO2-100 \\
\hline Uniport olfactometer & $\begin{array}{l}\text { Dwyer Instru- } \\
\text { ment Inc. }\end{array}$ & $\begin{array}{l}\text { Catalog \# VFA-4- } \\
\text { SSV }\end{array}$ \\
\hline Carbon dioxide monitor & $\begin{array}{l}\text { L'eggs brand, } \\
\text { Hanes }\end{array}$ & Model \# 39400 \\
\hline Acrylic flowmeter & $\begin{array}{l}\text { Fisher } \\
\text { Scientific }\end{array}$ & $\begin{array}{l}\text { Catalog \# 12-141- } \\
364\end{array}$ \\
\hline Suntan knee-high pantyhose & & \\
\hline Disposable pellet pestles & & \\
\hline & &
\end{tabular}




\section{References}

[1] Friend WG, Dadd RH. Insect nutrition: a comparative perspective. Adv Nutr Res 1982;4:205-47.

[2] Severson DW, Behura SK. Genome Investigations of Vector Competence in Aedes aegypti to Inform Novel Arbovirus Disease Control Approaches. Insects 2016;7:58. doi:10.3390/insects7040058.

[3] Petersen LR, Jamieson DJ, Powers AM, Honein MA. Zika Virus. N Engl J Med 2016;374:1552-63. doi:10.1056/NEJMra1602113.

[4] Daykin PN, Kellogg FE, Wright RH. Host-Finding and Repulsion of Aedes aegypti. Can Entomol 1965;97:239-63. doi:10.4039/Ent97239-3.

[5] Gibson G, Torr SJ. Visual and olfactory responses of haematophagous Diptera to host stimuli. Med Vet Entomol 1999;13:2-23.

[6] Raji JI, DeGennaro M. Genetic analysis of mosquito detection of humans. Curr Opin Insect Sci 2017;20:34-8. doi:10.1016/j.cois.2017.03.003.

[7] Montell C, Zwiebel LJ. Mosquito Sensory Systems. Advances in Insect Physiology 2016;51:293-328. doi:10.1016/bs.aiip.2016.04.007.

[8] Skinner WA, Tong H, Pearson T, Strauss W, Maibach H. Human sweat components attractive to mosquitoes. Nature 1965;207:661-2.

[9] Bernier UR, Booth MM, Yost RA. Analysis of human skin emanations by gas chromatography/mass spectrometry. 1. Thermal desorption of attractants for the yellow fever mosquito (Aedes aegypti) from handled glass beads. Anal Chem 1999;71:1-7.

[10] Bernier UR, Kline DL, Barnard DR, Schreck CE, Yost RA. Analysis of human skin emanations by gas chromatography/mass spectrometry. 2. Identification of volatile compounds that are candidate attractants for the yellow fever mosquito (Aedes aegypti). Anal Chem 2000;72:747-56.

[11] Takken W, Knols BG. Odor-mediated behavior of Afrotropical malaria mosquitoes. Annu Rev Entomol 1999;44:131-57. doi:10.1146/annurev.ento.44.1.131.

[12] McBride CS. Genes and Odors Underlying the Recent Evolution of Mosquito Preference for Humans. Curr Biol 2016;26:R41-6. doi:10.1016/j.cub.2015.11.032. 
[13] Verhulst NO, Beijleveld H, Knols BG, Takken W, Schraa G, Bouwmeester HJ, et al. Cultured skin microbiota attracts malaria mosquitoes. Malar J 2009;8:302. doi:10.1186/1475-2875-8-302.

[14] Verhulst NO, Qiu YT, Beijleveld H, Maliepaard C, Knights D, Schulz S, et al. Composition of human skin microbiota affects attractiveness to malaria mosquitoes. PLoS ONE 2011;6:e28991. doi:10.1371/journal.pone.0028991.

[15] Verhulst NO, Takken W, Dicke M, Schraa G, Smallegange RC. Chemical ecology of interactions between human skin microbiota and mosquitoes. FEMS Microbiol Ecol 2010;74:1-9. doi:10.1111/j.1574-6941.2010.00908.x.

[16] Acree F, Turner RB, Gouck HK, Beroza M, Smith N. L-Lactic acid: a mosquito attractant isolated from humans. Science 1968;161:1346-7.

[17] Davis EE, Davis EE, Sokolove PG. Lactic acid-sensitive receptors on the antennae of the mosquito, Aedes aegypti. J Comp Physiol 1976;105:43-54. doi:10.1007/BF01380052.

[18] Braks MAH, Meijerink J, Takken W. The response of the malaria mosquito, Anopheles gambiae, to two components of human sweat, ammonia and 1-lactic acid, in an olfactometer. Physiological Entomology 2001;26:142-8. doi:10.1046/j.1365-3032.2001.00227.x.

[19] Bernier UR, Kline DL, Posey KH, Booth MM, Yost RA, Barnard DR. Synergistic attraction of Aedes aegypti (L.) to binary blends of L-lactic acid and acetone, dichloromethane, or dimethyl disulfide. J Med Entomol 2003;40:653-6.

[20] Smallegange RC, Qiu YT, Bukovinszkiné-Kiss G, van Loon JJA, Takken W. The effect of aliphatic carboxylic acids on olfaction-based host-seeking of the malaria mosquito Anopheles gambiae sensu stricto. J Chem Ecol 2009;35:93343. doi:10.1007/s10886-009-9668-7.

[21] Majeed S, Hill SR, Birgersson G, Ignell R. Detection and perception of generic host volatiles by mosquitoes modulate host preference: context dependence of (R)-1-octen-3-ol. Royal Society Open Science 2016;3:160467. doi:10.1098/rsos.160467.

[22] Pitts RJ, Derryberry SL, Zhang Z, Zwiebel LJ. Variant ionotropic receptors in the malaria vector mosquito Anopheles gambiae tuned to amines and carboxylic acids. Sci Rep 2017;7:40297. doi:10.1038/srep40297. 
[23] Pitts RJ, Rinker DC, Jones PL, Rokas A, Zwiebel LJ. Transcriptome profiling of chemosensory appendages in the malaria vector Anopheles gambiae reveals tissue- and sex-specific signatures of odor coding. BMC Genomics 2011;12:271. doi:10.1186/1471-2164-12-271.

[24] Matthews BJ, McBride CS, DeGennaro M, Despo O, Vosshall LB. The neurotranscriptome of the Aedes aegypti mosquito. BMC Genomics 2016;17:504-20. doi:10.1186/s12864-015-2239-0.

[25] Croset V, Rytz R, Cummins SF, Budd A, Brawand D, Kaessmann H, et al. Ancient protostome origin of chemosensory ionotropic glutamate receptors and the evolution of insect taste and olfaction. PLoS Genet 2010;6:e1001064. doi:10.1371/journal.pgen.1001064.

[26] Kaupp UB. Olfactory signalling in vertebrates and insects: differences and commonalities. Nat Rev Neurosci 2010;11:188-200. doi:10.1038/nrn2789.

[27] Hansson BS, Stensmyr MC. Evolution of insect olfaction. Neuron 2011;72:698711. doi:10.1016/j.neuron.2011.11.003.

[28] Vosshall LB, Amrein H, Morozov PS, Rzhetsky A, Axel R. A spatial map of olfactory receptor expression in the Drosophila antenna. Cell 1999;96:725-36.

[29] Bohbot J, Pitts RJ, Kwon H-W, Rützler M, Robertson HM, Zwiebel LJ. Molecular characterization of the Aedes aegypti odorant receptor gene family. Insect Mol Biol 2007;16:525-37. doi:10.1111/j.1365-2583.2007.00748.x.

[30] Benton R, Vannice KS, Gomez-Diaz C, Vosshall LB. Variant ionotropic glutamate receptors as chemosensory receptors in Drosophila. Cell 2009;136:149-62. doi:10.1016/j.cell.2008.12.001.

[31] Clyne PJ, Warr CG, Freeman MR, Lessing D, Kim J, Carlson JR. A novel family of divergent seven-transmembrane proteins: candidate odorant receptors in Drosophila. Neuron 1999;22:327-38.

[32] Jones WD, Cayirlioglu P, Kadow IG, Vosshall LB. Two chemosensory receptors together mediate carbon dioxide detection in Drosophila. Nature 2007;445:8690. doi:10.1038/nature05466.

[33] Kwon JY, Dahanukar A, Weiss LA, Carlson JR. The molecular basis of $\mathrm{CO}_{2}$ reception in Drosophila. Proc Natl Acad Sci USA 2007;104:3574-8. doi:10.1073/pnas.0700079104. 
[34] Lu T, Qiu YT, Wang G, Kwon JY, Rutzler M, Kwon H-W, et al. Odor coding in the maxillary palp of the malaria vector mosquito Anopheles gambiae. Curr Biol 2007;17:1533-44. doi:10.1016/j.cub.2007.07.062.

[35] Turner SL, Li N, Guda T, Githure J, Cardé RT, Ray A. Ultra-prolonged activation of CO2-sensing neurons disorients mosquitoes. Nature 2011;474:8791. doi:10.1038/nature10081.

[36] Tauxe GM, MacWilliam D, Boyle SM, Guda T, Ray A. Targeting a dual detector of skin and CO2 to modify mosquito host seeking. Cell 2013;155:1365-79. doi:10.1016/j.cell.2013.11.013.

[37] Larsson MC, Domingos AI, Jones WD, Chiappe ME, Amrein H, Vosshall LB. Or83b encodes a broadly expressed odorant receptor essential for Drosophila olfaction. Neuron 2004;43:703-14. doi:10.1016/j.neuron.2004.08.019.

[38] Benton R, Sachse S, Michnick SW, Vosshall LB. Atypical membrane topology and heteromeric function of Drosophila odorant receptors in vivo. PLoS Biol 2006;4:e20. doi:10.1371/journal.pbio.0040020.

[39] Sato K, Pellegrino M, Nakagawa T, Nakagawa T, Vosshall LB, Touhara K. Insect olfactory receptors are heteromeric ligand-gated ion channels. Nature 2008;452:1002-6. doi:10.1038/nature06850.

[40] Butterwick JA, Del Mármol J, Kim KH, Kahlson MA, Rogow JA, Walz T, et al. Cryo-EM structure of the insect olfactory receptor Orco. Nature 2018;560:44752. doi:10.1038/s41586-018-0420-8.

[41] Wicher D, Schäfer R, Bauernfeind R, Stensmyr MC, Heller R, Heinemann SH, et al. Drosophila odorant receptors are both ligand-gated and cyclic-nucleotideactivated cation channels. Nature 2008;452:1007-11. doi:10.1038/nature06861.

[42] DeGennaro M, McBride CS, Seeholzer L, Nakagawa T, Dennis EJ, Goldman C, et al. orco mutant mosquitoes lose strong preference for humans and are not repelled by volatile DEET. Nature 2013;498:487-91. doi:10.1038/nature12206.

[43] McMeniman CJ, Corfas RA, Matthews BJ, Ritchie SA, Vosshall LB. Multimodal integration of carbon dioxide and other sensory cues drives mosquito attraction to humans. Cell 2014;156:1060-71. doi:10.1016/j.cell.2013.12.044.

[44] Silbering AF, Rytz R, Grosjean Y, Abuin L, Ramdya P, Jefferis GSXE, et al. Complementary function and integrated wiring of the evolutionarily distinct Drosophila olfactory subsystems. J Neurosci 2011;31:13357-75. doi:10.1523/JNEUROSCI.2360-11.2011. 
[45] Abuin L, Bargeton B, Ulbrich MH, Isacoff EY, Kellenberger S, Benton R. Functional architecture of olfactory ionotropic glutamate receptors. Neuron 2011;69:44-60. doi:10.1016/j.neuron.2010.11.042.

[46] Matthews BJ, Dudchenko O, Kingan SB, Koren S, Antoshechkin I, Crawford JE, et al. Improved reference genome of Aedes aegypti informs arbovirus vector control. Nature 2018;563:501-7. doi:10.1038/s41586-018-0692-z.

[47] Ai M, Min S, Grosjean Y, Leblanc C, Bell R, Benton R, et al. Acid sensing by the Drosophila olfactory system. Nature 2010;468:691-5. doi:10.1038/nature09537.

[48] Ai M, Blais S, Park J-Y, Min S, Neubert TA, Suh GSB. Ionotropic glutamate receptors IR64a and IR8a form a functional odorant receptor complex in vivo in Drosophila. J Neurosci 2013;33:10741-9. doi:10.1523/JNEUROSCI.541912.2013.

[49] Hallem EA, Carlson JR. Coding of Odors by a Receptor Repertoire. Cell 2006;125:143-60. doi:10.1016/j.cell.2006.01.050.

[50] Carey AF, Wang G, Su C-Y, Zwiebel LJ, Carlson JR. Odorant reception in the malaria mosquito Anopheles gambiae. Nature 2010;464:66-71. doi:10.1038/nature08834.

[51] Hussain A, Zhang M, Üçpunar HK, Svensson T, Quillery E, Gompel N, et al. Ionotropic chemosensory receptors mediate the taste and smell of polyamines. PLoS Biol 2016;14:e1002454. doi:10.1371/journal.pbio.1002454.

[52] Steib BM, Geier M, Boeckh J. The effect of lactic acid on odour-related host preference of yellow fever mosquitoes. Chem Senses 2001;26:523-8.

[53] Dekker T, Steib B, Carde RT, Geier M. L-lactic acid: a human-signifying host cue for the anthropophilic mosquito Anopheles gambiae. Med Vet Entomol 2002;16:91-8.

[54] Zhang YV, Ni J, Montell C. The molecular basis for attractive salt-taste coding in Drosophila. Science 2013;340:1334-8. doi:10.1126/science.1234133.

[55] Chen C, Buhl E, Xu M, Croset V, Rees JS, Lilley KS, et al. Drosophila Ionotropic Receptor 25a mediates circadian clock resetting by temperature. Nature 2015;527:516-20. doi:10.1038/nature16148.

[56] Enjin A, Zaharieva EE, Frank DD, Mansourian S, Suh GSB, Gallio M, et al. Humidity Sensing in Drosophila. Curr Biol 2016;26:1352-8. doi:10.1016/j.cub.2016.03.049. 
[57] Knecht ZA, Silbering AF, Ni L, Klein M, Budelli G, Bell R, et al. Distinct combinations of variant ionotropic glutamate receptors mediate thermosensation and hygrosensation in Drosophila. eLife 2016;5:44. doi:10.7554/eLife.17879.

[58] Knecht ZA, Silbering AF, Cruz J, Yang L, Croset V, Benton R, et al. Ionotropic Receptor-dependent moist and dry cells control hygrosensation in Drosophila. eLife 2017;6:44. doi:10.7554/eLife.26654.

[59] Silbering AF, Bell R, Münch D, Cruchet S, Gomez-Diaz C, Laudes T, et al. Ir40a neurons are not DEET detectors. Nature 2016;534:E5-7. doi:10.1038/nature18321.

[60] Ahn J-E, Chen Y, Amrein H. Molecular basis of fatty acid taste in Drosophila. eLife 2017;6:44. doi:10.7554/eLife.30115.

[61] Chen Y, Amrein H. Ionotropic receptors mediate Drosophila oviposition preference through sour gustatory receptor neurons. Curr Biol 2017;27:2741-4. doi:10.1016/j.cub.2017.08.003.

[62] van Breugel F, Huda A, Dickinson MH. Distinct activity-gated pathways mediate attraction and aversion to $\mathrm{CO}_{2}$ in Drosophila. Nature 2018;564:420-4. doi:10.1038/s41586-018-0732-8.

[63] Liu C, Pitts RJ, Bohbot JD, Jones PL, Wang G, Zwiebel LJ. Distinct olfactory signaling mechanisms in the malaria vector mosquito Anopheles gambiae. PLoS Biol 2010;8:e1000467. doi:10.1371/journal.pbio.1000467.

[64] Rinker DC, Zhou X, Pitts RJ, Rokas A, Zwiebel LJ. Antennal transcriptome profiles of anopheline mosquitoes reveal human host olfactory specialization in Anopheles gambiae. BMC Genomics 2013;14:749. doi:10.1186/1471-2164-14749.

[65] Kistler KE, Vosshall LB, Matthews BJ. Genome engineering with CRISPR-Cas9 in the mosquito Aedes aegypti. Cell Rep 2015;11:51-60. doi:10.1016/j.celrep.2015.03.009.

[66] Huang J, Zhou W, Dong W, Watson AM, Hong Y. From the Cover: Directed, efficient, and versatile modifications of the Drosophila genome by genomic engineering. Proc Natl Acad Sci USA 2009;106:8284-9. doi:10.1073/pnas.0900641106.

[67] Zhang X-H, Tee LY, Wang X-G, Huang Q-S, Yang S-H. Off-target effects in CRISPR/Cas9-mediated genome engineering. Mol Ther Nucleic Acids 2015;4:e264. doi:10.1038/mtna.2015.37. 
[68] Ja WW, Carvalho GB, Mak EM, la Rosa de NN, Fang AY, Liong JC, et al. Prandiology of Drosophila and the CAFE assay. Proc Natl Acad Sci USA 2007;104:8253-6. doi:10.1073/pnas.0702726104.

[69] Liesch J, Bellani LL, Vosshall LB. Functional and genetic characterization of neuropeptide Y-like receptors in Aedes aegypti. PLoS Negl Trop Dis 2013;7:e2486. doi:10.1371/journal.pntd.0002486.

[70] Smallegange RC, Qiu YT, van Loon JJA, Takken W. Synergism between ammonia, lactic acid and carboxylic acids as kairomones in the host-seeking behaviour of the malaria mosquito Anopheles gambiae sensu stricto (Diptera: Culicidae). Chem Senses 2005;30:145-52. doi:10.1093/chemse/bji010.

[71] Geier M, Bosch OJ, Boeckh J. Ammonia as an attractive component of host odour for the yellow fever mosquito, Aedes aegypti. Chem Senses 1999;24:64753.

[72] Allan SA, Bernier UR, Kline DL. Laboratory evaluation of lactic acid on attraction of Culex spp. (Diptera: Culicidae). J Vector Ecol 2010;35:318-24. doi:10.1111/j.1948-7134.2010.00089.x.

[73] Hallem EA, Ho MG, Carlson JR. The molecular basis of odor coding in the Drosophila antenna. Cell 2004;117:965-79. doi:10.1016/j.cell.2004.05.012.

[74] Couto A, Alenius M, Dickson BJ. Molecular, anatomical, and functional organization of the Drosophila olfactory system. Curr Biol 2005;15:1535-47. doi:10.1016/j.cub.2005.07.034.

[75] Benton R, Dahanukar A. Electrophysiological recording from Drosophila olfactory sensilla. Cold Spring Harb Protoc 2011;2011:824-38.

doi:10.1101/pdb.prot5630.

[76] Cosgrove JB, Wood RJ. Probing and gorging responses of three mosquito species to a membrane feeding system at a range of temperatures. J Am Mosq Control Assoc 1995;11:339-42.

[77] Willis ER, Roth LM. Reactions of Aedes aegypti (L.) to carbon dioxide. Journal of Experimental Zoology 1952;121:149-79. doi:10.1002/jez.1401210107.

[78] Healy TP, Copland MJW. Activation of Anopheles gambiae mosquitoes by carbon dioxide and human breath. Med Vet Entomol 1995;9:331-6. doi:10.1111/j.1365-2915.1995.tb00143.x. 
[79] Dekker T, Geier M, Cardé RT. Carbon dioxide instantly sensitizes female yellow fever mosquitoes to human skin odours. Journal of Experimental Biology 2005;208:2963-72. doi:10.1242/jeb.01736.

[80] Dekker T, Cardé RT. Moment-to-moment flight manoeuvres of the female yellow fever mosquito (Aedes aegypti L.) in response to plumes of carbon dioxide and human skin odour. J Exp Biol 2011;214:3480-94.

doi:10.1242/jeb.055186.

[81] van Loon JJA, Smallegange RC, Bukovinszkiné-Kiss G, Jacobs F, De Rijk M, Mukabana WR, et al. Mosquito attraction: crucial role of carbon dioxide in formulation of a five-component blend of human-derived volatiles. J Chem Ecol 2015;41:567-73. doi:10.1007/s10886-015-0587-5.

[82] Scott K, Brady R, Cravchik A, Morozov P, Rzhetsky A, Zuker C, et al. A chemosensory gene family encoding candidate gustatory and olfactory receptors in Drosophila. Cell 2001;104:661-73.

[83] Suh GSB, Wong AM, Hergarden AC, Wang JW, Simon AF, Benzer S, et al. A single population of olfactory sensory neurons mediates an innate avoidance behaviour in Drosophila. Nature 2004;431:854-9. doi:10.1038/nature02980.

[84] Suh GSB, Ben-Tabou de Leon S, Tanimoto H, Fiala A, Benzer S, Anderson DJ. Light activation of an innate olfactory avoidance response in Drosophila. Curr Biol 2007;17:905-8. doi:10.1016/j.cub.2007.04.046.

[85] Cork A, Park KC. Identification of electrophysiologically-active compounds for the malaria mosquito, Anopheles gambiae, in human sweat extracts. Med Vet Entomol 1996;10:269-76.

[86] Okumu FO, Killeen GF, Ogoma S, Biswaro L, Smallegange RC, Mbeyela E, et al. Development and field evaluation of a synthetic mosquito lure that is more attractive than humans. PLoS ONE 2010;5:e8951.

doi:10.1371/journal.pone.0008951. 


\title{
Chapter 3: Aedes aegypti Ir8a mutant female mosquitoes show increased attraction to standing water
}

\author{
"Mosquitoes are like family. Annoying, but they carry your blood."
}

\author{
Anonymous
}

\subsection{Abstract}

The detection of water sources is crucial for insects such as mosquitoes to avoid desiccation and survive. In addition, mosquitoes use humidity cues to successfully navigate the environment in search for a suitable oviposition site. Previous studies on Drosophila have implicated some members of the ionotropic receptor family in humidity sensing. Here, we investigate if an IR8a co-receptor mediates water detection in Aedes aegypti mosquitoes. Using a simple behavioral assay, we examined the attraction of $\operatorname{Ir} 8 a$ mutant mosquitoes to standing water. The Ir $8 a$ mutant mosquitoes were able discriminate between traps containing water and those without as well as wild type and heterozygous control females. Surprisingly, the female mutants were more robustly drawn to standing water than control mosquitoes. Further investigation revealed that the strong behavioral attraction to water is not mediated by a metabolic need or an activity defect.

\subsection{Introduction}

The ability to sense water in the environment (hygrosensation) has been previously studied in different insects [1-5]. The availability of water impacts insect longevity, fitness and geographic distribution [6]. Although insects are covered by chitinous exoskeleton, they constantly experience water loss via the cuticle and through their open respiratory systems [7]. Insects with large surface area-to-volume ratios such 
as mosquitoes must figure out a way to replenish water loss and maintain internal osmotic balance. Water vapor emanating from oviposition sites have been shown to elicit preoviposition behavior in Anopheles gambiae [3]. Anthropophilic mosquitoes do not only rely on heat, odor and visual cues to find their human hosts [8], the detection of hygrosensory cues has also been proposed to be important during host-seeking [9]. Functional mapping of the pathways that mediate water-seeking behavior could inform how mosquitoes monitor and adjust its hydration state to maintain optimum physiological homeostasis or seek oviposition sites. Understanding the molecular basis of mosquito water-seeking behavior could lead to novel approaches for controlling mosquito populations and manipulating gravid female attraction to water-baited traps.

Insects possess two distinct systems for detecting water sources: the gustatory system, which is tuned to sensing liquid water [10,11], and the hygrosensory system required for detecting water vapor [4,5]. In Drosophila, behavioral response to liquid water was disrupted by ablating the $p p k 28$ gene function which labels the gustatory water sensory neurons [11]. The gustatory system was activated only after the sensory neurons had made direct contact with liquid water. The observation draws attention to the hygrosensory system that detects water vapor from a distance. The TRP channels, nan and wtrw, previously identified in Drosophila mediate two contrasting behavioral responses to dry air and moist air respectively [12]. Studies have shown the existence of water sensitive receptors expressed in the coeloconic sensilla of the Drosophila antennae [13]. Some ionotropic receptors (IRs) including IR25a, IR93a, IR68a and IR40a which are expressed in these sensilla have been reported to mediate humidity sensing in Drosophila $[4,5,14]$. 


\subsection{Methods and Results}

We recently reported that the $\operatorname{Ir} 8 a$ gene (AAEL002922) is key for yellow fever mosquitoes to detect acids in human sweat [15]. Here, we asked if the IR8a pathway also drives water-seeking behavior. To test this, we presented two ramekins $(3.8 \mathrm{~cm}$ height by $5 \mathrm{~cm}$ width) housed in a trap (16 $\mathrm{cm}$ height, $9 \mathrm{~cm}$ width, $6 \mathrm{~cm}$ diameter) and set at an angle $45^{\circ}$ opposite and placed $3.7 \mathrm{~cm}$ apart from each other inside a rearing cage $(30 \mathrm{~cm}$ height, $28 \mathrm{~cm}$ diameter, $15 \mathrm{~cm}$ diameter). One of the ramekins contained $25 \mathrm{ml}$ deionized water whereas the other was left blank (Figure 8A-D). A total of 50 mosquitoes aged 7-10 days old, previously starved on water for $24 \mathrm{hr}$ were introduced into the cage. The assay lasted for $15 \mathrm{hrs}\left(27^{\circ} \mathrm{C}, 40 \% \mathrm{RH}\right)$ under a $14: 10$ light-dark cycle (lights on at $\left.8 \mathrm{am}\right)$.

Thereafter, mosquitoes were cold anesthetized at $4^{\circ} \mathrm{C}$ for 30 mins. The number of mosquitoes inside each trap was visually scored. In order to control for possible position effect, the ramekins containing water was swapped after each trial. Surprisingly, Ir $8 a$ mutant female mosquitoes were more strongly attracted to the water trap than the wildtype and heterozygous controls (Fig. 9A). The behavior is sexually dimorphic as it was observed in the Ir8a mutant females but not males (Fig. 9B). All the genotypes tested including males and females show strong preference for water trap over the blank one (Fig. 9C-D). The observation suggests that $\operatorname{Ir} 8 a$ is not required to find standing water, but rather it influences the intensity of the response to water. 
A

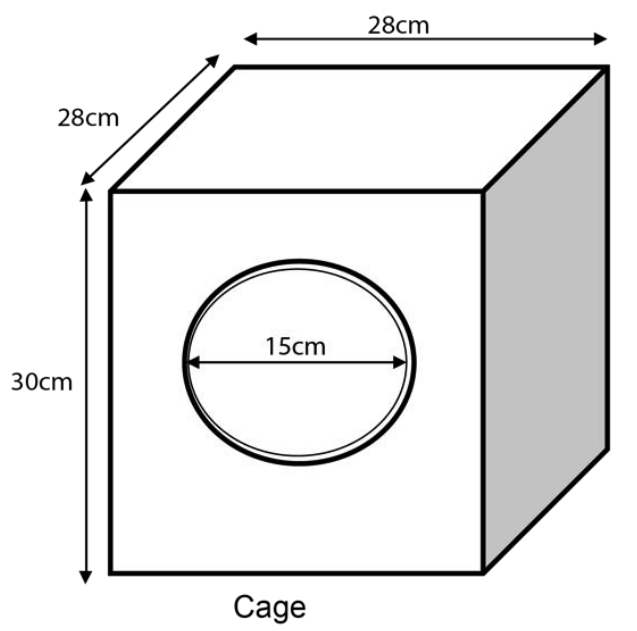

C

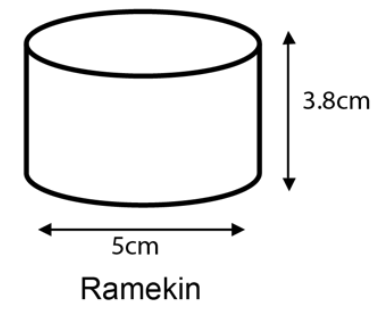

B
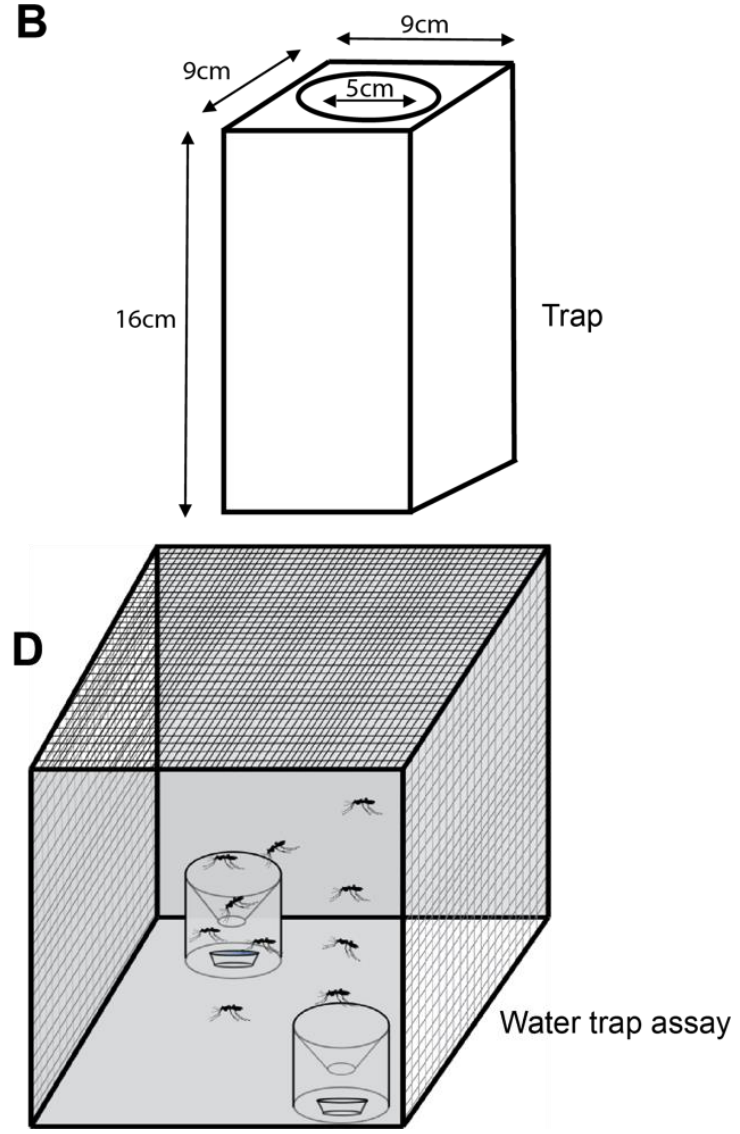

Figure 8: Material designs for the water trap assay. (A) Illustrations showing the dimensions of a mosquito cage, (B) trap, and (C). ramekin used for the water trap assay (D) Illustration showing ramekin housed in a trap and set at an angle $45^{\circ}$ opposite each other and $3.7 \mathrm{~cm}$ apart. One of the ramekins contained $25 \mathrm{ml}$ deionized water whereas the other was left blank. 

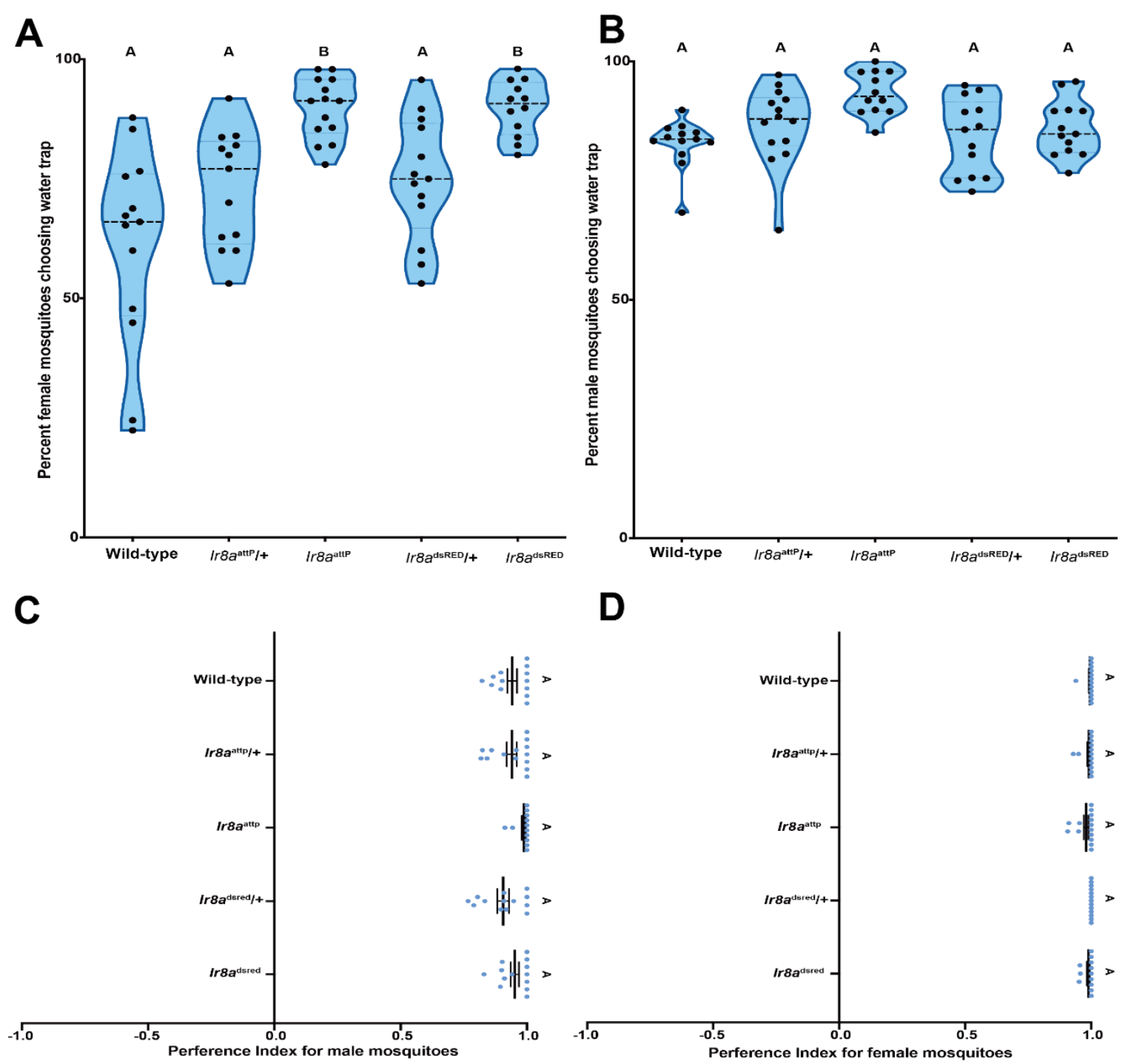

Figure 9: Ir8a mutant female mosquitoes are more attracted to water (A) Response of female mosquitoes and (B) male mosquitoes to water over a period of 15 hours. Genotypes varied in their response to water. Females (one-way ANOVA, $p<0.0001 \mathrm{n}=$ 12-14). Males (one-way ANOVA $p=0.0023, \mathrm{n}=12-14$ ). (C) Figure showing female (one-way ANOVA, $p=0.213, \mathrm{n}=12-14$ ) and (D) male mosquitoes' preference towards water source (one-way ANOVA, $p=0.055, \mathrm{n}=12-14$ ). Genotypes marked with different letters are significantly different by post hoc Tukey's HSD test. On the violin plot, the central line represents the median. The shape of the kernel represents the density of the population. Wider sections of the violin plot represent a higher probability that members of the population will fall within the section. 
We asked if the strong attraction to water recorded in $\operatorname{Ir} 8 a$ mutant female is due to physiological need for hydration or carbohydrates. Using the capillary feeder assay (CAFE) as previously described [16], we quantified the amount of water ingested after $2 \mathrm{hrs}$, and compared to the wild-type and heterozygous controls. Interestingly, we found no significant difference in the total volume of water ingested by $\operatorname{Ir} 8 a$ mutants when compared to the wild type and heterozygous controls (Fig. 10A). We then wondered if Ir $8 a$ mutant females are more attracted to the water source because they are looking for a sugar meal. A water solution containing $10 \%$ sucrose was presented to the mosquitoes using the CAFE assay. After 4hrs of ad libitum feeding, we could not record any feeding difference between the wild-type and Ir8a mutant females (Fig. 10B) similar to what has been previously reported for 18 hours of feeding [15]. Taken together, these findings suggest that the increased attraction to water seen in Ir8a mutants cannot be explained by thirst or lack of carbohydrate reserves.

We next investigated if $\operatorname{Ir} 8 a$ mutant females have increased activity in humid environments. We previously reported that the IR8a pathway does not regulate mosquito activity [15]. As reported, the glass tube was plugged with a dry and a water-saturated cotton at opposite ends to create a humidity gradient. We reasoned that water saturating both cottons would simulate a wet environment that favors the Ir $8 a$ mutants, and we could record higher infrared beam breaks triggered by the water-seeking behavior of the mutants. Using a locomotor activity assay adapted to mosquitoes (Fig. 10C) [17], we found no difference in activity in the $\operatorname{Ir} 8 a$ mutants when compared to the wild-type and heterozygous controls (Fig. 10D). 


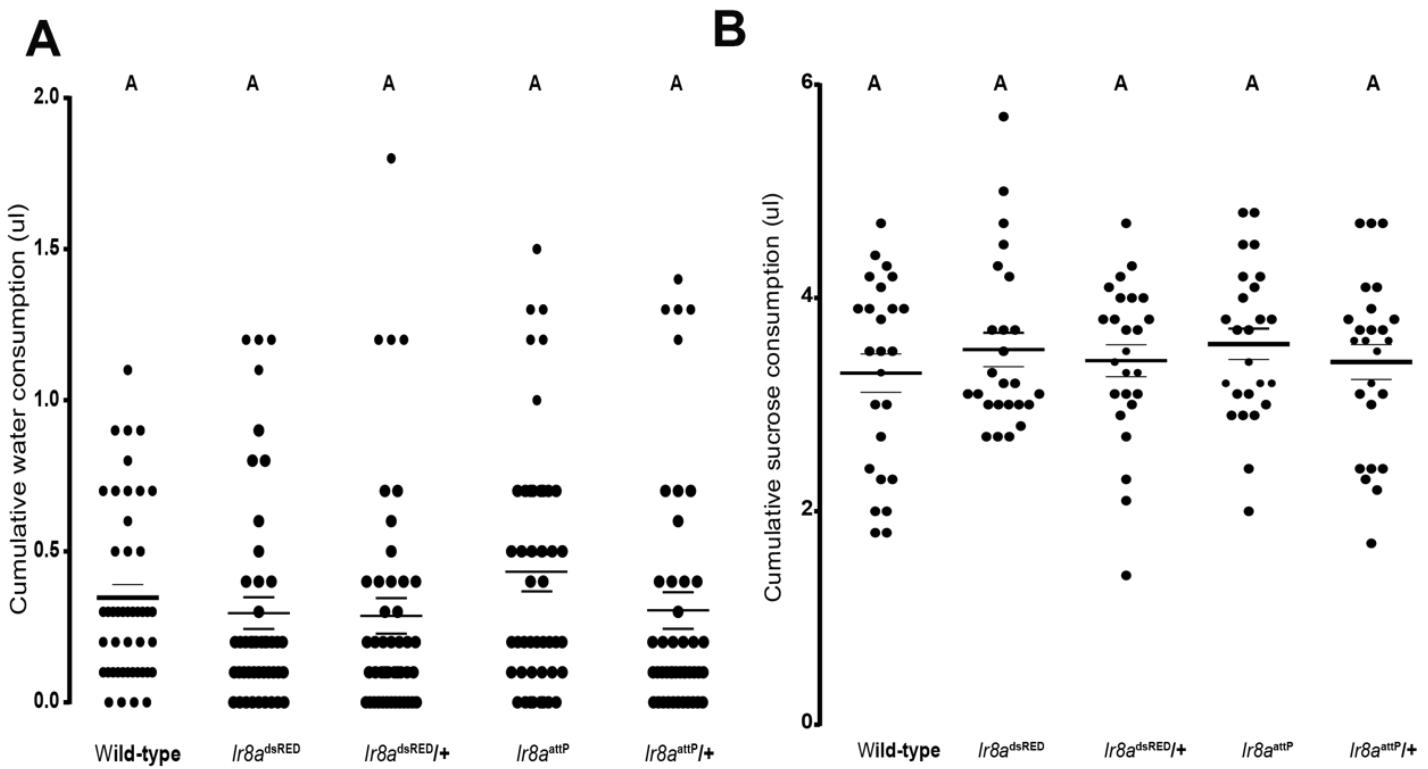

C
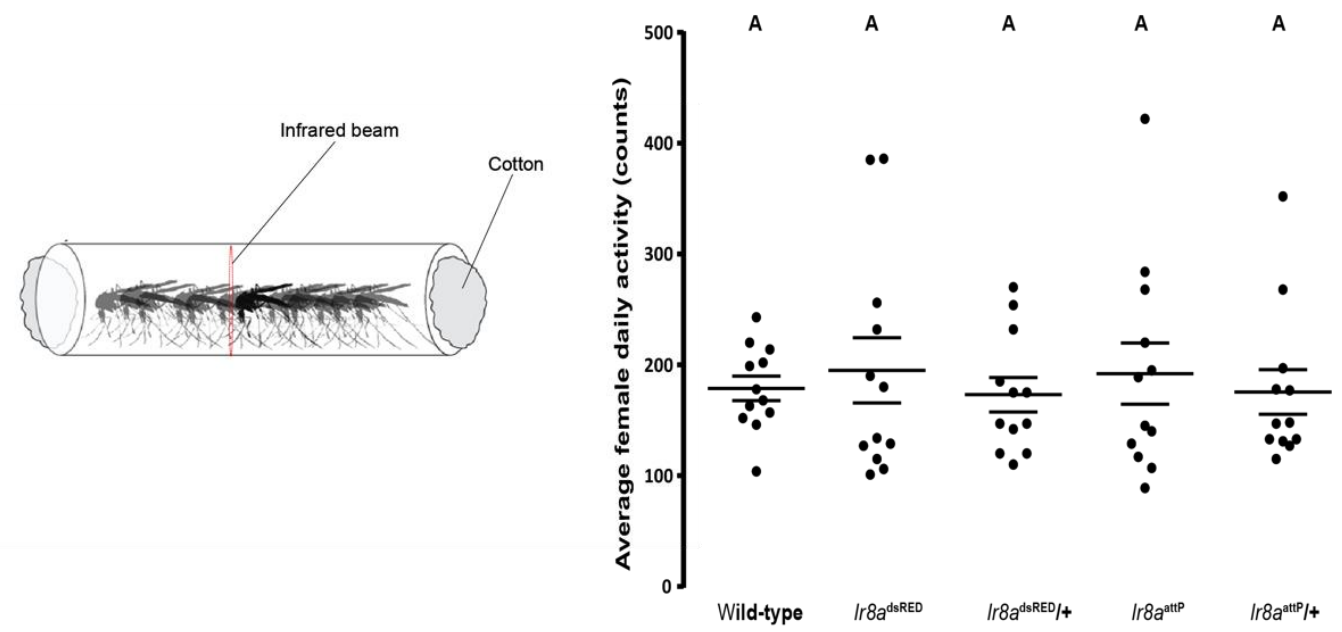

Figure 10: Ir8a mutant female mosquitoes feed normally on water and sugar, and show normal activity. (A)Water ingestion quantified after $2 \mathrm{hrs}$ (one-way ANOVA $p=$ $0.3525, \mathrm{n}=45$ ) of drinking. (B) Sucrose consumption recorded after 4 hrs of feeding, (one-way ANOVA $p=0.7772, \mathrm{n}=25$ ). (C) Illustration of the beam break assay. The red line represent the infrared beam triggered by mosquito movement in the glass tube. An activity count is recorded when a mosquito moves past the beam. (D) Average daily locomotor activity after 4 days of fasting on water, measured by the number of infrared beam breaks (counts). There were no statistical differences among genotypes $(p=0.9320$, $n=12$ ). On the dot plots, long lines represent the mean and short lines represent standard error. Data was analyzed by one-way ANOVA, and genotypes marked with the same letters are not significantly different by post hoc Tukey's HSD test. 


\subsection{Conclusion}

Taken together, the robust water-seeking behavior recorded in the Ir8a mutant female mosquitoes cannot be explained by a physiological need for water or sugar. Also, the mutants show no locomotor activity difference as inferred from the activity assay. We propose that the strong attraction to standing water could be mediated by chemosensation. A possibility is that $\operatorname{Ir} 8 a$ mutant females might be compensating for the loss of intact olfactory sensory modality by priming the sensory system towards vital resources key for survival. This evidence supports the claim that the loss of one sensory input may cause enhanced sensitivity to a completely different sense [18]. Another hypothesis is that $\operatorname{Ir} 8 a$ could be part of a neural circuit that represses water sensing when female mosquitoes are hydrated. Ir $8 a$ may also be important for finding a suitable habitat that is less humid. Future study is needed to uncover the relative contribution of the Ae. aegypti IR8a pathway in water-seeking behavior. 


\section{References}

1. Rowley M, Hanson F. Humidity detection and hygropreference behavior in larvae of the tobacco hornworm, Manduca sexta. J Insect Sci. 2007;7(39):1-10. PMID: 20302460; DOI: 10.1673/031.007.3901.

2. Arx von M, Goyret J, Davidowitz G, Raguso RA. Floral humidity as a reliable sensory cue for profitability assessment by nectar-foraging hawkmoths. Proc Natl Acad Sci USA. 2012;109(24):9471-6. PMID: 22645365; DOI: 10.1073/ /pnas.1121624109.

3. Okal MN, Francis B, Herrera-Varela M, Fillinger U, Lindsay SW. Water vapour is a pre-oviposition attractant for the malaria vector Anopheles gambiae sensu stricto. Malar J. BioMed Central. 2013; 12(1):365. PMID: 24120083; DOI: 10.1186/14752875-12-365.

4. Enjin A, Zaharieva EE, Frank DD, Mansourian S, Suh GSB, Gallio M, Stensmyr MC. Humidity sensing in Drosophila. Curr Biol. 2016;26(10):1352-8. PMID: 27161501; DOI: 10.1016/j.cub.2016.03.049.

5. Knecht ZA, Silbering AF, Ni L, Klein M, Budelli G, Bell R, Abuin L, Ferrer AJ, Samuel AD, Benton R, Garrity PA. Distinct combinations of variant ionotropic glutamate receptors mediate thermosensation and hygrosensation in Drosophila. eLife. 2016;5:44. PMID: 27656904; DOI: 10.7554/eLife.17879.

6. Chown SL, Sørensen JG, Terblanche JS. Water loss in insects: an environmental change perspective. J Insect Physiol. 2011;57(8):1070-84. PMID: 21640726; DOI: 10.1016/j.jinsphys.2011.05.004.

7. Schilman PE, Lighton JRB, Holway DA. Respiratory and cuticular water loss in insects with continuous gas exchange: comparison across five ant species. J Insect Physiol. 2005;51(12):1295-305. PMID: 16154585; DOI: 10.1016/j.jinsphys.2005.07.008.

8. Raji JI, DeGennaro M. Genetic analysis of mosquito detection of humans. Curr Opin Insect Sci. 2017;20:34-8. PMID: 28428935; DOI:10.1016/j.cois.2017.03.003

9. Brown AW. The attraction of mosquitoes to hosts. JAMA. $1966 \mathrm{Apr}$ 18;196(3):249-52. PMID: 4379555.

10. Inoshita T, Tanimura T. Cellular identification of water gustatory receptor neurons and their central projection pattern in Drosophila. Proc Natl Acad Sci USA. 2006;103(4):1094-9. PMID: 16415164; DOI: 10.1073/pnas.0502376103. 
11. Cameron P, Hiroi M, Ngai J, Scott K. The molecular basis for water taste in Drosophila. Nature. 2010;465(7294):91-5. PMID: 20364123; DOI: 10.1038/nature09011

12. Liu L, Li Y, Wang R, Yin C, Dong Q, Hing H, Kim C, Welsh MJ. Drosophila hygrosensation requires the TRP channels water witch and nanchung. Nature. 2007;450(7167):294-8. PMID: 17994098; DOI: 10.1038/nature06223

13. Yao CA, Ignell R, Carlson JR. Chemosensory coding by neurons in the coeloconic sensilla of the Drosophila antenna. J Neurosci. 2005;25(37):8359-67. PMID: 16162917; DOI: 10.1523/JNEUROSCI.2432-05.2005

14. Knecht ZA, Silbering AF, Cruz J, Yang L, Croset V, Benton R, Garrity PA. Ionotropic Receptor-dependent moist and dry cells control hygrosensation in Drosophila. eLife 2017;6:44. PMID: 28621663; DOI: 10.7554/eLife.26654.

15. Raji JI, Melo N, Castillo JS, Gonzalez S, Saldana V, Stensmyr MC, DeGennaro M. Aedes aegypti Mosquitoes Detect Acidic Volatiles Found in Human Odor Using the IR8a Pathway. Curr Biol. 2019;29(8):1253-7. PMID: 30930038; DOI: 10.1016/j.cub.2019.02.045.

16. Liesch J, Bellani LL, Vosshall LB. Functional and genetic characterization of neuropeptide Y-like receptors in Aedes aegypti. PLoS Negl Trop Dis. 2013;7(10):e2486. PMID: 24130914; DOI: 10.1371/journal.pntd.0002486.

17. DeGennaro M, McBride CS, Seeholzer L, Nakagawa T, Dennis EJ, Goldman C, Jasinskiene N, James AA, Vosshall LB. orco mutant mosquitoes lose strong preference for humans and are not repelled by volatile DEET. Nature. 2013;498(7455):487-91. PMID: 23719379; DOI: 10.1038/nature12206

18. Lomber SG, Meredith MA, Kral A. Cross-modal plasticity in specific auditory cortices underlies visual compensations in the deaf. Nature Neuroscience. 2010;13(11):1421-7. PMID: 20935644; DOI: 10.1038/nn.2653 


\title{
Chapter 4: Carbon dioxide mediates increased visual attention in tethered
}

\section{Aedes aegypti and Drosophila melanogaster}

\author{
"A mosquito can fly, but a fly cannot mosquito."
}

Anonymous

\subsection{Abstract}

Insects strongly rely on visual processing during flight to steer towards targets, avoid obstacles, and make corrections when wind or other factors introduce perturbations. Given that Aedes aegypti and Drosophila melanogaster are distantly related dipterans, we reasoned that both insects would possess diverse visuomotor reflexes. Using a tethered flight experiment, we investigated the interaction between olfactory and visual stimuli on the control of wing kinematics in the yellow fever mosquitoes and fruit flies. When given a choice between star field and a bar in the absence of positive olfactory cues, vinegar flies show strong preference for wide-field motion over object tracking. However, mosquitoes show no preference for both visual cues. Supplementing the assay with $\mathrm{CO}_{2}$ elicits robust tracking response in both dipterans. Using reverse genetics, we provide evidence that the $\mathrm{CO}_{2}$ sensory pathway is necessary for Ae. aegypti mosquitoes to effectively track visual information. $\mathrm{CO}_{2}$ insensitive Gr3 mutant mosquitoes cannot associate $\mathrm{CO}_{2}$ with visual cues. In addition, $\mathrm{CO}_{2}$ rescues weak sensitivity to visual contrasts in mosquitoes but slight effect was recorded in the vinegar fly. Taken together, we provide evidence that $\mathrm{CO}_{2}$ enhance attention to visual cues in the two dipterans. 


\subsection{Introduction}

Studies in many insects demonstrate that visual feedback is a key to flight control (Grimaldi, and Engel, 2005). It is the primary means by which they maintain altitude, avoid obstacles, and approach targets (Gotz, 1968). Olfaction complements vision by allowing insects to locate resources and avoid hazards that are obscured or too far off to be seen, such as steering towards food or away from predators (Murlis et al., 1992). Much less understood is the interaction between vision and olfaction but integrating the two cues is important for effective navigation (Vinauger et al., 2019; van Breugel et al., 2015; Duistermars and Frye, 2008), allowing neural circuits to activate behaviors in a context-specific manner.

Flying to a target successfully requires first setting a heading that steers towards a target, then making corrections when perturbed by wind (Combes and Dudley, 2009; Ravi et al., 2013). Although natural scenes contain countless intermediate visual stimuli, and neural pathways are now known to include neurons that process motion in complex ways (Bahl et al., 2013, Fenk et al., 2014, Theobald et al., 2008), at least some neurons respond preferentially to small moving targets, while others respond to wide moving flow fields (O'Carroll, 1993). As a result, both small visual features, such as vertical bars, and wide visual fields, such as the optic-flow produced by self-motion, can elicit robust behavioral responses in flight (Maimon et al., 2008; Krapp et al., 2012). The smaller targets can be prey, predators, mates, flowers, or nearly any other small image that an insect might want to approach or avoid. The wide fields on the other hand, fill large swaths of the visual field, and when all the images flow in a characteristic way, provide a strong cue of self-motion (Krapp et al., 2000; Taylor and Krapp 2000; Borst et al., 2010). 
But even combined with more sophisticated visual processing (Theobald et al., 2010), these strategies can be insufficient to detect vital features if they are far off, visually obstructed, or obscured in the visual clutter-especially when viewed by low-resolution insect eyes (Land and Nilsson et al., 2012).

Olfaction provides a means for insects to find less visible resources, as odors can signal the presence of food, mates, or predators. However, the plumes that carry odors are structurally complex and quickly varying, so by themselves they are a poor directional cue (Murlis et al., 1992). Instead, odors can operate together with visual cues by modifying responses to targets and optic flow, and hence influencing flight paths (Chow and Frye, 2008). These flight-mediated responses enable olfactory navigation (Chow et al., 2011). Odor and visual cues can also elicit synergistic behaviors that insects will not perform without both cues combined. For example, moths will not track odor plumes reliably without simultaneous presentation of visual cues (Raguso and Willis, 2005), fruit flies alter the gain of their wide-field steering responses when they smell attractive odors (Chow et al., 2011), and $\mathrm{CO}_{2}$ causes mosquitoes to initiate a search for visual objects in a wind tunnel (van Breugel et al., 2015). Here, we investigate the interaction between olfactory and visual stimuli on the motor control of wing kinematics in Ae. aegypti and D. melanogaster. 


\subsection{Materials and Methods}

\subsubsection{Insect rearing and preparation}

The Ae. aegypti mosquitoes were reared and maintained at $25-28^{\circ} \mathrm{C}, 75 \%$ relative humidity under a 14:10 light-dark cycle (lights on at 08:00h). Non-blood fed wild-type female Orlando strain and Gr3 mutant mosquito lines aged 5-7 days old were used in the study. Mosquitoes were fed ad libitum on sugar and were not starved before the experiment. Female D. melanogaster were raised on a standard food medium, maintained on a 16h: $8 \mathrm{~h}$ light: dark cycle and collected $4-6$ days post eclosion. Mosquitoes and flies were cold anesthetized and glued by the dorsal thorax to a rigid tungsten rod. We allowed them to rest and recover by placing a small piece of tissue paper on their legs, which stops their wings beating. The insects are then affixed into the center of the flight arena, still suspended by the rod, at which point they initiate tethered flight.

\subsubsection{Experimental equipment}

A custom-built flight arena delivered simultaneous visual and olfactory stimulation to rigidly tethered flying mosquitoes and flies. The arena is a Perspex cube with $200 \mathrm{~mm}$ edges, covered with back projection screen material and first-surface mirrors affixed at 45 degrees to the sides with the back left open for access (Fig 11A). A projector illuminates five sides, covering 10.47 steradians of the visual field. The projector images a three-dimensional scene onto each face at 360 frames per second, perspective-corrected for the center of the cube.

\subsubsection{Measuring steering responses}

Within the arena, mosquitoes and flies were positioned between an infrared light above, and a pair of photodiodes below. The shadow of each wing on the photodiode 
measures the amplitude for every stroke, recorded as voltage (Fig. 11B). Flies have higher wing beat amplitude and lower wing beat frequency compared to mosquitoes, which we accommodated by adjusting the gain and gate width of the wing beat analyzer. Drosophila responds to visual cues by modulating the relative amplitudes of right and left wing beats (Gotz, 1968), giving an indication of steering effort (Frye and Dickinson, 2004).

\subsubsection{Olfactory Stimulus}

For assays supplemented with olfactory cues such as air and $\mathrm{CO}_{2}$, the gas flow rate was measured by an acrylic flowmeter Model VFA-4-SSV (Dwyer Instruments Inc., IN, USA) set to release the air or carbon dioxide at $0.5 \mathrm{SCFH}$ via the four forward facing corners of the arena. The final concentration of $\mathrm{CO}_{2}$ leaving the arena was maintained between 25000ppm - 29000ppm measured by a $\mathrm{CO}_{2}$ meter (Catalog \# CO2-100, Amprobe, Everett, WA).

\subsubsection{Visual Stimulus}

Object tracking was tested with moving vertical bars projected near the frontal visual field, and wide-field tracking was tested with moving star fields projected in the front and periphery, both in open-loop. Tracking tests were interspersed with 3s closed-loop bar fixation, where an insect can stabilize a bar with its wing beat responses (Fig. 11C-D). Insects that failed to hold a stable bar, or beat wings throughout an experiment, were eliminated from further analysis. For the sinusoidal grating experiment, the visual information contains 10 levels of light intensities and the scene can move either left or right. 
A
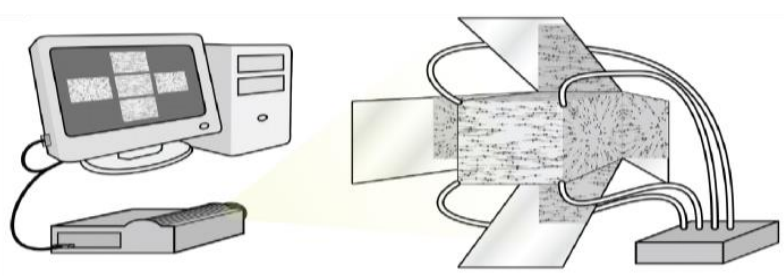

B
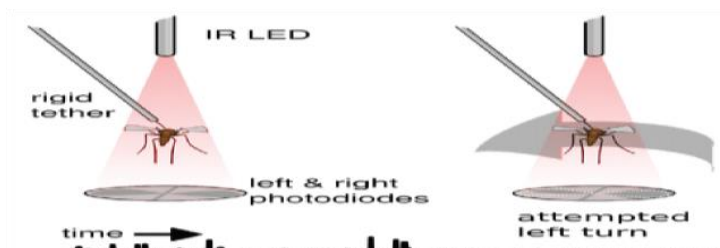

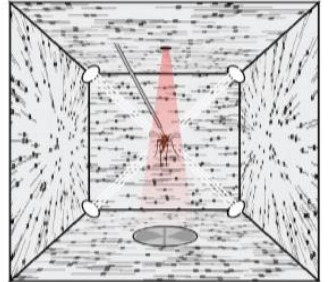

U

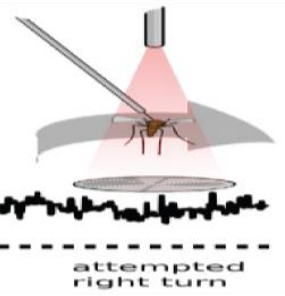

C
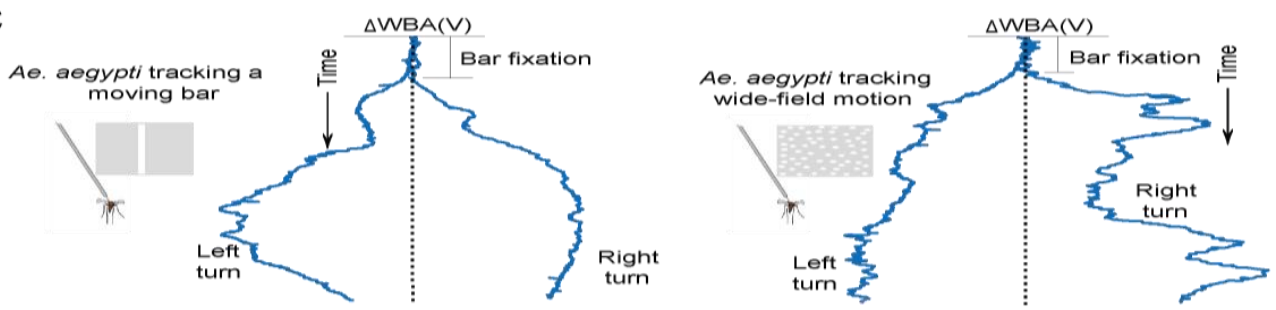

D

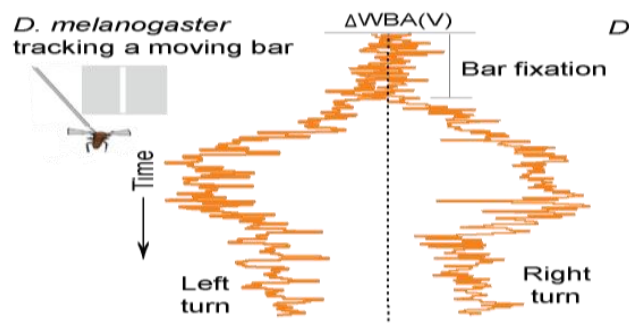

D. melanogaster tracking $\triangle \mathrm{WBA}(\mathrm{V})$

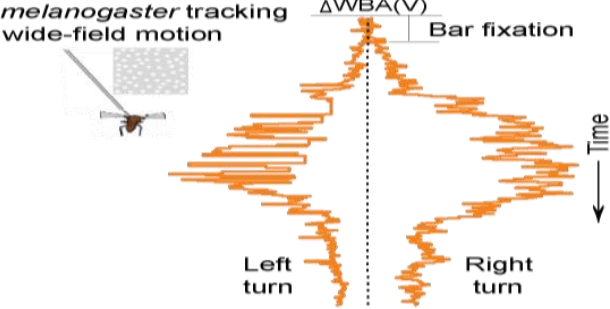

Figure 11. An arena for simultaneous delivery of visual and olfactory stimuli (A) Computer controls a high-speed projector, and an odor delivery manifold, to coordinate the experimental delivery of perspective-corrected, panoramic images with airborne odor delivery from four directions. Right image shows the inside of the flight arena. (B) Turning attempts manifest in differential wing beat amplitudes (bottom trace), which are captured as infrared shadows cast onto a pair of photodiodes below the insect, producing a record of steering effort with each wing beat. (C) Representative traces showing the tracking behavior of a flying tethered mosquito to a bar (left) and star field (right). Representative traces showing the tracking behavior of a flying tethered fruit fly to a bar (left) and star field (right). 


\subsection{Results and Discussion}

\subsubsection{Object and wide-field tracking differ in Ae. aegypti and D. melanogaster}

Mosquitoes and fruit flies are distantly related dipterans (Severson et al., 2004) with distinct feeding behaviors. By presenting bars and star field, we asked if different visual cues could elicit distinct tracking responses in both insects. We used eight types of visual information consisting of a star field moving either left or right; a bar moving either left or right; a bar and star field simultaneously moving together; and a bar and star field simultaneously displayed but moving in opposite directions. The order of tests was randomized to avoid hysteresis.

Interestingly, we found marked differences in the tracking behavior of the two dipterans. In visual test condition where bar and point fields move in opposite directions, mosquitoes show no preference for either $(\mathrm{p}=0.632)$. On the contrary, fruit flies show a strong preference for the wide field over a moving bar when both cues move in opposite direction $(\mathrm{p}=0.0016)$. The preference implies that Drosophila prefers to track wide field motion that fills large swaths of the visual field over a single object. Since fruit flies are cosmopolitan and generalist species, a visual field presenting a wide scene may be indicative of food or mates. In addition, when the bar and point fields move in the same direction, the responses recorded in Ae. aegypti is summative of the steering efforts when either bar or star field was presented. Since object tracking is enhanced when the wide field moves in the same direction, mosquitoes may also pay attention to the background of a potential host while tracking. However, no summative response is recorded in the flies (Fig. 12A). Drosophila showed a robust tracking of all the visual information displayed, whereas mosquitoes show very weak responses. 
Since mosquitoes integrate several cues to detect their human hosts (Raji and DeGennaro, 2017), visual information alone may not be a strong cue for finding resources.

\subsection{2 $\mathrm{CO}_{2}$ increases attention to visual cues in Ae. aegypti and D. melanogaster}

Earlier studies have reported that mosquitoes can associate vision with olfactory cues and heat to find a target (van Breugel et al., 2015). We reasoned that supplementing the tethering arena with positive olfactory cues might enhance mosquitoes' attention to fixate on visual stimuli. We delivered $\mathrm{CO}_{2}$ into the arena at the rate of 0.5 Square per Cubic Feet per Hour (SCFH) to maintain a final concentration that fluctuated between 2500$2900 \mathrm{ppm}$. For an assay without additional $\mathrm{CO}_{2}$, we replaced with dry air set at the same flow rate.

When $\mathrm{CO}_{2}$ was added, a moving bar became more salient to mosquitoes $(\mathrm{p}=$ 0.015 ) but not the wide field ( $\mathrm{p}=0.9657$, Fig. $12 \mathrm{~B})$. Since $\mathrm{CO}_{2}$ is a very important cue that sensitizes mosquito host detection system (Raji et al., 2019; McMenniman et al., 2014), it is likely that the tethered mosquitoes take the moving bar for a vertebrate host. A possibility is that $\mathrm{CO}_{2}$ primes mosquitoes' host detection system to seek potential hosts. As a search strategy to find resources, insects assign subjective value to inanimate objects (Robie et al., 2010). Since visual representation of the star field does not closely relate to a host, this may explain why tracking response to the wide-field motion was not robustly enhanced. Mosquitoes' response in trials where the bar and point-field move in the same direction was significantly more than when $\mathrm{CO}_{2}$ was not added to the assay $(\mathrm{p}<$ 0.001). This strengthens the role of $\mathrm{CO}_{2}$ in enhancing visual tracking behavior in $A e$. aegypti. 

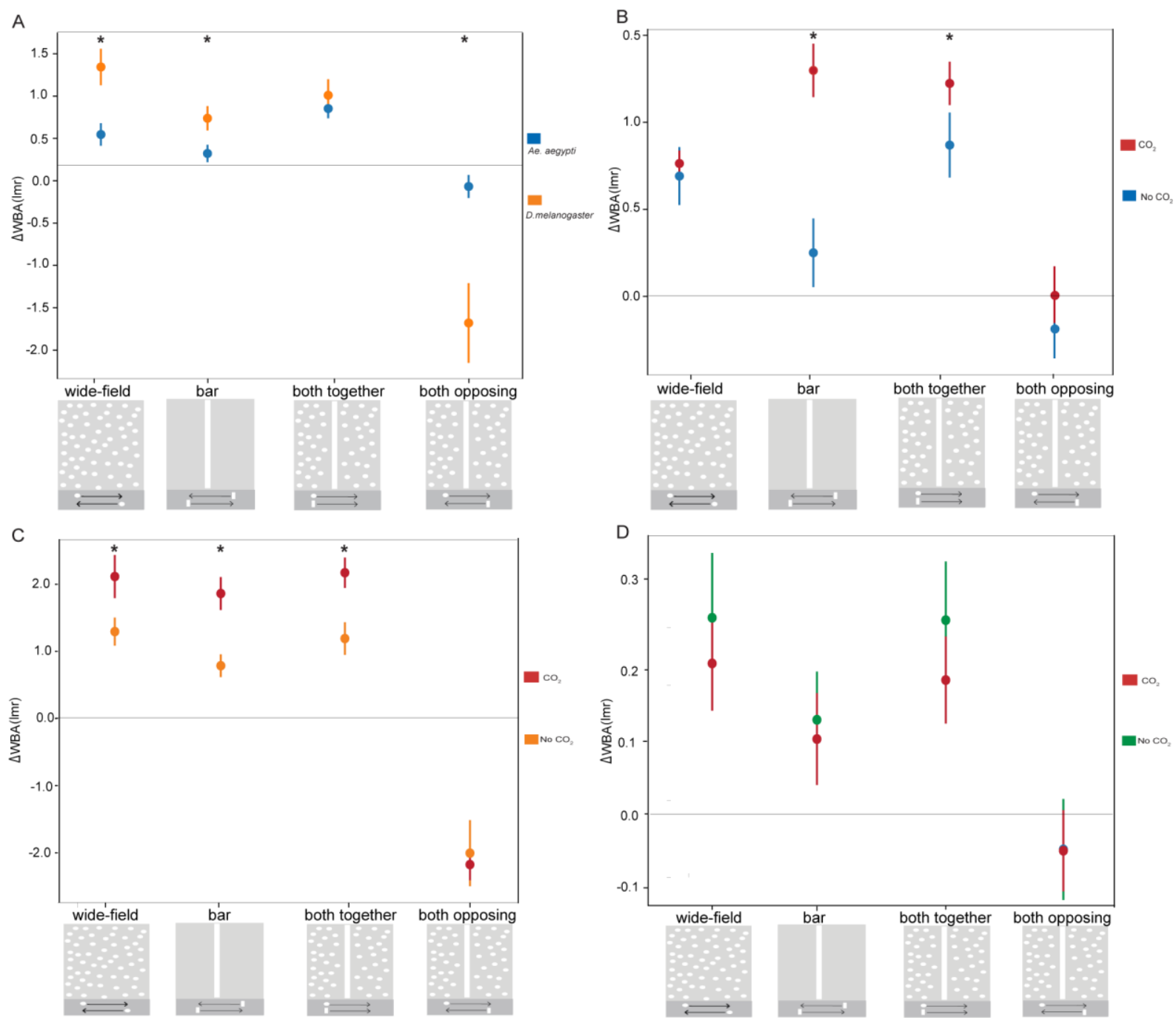

Figure 12. Carbon dioxide increases attention to visual cues in Ae. aegypti and $D$. melanogaster $(\mathrm{A})$ Response of Ae. aegypti mosquitoes $(\mathrm{n}=24)$ and D. melanogaster $(\mathrm{n}=$ 14) to visual cues in the absence of positive olfactory cues. (B) Response of Ae. aegypti mosquitoes to visual cues in the presence $(\mathrm{n}=21)$ and absence $(\mathrm{n}=18)$ of $\mathrm{CO}_{2} .(\mathrm{C})$ Response of D. melanogaster to visual cues in the presence $(\mathrm{n}=15)$ and absence $(\mathrm{n}=12)$ of $\mathrm{CO}_{2}$. (D) Response of $\mathrm{Gr} 3 \mathrm{Ae}$. aegypti mutant mosquitoes to visual cues in the presence $(n=24)$ and absence $(n=15)$ of $\mathrm{CO}_{2}$. Visual cues tested are illustrated below each graph. Figures marked with asterisks are significantly different when analyzed by paired t-test. 
A

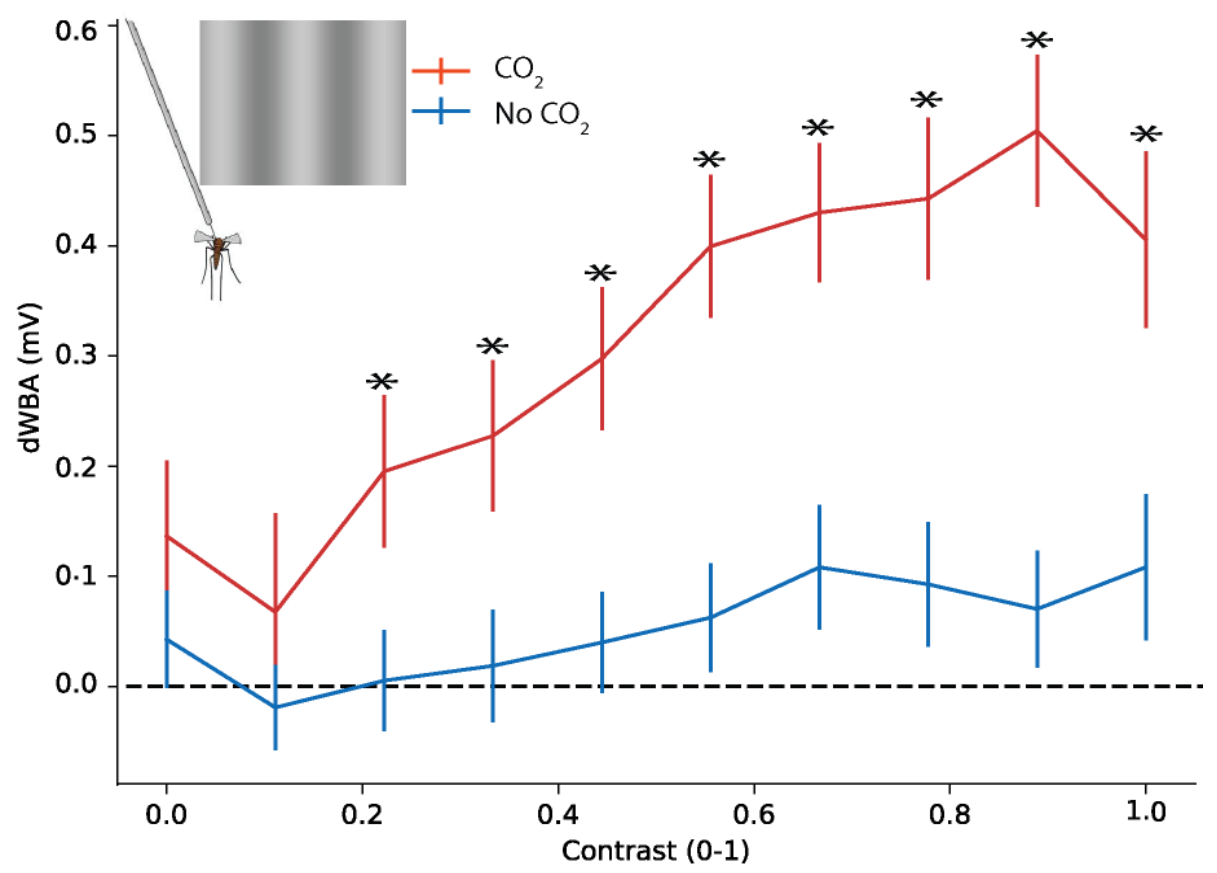

B

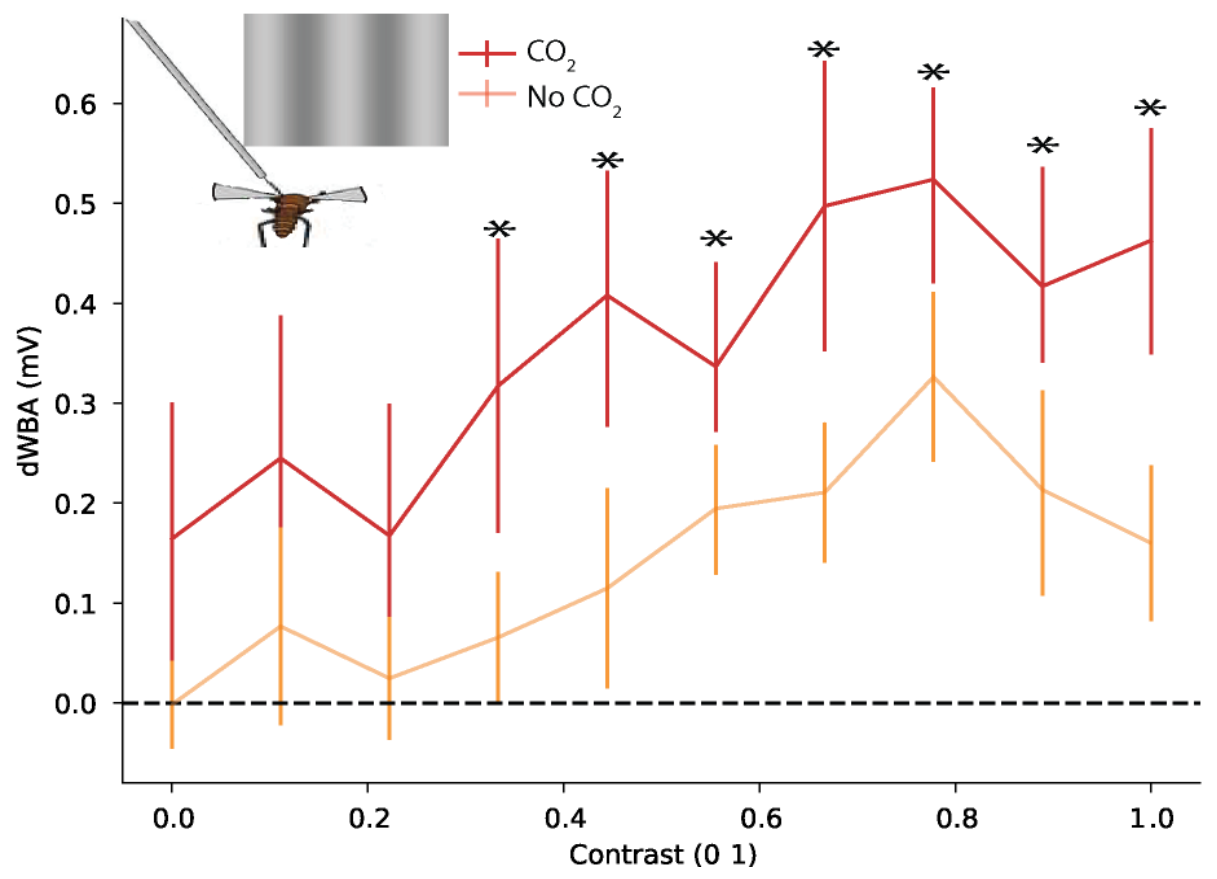

Figure 13. Carbon dioxide enhances sensitivity to visual contrast in Ae. aegypti and D. melanogaster. (A) Mosquitoes' response to sinusoidal grating in the presence $(n=17)$ and absence $(\mathrm{n}=10)$ of $\mathrm{CO}_{2}$. Fruit flies' response to sinusoidal grating in the presence ( $\mathrm{n}$ $=22)$ and absence $(\mathrm{n}=12)$ of $\mathrm{CO}_{2}$. Figures marked with asterisks are significantly different when analyzed by paired t-test. 
In tethered $D$. melanogaster, intermittent release of $\mathrm{CO}_{2}$ robustly enhanced visual response to both wide field and object in motion (Fig. 12C). Suggesting that the detection of $\mathrm{CO}_{2}$ cue is not limited to blood-sucking insects. Generalist insect species such as fruit flies may rely on $\mathrm{CO}_{2}$ sensory modality to find food sources. Interestingly, when the direction of the bar contradicts the star fields, fruit flies show a very strong preference towards the star fields independent of the presence of $\mathrm{CO}_{2}$. In contrast, overall tracking response $(\triangle \mathrm{WBA})$ of mosquitoes to the opposing visual cues is not significantly different from the baseline $(\mathrm{P}>0.05)$. Supplementing the arena with $\mathrm{CO}_{2}$ is not sufficient to rescue object tracking when the direction contrasts the wide field. This suggests a possibility that mosquitoes rely on the background motion of a potential host to effectively fixate.

The presence of $\mathrm{CO}_{2}$ has been shown to increase mosquitoes' attraction to a human arm in a uniport olfactometer tunnel (Raji et al., 2019). This was recorded in the wild-type Orlando strain but not in the $\mathrm{CO}_{2}$-insensitive $\mathrm{Gr} 3$ mutant mosquitoes. We reasoned that the addition of $\mathrm{CO}_{2}$ would make no difference in the response of $G r 3$ mutant mosquitoes to a moving bar. The recent advancement in gene editing allowed creating loss-of-function mutation and study gene of interest. Thus, we tested Gr3 mutant lines to visual cues in the presence and absence of added $\mathrm{CO}_{2}$. Based on our data, neither object $(\mathrm{p}=0.967)$ nor point field motion tracking $(\mathrm{p}=0.898)$ is enhanced when the assay was supplemented with $\mathrm{CO}_{2}$. It is worth noting that visual tracking is greatly impaired in the Ae. aegypti Gr3 mutants as inferred from the wing beat amplitude (Fig. 12D). This finding provides evidence that $\mathrm{CO}_{2}$ gates response to visual cues in Ae. aegypti mosquitoes. Unlike Gr3 mutant mosquitoes that cannot associate $\mathrm{CO}_{2}$ plumes with visual cues during a tethered flight (Fig. 12D), the disruption of the canonical $\mathrm{CO}_{2}$ pathway in 
fruit flies does not abolish in-flight attraction to $\mathrm{CO}_{2}$ (Wasserman et al., 2013). These findings suggest that differences may exist in the visual-olfactory integration of the two dipterans.

Surprisingly, $\mathrm{CO}_{2}$ flow rate induce differential behavioral responses in the two insects. The ability of the two dipterans to fixate is severely impaired when the $\mathrm{CO}_{2}$ flow rate was increased to $3 \mathrm{SCFH}$. This suggests that $\mathrm{CO}_{2}$ concentration threshold exists beyond which tracking behavior is impacted. Even at low $\mathrm{CO}_{2}$ consistent flow rate $(0.5 \mathrm{SCFH})$, fruit flies showed poor tracking performance compared to when the gas was released intermittently. However, the consistent $\mathrm{CO}_{2}$ flow rate $(0.5 \mathrm{SCFH})$ elicits robust mosquito tracking activity (Fig. 12B). A possibility is that fruit flies have relatively smaller body size, which makes the wing kinematics more liable to perturbation by elevated airflow. It also remains unclear whether fruit flies are more susceptible to $\mathrm{CO}_{2}$ induced anesthesia. Studies have shown that $\mathrm{CO}_{2}$ can impact flight behavior in fruit flies (Bartholomew et al., 2015) and cause disorientation in mosquitoes (Turner et al., 2011). The gas release rate was corrected for D. melanogaster in our experiments by transiently releasing $\mathrm{CO}_{2}$ gas every $30 \mathrm{sec}$ and set it to flow for $1 \mathrm{sec}$ at $0.5 \mathrm{SCFH}$ rate.

\subsection{3 $\mathrm{CO}_{2}$-induced sensitivity to visual contrasts is markedly enhanced in $A e$. aegypti mosquitoes than $D$. melanogaster}

We next investigated the visual acuity of mosquitoes and fruit flies to bright scenes on a dark background set to move at a constant motion but varying contrast. It is known that vision becomes blurry as the contrast between an object and its background decreases (O'Carrol and Wiederman, 2014). We hypothesized that the tracking behavior of the two dipterans will correlate with increased contrast and dependent on $\mathrm{CO}_{2}$. Contrary to what 
we observed in the fruit flies, mosquitoes show a very weak response to increased contrast in the absence of $\mathrm{CO}_{2}$ (Fig. 13A). However, visual response in fruit flies correlates with increased contrast, until it reached a saturation point where sensitivity begins to plummet (Fig. 13B).

Given that $\mathrm{CO}_{2}$ robustly enhanced object tracking in Ae. aegypti (Fig. 12B) and D. melanogaster (Fig. 12C), we reasoned that the addition of $\mathrm{CO}_{2}$ plumes to the assay would increase contrast sensitivity. Interestingly, we recorded a very robust response by mosquitoes to the visual presentations when $\mathrm{CO}_{2}$ was added (Fig. 13A). Similarly, the addition of $\mathrm{CO}_{2}$ increases visual attention in the fruit flies. However, the response from fruit flies (Fig. 13B) was not as dramatic compared to what was observed in mosquitoes (Fig. 13A). Other behavioral studies in these dipterans also showed that they integrate visual and olfactory cues to effectively respond in a complex environment (van Breugel et al., 2015; Frye et al., 2004). Mosquitoes appear to be less interested in visual cues and would rely on $\mathrm{CO}_{2}$ sensitization to associate a subjective value to an inanimate object within their visual field. We observed a saturation point to visual contrast in both insects, suggesting that visual acuity can be lost when the visual contrast is too high. Even at a very low visual contrast, visual tracking was greatly impaired. Study has shown that the ability to discriminate the finest detail between bright objects on a black background can be lost due to the unreliability of the photon catch (Barow, 1964).

These results implicate the $\mathrm{CO}_{2}$-sensing pathway in visual tracking of information. Recent study also supports our finding that olfactory and visual cues integrate as to enhance tracking behavior in yellow fever mosquito (Vinauger, et al 2019). But another group reported a different result that $\mathrm{CO}_{2}$ does not enhance visual 
tracking in Ae. aegypti (Liu and Vosshall et al., 2019). The method of CO2 delivery and the shape of visual cues presented could explain the different results. Study has shown that mosquitoes use visual cues to associate odor plumes with heat, but this conclusion is not supported by genetic evidence. Using the Gr3 mutant mosquitoes, we provide the evidence that visual tracking in yellow fever mosquito is dependent on $\mathrm{CO}_{2}$ detection.

A comparative study of spatial and temporal acuity in the two dipterans would be a step forward to understanding how insects' innate behavior can modulate visual perception. Given that mosquito host seeking behavior is state dependent, it is unknown whether gravid blood-fed female mosquitoes would prefer wide field motion, which could indicate an oviposition site. Future study is needed to determine if stages of mosquito gonotrophic cycle can influence visual and olfactory processing. The neurophysiological basis of olfactory driven behavior has only begun to be understood (Lutz et al., 2017), however relatively less is known about visual-olfactory integration in the insect brain. Addressing these research gaps would enhance our understanding of how $\mathrm{CO}_{2}$ modulates visuomotor reflexes in insects. 


\section{References}

Bahl, A., Ammer, G., Schilling, T. \& Borst, A. Object tracking in motion-blind flies. Nat. Neurosci. 16, 730-738 (2013).

Bartholomew, N. R., Burdett, J. M., Vanden-Brooks, J. M., Quinlan, M. C., and Call, G. B. (2015). Impaired climbing and flight behaviour in Drosophila melanogaster following carbon dioxide anaesthesia Sci Rep. 5: 15298.

Brodsky, A. K. The Evolution of Insect Flight. (Oxford University Press, Oxford, 1994).

Borst, A., Haag, J. \& Reiff, D. F. Fly Motion Vision. Annu. Rev. Neurosci. 33, 49-70 (2010).

Bolshakov, V.N. et al. (2002). A comparative genomic analysis of two distant diptera, the fruitfly, Drosophila melanogaster, and the malaria mosquito, Anopheles 0 gambiae. Genome Res 12, 57-66.

Chow, D. M. \& Frye, M. A. Context-dependent olfactory enhancement of optomotor flight control in Drosophila. J. Exp. Biol. 211, 2478-2485 (2008).

Chow, D. M., Theobald, J. C. \& Frye, M. A. An olfactory circuit increases the fidelity of visual behavior. J. Neurosci. 31, 15035-15047 (2011).

Combes, S. A. \& Dudley, R. Turbulence-driven instabilities limit insect flight performance. Proc. Natl. Acad. Sci. 106, 9105-9108 (2009).

David C. O'Carroll and Steven D. Wiederman (2014). Contrast sensitivity and the detection of moving patterns and features. Philos Trans R Soc Lond B Biol Sci. 369(1636): 20130043. doi: 10.1098/rstb.2013.0043

Duistermars, B. J. \& Frye, M. A. Crossmodal visual input for odor tracking during fly flight. Curr. Biol. 18, 270-275 (2008).

Fenk, L. M., Poehlmann, A. \& Straw, A. D. Asymmetric Processing of Visual Motion for Simultaneous Object and Background Responses. Curr. Biol. 24, 2913-2919 (2014).

Frye, M. A., Tarsitano, M. \& Dickinson, M. H. Odor localization requires visual feedback during free flight in Drosophila melanogaster. J. Exp. Biol. 206, 843855 (2003).

Frye, M. A. \& Dickinson, M. H. Motor output reflects the linear superposition of visual and olfactory inputs in Drosophila. J. Exp. Biol. 207, 123-131 (2004). 
Gotz KG. 1968 Flight control in Drosophila by visual perception of motion. Kybernetik 4, 199-208. (doi:10.1007/BF00272517).

Götz, K. G. Course-control, metabolism and wing interference during ultralong tethered flight in Drosophila melanogaster. J. Exp. Biol. 128, 35-46 (1987).

Götz, K. G. Flight control in Drosophila by visual perception of motion. Biol. Cybern. 4, 199-208 (1968).

Grimaldi, D. \& Engel, M. Evolution of the Insects. Cambridge University Press, Cambridge, MA, 2005.

Krapp, H. G. Neuronal matched filters for optic flow processing in flying insects. Int. Rev. Neurobiol. 44, 93-120 (2000).

Krapp, H. G., Taylor, G. K. \& Humbert, J. S. in Front. Sens. (eds. Barth, F. G., Humphrey, J. A. C. \& Srinivasan, M. V.) 101-114 (Springer Vienna, 2012).

Land, M. F. \& Nilsson, D.-E. Animal Eyes. (Oxford University Press, 2012).

Liu, M.Z and Vosshall, L.B. (2019). General visual and contingent thermal cues interact to elicit attraction in female Aedes aegypti mosquitoes. Current Biology doi: 8;29(13):2250-2257.e4.

Longuet-Higgins, H. C. \& Prazdny, K. The Interpretation of a Moving Retinal Image. Proc. R. Soc. Lond. B Biol. Sci. 208, 385-397 (1980).

Lutz, E.K., Lahondère, C., Vinauger, C., and Riffell, J.A. (2017). Olfactory learning and chemical ecology of olfaction in disease vector mosquitoes: a life history perspective. Curr. Opin. Insect Sci. 20:75-83

Maimon, G., Straw, A. D. \& Dickinson, M. H. A simple vision-based algorithm for decision making in flying Drosophila. Curr. Biol. 18, 464-470 (2008).

Murlis, J., Elkinton, J. S. \& Carde, R. T. Odor Plumes and How Insects Use Them. Annu. Rev. Entomol. 37, 505-532 (1992).

O’Carroll, D. Feature-detecting neurons in dragonflies. Nature 362, 541-43 (1993).

Raguso, R. A. \& Willis, M. A. Synergy between visual and olfactory cues in nectar feeding by wild hawkmoths, Manduca sexta. Anim. Behav. 69, 407-18 (2005).

Raji JI, DeGennaro M. Genetic analysis of mosquito detection of humans. Curr Opin Insect Sci. 20:34-8 (2017). 
Raji JI, Melo N, Castillo JS, Gonzalez S, Saldana V, Stensmyr MC, DeGennaro M. Aedes aegypti Mosquitoes Detect Acidic Volatiles Found in Human Odor Using the IR8a Pathway. Curr Biol. 29(8):1253-7 (2019).

Ravi, S., Crall, J. D., Fisher, A. \& Combes, S. A. Rolling with the flow: bumblebees flying in unsteady wakes. J. Exp. Biol. 216, 4299-4309 (2013).

Robie, A. A, Straw, A. D and Dickinson, M.H. Object preference by walking fruit flies, Drosophila melanogaster, is mediated by vision and graviperception. $J$ Exp Biol. 2010 213(14): 2494-2506.

Severson DW, DeBruyn B, Lovin DD, Brown SE, Knudson DL, Morlais I. (2004). Comparative genome analysis of the yellow fever mosquito Aedes aegypti with Drosophila melanogaster and the malaria vector mosquito Anopheles gambiae. $J$. Hered. 95(2):103-13.

Taylor, G. C. \& Krapp, H. G. Sensory systems and flight stability: what do insects measure and why? in Insect Mech. Control (eds. Casas, J. \& Simpson, S. J.) 34, 231-316 Academic Press: London, 2008.

Theobald, J. C., Duistermars, B. J., Ringach, D. L. \& Frye, M. A. Flies see second-order motion. Curr. Biol. 18, R464-R165 (2008).

Theobald, J. C., Shoemaker, P. A., Ringach, D. L. \& Frye, M. A. Theta motion processing in fruit flies. Front. Behav. Neurosci. 4, (2010).

Turner, S.L., Li, N., Guda, T., Githure, J., Cardé, R.T., and Ray, A. (2011). Ultraprolonged activation of $\mathrm{CO}_{2}$-sensing neurons disorients mosquitoes. Nature 474, 87-91.

van Breugel, F., Riffell, J., Fairhall, A. \& Dickinson, M. H. (2015). Mosquitoes Use Vision to Associate Odor Plumes with Thermal Targets. Curr. Biol. doi:10.1016/j.cub.2015.06.046

Vinauger, C., van Breugel, F., Locke, L. T., Tobin, K.S., Dickinson, M. H., Fairhall, A., Akbari, O. S., Riffell, J. A. (2019). Visual-olfactory integration in the human disease vector mosquito, Aedes aegypti. bioRxiv 512996

Willis, M. A. \& Arbas, E. A. Odor-modulated upwind flight of the sphinx moth, Manduca sexta L. J. Comp. Physiol. A 169, 427-440 (1991). 


\section{Chapter 5: Conclusions and Future Directions}

"Progress in science depends on new techniques, new discoveries and new

ideas, probably in that order."

\section{Sydney Brenner}

\subsection{Conclusions}

Mosquitoes must bite to transmit diseases to humans. This observation stresses the importance of understanding how mosquitoes find their human hosts. The specific genes and neural circuits mosquitoes use when host-seeking are largely unknown, but it is clear that olfaction plays an essential role at a far distance, whereas visual cues are critical at close range. We present evidence that strongly suggests that $\operatorname{Ir} 8 a$ is a crucial mediator of mosquito attraction to humans and human odor. Ir $8 a$ is necessary for the electrophysiological response of the mosquito antenna to acidic volatiles found in human odor including lactic acid. It is also shown that $\operatorname{Ir} 8 a$ enables mosquito attraction to humans, human odor, and lactic acid. By varying $\mathrm{CO}_{2}$ in our behavioral assays and testing the genetic interactions between $\operatorname{Ir} 8 a$ and orco as well as $\operatorname{Ir} 8 a$ and $G r 3$, the $\operatorname{Ir} 8 a$ pathway to the overall integration of human host cues by mosquitoes have been connected. Taken together, our evidence supports the conclusion that the Ir $8 a$ pathway is a key participant in the multimodal integration of host odor cues by Ae. aegypti mosquitoes whose absence cannot be compensated for by other olfactory receptors.

This study represents the first genetic analysis of the IR8a co-receptor in $A e$. aegypti and builds upon knowledge gained from studies in other Dipterans. In Drosophila, RNAi mediated knockdown of $\operatorname{Ir} 8 a$ and mutants lacking $\operatorname{Ir} 8 a$ showed physiological and behavioral defects in sensing acidic volatiles (Ai et al., 2013). 
Drosophila Ir8a mutants show humidity preference similar to wild-type controls suggesting that IR8a is not involved in humidity detection in this species (Enjin et al., 2016; Knecht et al., 2016). IRs other than IR8a have been reported to mediate taste (Ahn et al., 2017; Chen and Amrein, 2017; Hussain et al., 2016; Zhang et al., 2013), circadian rhythm (Chen et al., 2015), and thermosensation (Enjin et al., 2016; Knecht et al., 2016). Our evidence suggests that IR8a is not required for heat or $\mathrm{CO}_{2}$ detection as Ir8a mutants respond similarly to wild-type controls to these stimuli. It is likely that IR8a is a coreceptor specific for the olfactory detection of chemical stimuli in insects. Although the general principles of IR function are likely conserved in insects particularly amongst coreceptors like IR8a, there are likely to be species-specific differences. Given the crucial role played by $\operatorname{Ir} 8 a$ in host seeking, it is important to understand the mosquito odor-tuned IRs that require the Ir $8 a$ co-receptor and connect these IRs with their odor-ligands. These could be interesting molecular targets for repellent design.

We have shown that Ae. aegypti mosquitoes lacking the Ir8a co-receptor cannot detect acidic human odor volatiles. Ir $8 a$ mutants lose odor-evoked responses to lactic acid and all carboxylic acid compounds represented in the odor panel tested in this study. Lactic acid and carboxylic acids are a major component of human sweat and may distinguish humans from other vertebrate hosts (Cork and Park, 1996; Dekker et al., 2002; Steib et al., 2001). Lactic acid acts synergistically with certain volatile compounds to increase the attractiveness of either odor blends or human odor to mosquito vectors (Allan et al., 2010; Dekker et al., 2002; Okumu et al., 2010; Smallegange et al., 2005; Steib et al., 2001). We show that Ir8a is also necessary for female Ae. aegypti mosquitoes to behaviorally respond to lactic acid and human odor when tested in olfactometer assays. 


\subsection{Genetic pathways for mosquito host seeking}

Host odor detection involves the interaction of multiple olfactory receptor pathways. The IR8a pathway is non-redundant and specialized to respond to acidic human odor volatiles, while the ORs sense a more diverse class of compounds including ketones, alcohols, and esters, not represented in the IR8a chemical space. GR3 is necessary for the detection of $\mathrm{CO}_{2}$. The epistasis analysis of the Ir8a, orco and $\mathrm{Gr} 3$ genes informed our understanding for the role of carbon dioxide in the sensitization of Ae. aegypti mosquitoes to human odor. The $\mathrm{CO}_{2}$ activation of the GR3 pathway permits the downstream activation and synergistic interaction of the IR8a, the OR pathway, and other olfactory receptors to promote host odor detection (Figure 14).

Since host detection is not completely abolished in any of the single or double mutants we tested and the orco mutant phenotype can be eliminated by the addition of $\mathrm{CO}_{2}$, we predict that other olfactory receptors could be crucial for host odor detection. Candidate genes include $\operatorname{Ir} 25 a$ and $\operatorname{Ir} 76 b$ which sense amines, but it remains unclear which olfactory receptors are attuned to other chemical compounds present in human odor such as ammonia. In the tethered flight experiment, we provide evidence that the GR3 pathway is crucial for mosquito to integrate $\mathrm{CO}_{2}$ with visual cues. The possible pathway with which GR3 interacts with other olfactory receptors to enhance host detection has been clearly illustrated (Fig. 14). 


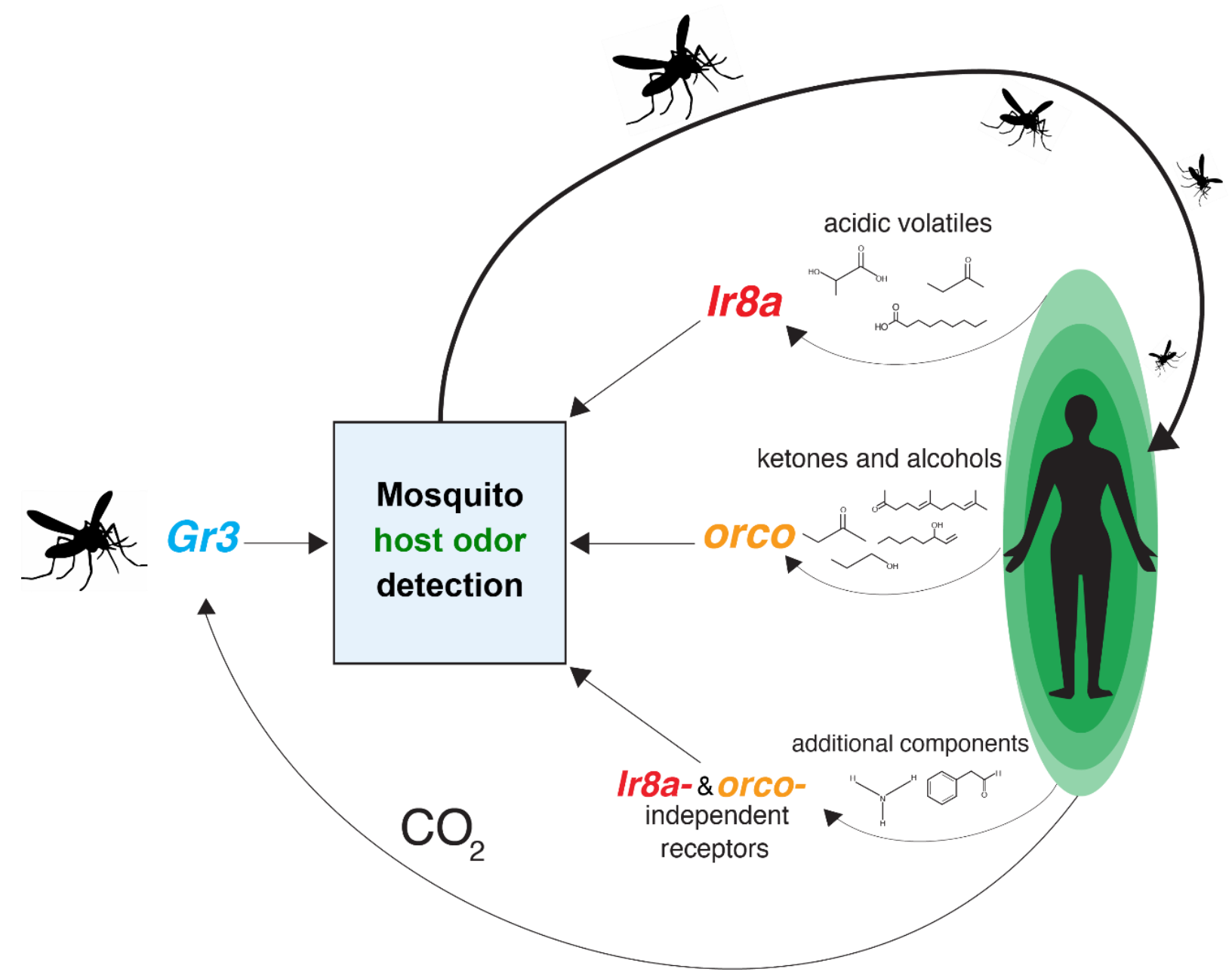

Figure 14. Model illustrating the genetic interactions between the olfactory receptor pathways during mosquito host detection. 


\subsection{Future directions}

Our results have implications not only for IRs but how the OR pathway (Orco and the odor-tuned ORs) and olfactory $\mathrm{CO}_{2}$-sensing GRs (GR1, GR2, and GR3) are integrated during mosquito host detection. The genetic evidence we present provides insight into how olfactory receptor pathways can genetically interact to mediate the detection of humans and their odor. However, the understanding of how these sensory responses are integrated to facilitate host detection is far from complete. Determining if the integration of cues occurs within the antennal lobe or in the mosquito brain will help reveal the dynamics of the innate neural circuits that enable mosquito host detection. Further study is necessary to uncover how mosquitoes sense their human hosts starting from the peripheral perception of cues, to the integration and processing of the information in the central nervous system, and finally, the motor circuit outputs that drive host-seeking behavior.

Molecular approaches that identify chemical compounds that hyper-activate olfactory receptor neurons in mosquitoes have been successfully established to provide a basis for developing next generation repellents (Chen and Luetje, 2012; Jones et al., 2011; 2012). This study implicates IR8a, Orco, and GR3 as promising targets to control mosquito-borne illnesses. High throughput screening assays can be used to identify chemical compounds that modulate the function of these receptor genes (Rinker et al., 2012). This can be used to design attractants and repellents to control mosquito behavior that are more effective than DEET (DeGennaro, 2015). Chemical compounds that activate these receptors can be used to lure mosquitoes into an odor-baited trap. 
Alternatively, humans can be made more difficult to detect using chemical compounds that inhibit these receptors. However, host-seeking behavior is ablated but not totally abolished in all the mutants screened in the study. It is worthy of note that $\operatorname{Ir} 25 a$ and $\operatorname{Ir} 76 b$, which remain intact in the mutants lacking the $\operatorname{Ir} 8 a$ - and orco-dependent olfactory receptor pathways could be responsible for the residual host-seeking seen in these double mutants. A recent study has shown that An. gambiae Ir $25 a$ and $\operatorname{Ir} 76 b$ receptors are tuned to amines (Pitts et al., 2017), a class of chemical compounds found in human skin emanations (Bernier et al., 2000). Ir25a is also crucial for sensing other cues that facilitate human hosts detection such as moisture and temperature (Enjin et al., 2016; Knecht et al., 2016; 2017). Future work is needed to identify the complete list of the olfactory receptors that are necessary for mosquito host seeking to determine how many molecular targets will need to be screened.

The functional characterization of the ionotropic chemoreceptor family in $A e$. aegypti is an important step towards understanding olfactory-driven behavior in an insect that continues to negatively impact human health in large areas of the world (Leta et al., 2018). It is expected that the evidence provided in this study will be applicable to other mosquito vectors. Current vector control strategies have been insufficient to stop the spread of arboviruses or eliminate malaria (Enayati and Hemingway, 2010; Fernandes et al., 2018). The use of insecticide treated bed nets and indoors residual spraying have been effective in reducing malaria cases by half since 2000, but resistance to insecticides is widespread and growing. Bed nets are also ineffective against day-biting mosquitoes such as Ae. aegypti. Thus, it is imperative to develop alternative vector control strategies. 
Our investigation on the role of IR8a also led us to uncovering its role in mediating strong attraction to water. Mosquitoes use humidity cues to successfully navigate the environment in search for a suitable oviposition site and also to rehydrate when thirsty. We propose that $\operatorname{Ir} 8 a$ may be important for finding a suitable habitat that is less humid. Future study is needed to uncover the relative contribution of the Ae. aegypti IR8a pathway in water-seeking behavior. A comprehensive understanding of genes like Ir $8 a$ that enable mosquito attraction to humans and water may provide molecular targets to generate new behavioral control reagents that could alter their sensory system from detecting a oviposition site. It could inform our knowledge on finding repellents to prevent mosquito bites as well as attractants to improve mosquito surveillance and population reduction strategies.

Having explored the aspect of visual and olfactory integration in Ae. aegypti, we learned that $\mathrm{CO}_{2}$ can make mosquitoes pilot a fictive course and enhance their attention to an inanimate visual representation. A comparative study of spatial and temporal acuity in the mosquitoes would be a step forward to understanding how behavior can modulate visual perception. Given that mosquito host seeking behavior is state dependent, it is unknown whether gravid blood-fed female mosquitoes would prefer wide field motion, which could indicate an oviposition site. Future study is needed to determine if stages of mosquito gonotrophic cycle can influence visual and olfactory processing. The neurophysiological basis of olfactory driven behavior has only begun to be understood (Lutz et al., 2017), however relatively less is known about visual-olfactory integration in the insect brain. Addressing these research gaps would enhance our understanding of how $\mathrm{CO}_{2}$ modulates visuomotor reflexes in insects. 


\section{References}

Ahn, J.-E., Chen, Y., and Amrein, H. (2017). Molecular basis of fatty acid taste in Drosophila. eLife 6, 44.

Ai, M., Blais, S., Park, J.-Y., Min, S., Neubert, T.A., and Suh, G.S.B. (2013). Ionotropic glutamate receptors IR64a and IR8a form a functional odorant receptor complex in vivo in Drosophila. J Neurosci 33, 10741-10749.

Allan, S.A., Bernier, U.R., and Kline, D.L. (2010). Laboratory evaluation of lactic acid on attraction of Culex spp. (Diptera: Culicidae). J Vector Ecol 35, 318-324.

Bernier, U.R., Kline, D.L., Barnard, D.R., Schreck, C.E., and Yost, R.A. (2000). Analysis of human skin emanations by gas chromatography/mass spectrometry. 2 .

Identification of volatile compounds that are candidate attractants for the yellow fever mosquito (Aedes aegypti). Anal. Chem. 72, 747-756.

Chen, C., Buhl, E., Xu, M., Croset, V., Rees, J.S., Lilley, K.S., Benton, R., Hodge, J.J.L., and Stanewsky, R. (2015). Drosophila Ionotropic Receptor 25a mediates circadian clock resetting by temperature. Nature 527, 516-520.

Chen, S., and Luetje, C.W. (2012). Identification of new agonists and antagonists of the insect odorant receptor co-receptor subunit. PLoS ONE 7, e36784.

Chen, Y., and Amrein, H. (2017). Ionotropic Receptors Mediate Drosophila Oviposition Preference through Sour Gustatory Receptor Neurons. Curr Biol 27, 27412750.e2744.

Cork, A., and Park, K.C. (1996). Identification of electrophysiologically-active compounds for the malaria mosquito, Anopheles gambiae, in human sweat extracts. Med Vet Entomol 10, 269-276.

DeGennaro, M. (2015). The mysterious multi-modal repellency of DEET. Fly 9, 45-51.

Dekker, T., Steib, B., Carde, R.T., and Geier, M. (2002). L-lactic acid: a humansignifying host cue for the anthropophilic mosquito Anopheles gambiae. Med Vet Entomol 16,91-98.

Enayati, A., and Hemingway, J. (2010). Malaria management: past, present, and future. Annu. Rev. Entomol. 55, 569-591.

Enjin, A., Zaharieva, E.E., Frank, D.D., Mansourian, S., Suh, G.S.B., Gallio, M., and Stensmyr, M.C. (2016). Humidity Sensing in Drosophila. Curr Biol 26, $1352-$ 1358. 
Fernandes, J.N., Moise, I.K., Maranto, G.L., and Beier, J.C. (2018). Revamping Mosquito-borne Disease Control to Tackle Future Threats. Trends Parasitol 34, 359-368.

Hussain, A., Zhang, M., Üçpunar, H.K., Svensson, T., Quillery, E., Gompel, N., Ignell, R., and Grunwald Kadow, I.C. (2016). Ionotropic Chemosensory Receptors Mediate the Taste and Smell of Polyamines. PLoS Biol 14, e1002454.

Jones, P.L., Pask, G.M., Rinker, D.C., and Zwiebel, L.J. (2011). Functional agonism of insect odorant receptor ion channels. Proc Natl Acad Sci USA 108, 8821-8825.

Jones, P.L., Pask, G.M., Romaine, I.M., Taylor, R.W., Reid, P.R., Waterson, A.G., Sulikowski, G.A., and Zwiebel, L.J. (2012). Allosteric antagonism of insect odorant receptor ion channels. PLoS ONE 7, e30304.

Knecht, Z.A., Silbering, A.F., Ni, L., Klein, M., Budelli, G., Bell, R., Abuin, L., Ferrer, A.J., Samuel, A.D., Benton, R., et al. (2016). Distinct combinations of variant ionotropic glutamate receptors mediate thermosensation and hygrosensation in Drosophila. eLife 5, 44.

Knecht, Z.A., Silbering, A.F., Cruz, J., Yang, L., Croset, V., Benton, R., and Garrity, P.A. (2017). Ionotropic Receptor-dependent moist and dry cells control hygrosensation in Drosophila. eLife 6, 44.

Leta, S., Beyene, T.J., De Clercq, E.M., Amenu, K., Kraemer, M.U.G., and Revie, C.W. (2018). Global risk mapping for major diseases transmitted by Aedes aegypti and Aedes albopictus. Int. J. Infect. Dis. 67, 25-35.

Okumu, F.O., Killeen, G.F., Ogoma, S., Biswaro, L., Smallegange, R.C., Mbeyela, E., Titus, E., Munk, C., Ngonyani, H., Takken, W., et al. (2010). Development and field evaluation of a synthetic mosquito lure that is more attractive than humans. PLoS ONE 5, e8951.

Pitts, R.J., Derryberry, S.L., Zhang, Z., and Zwiebel, L.J. (2017). Variant Ionotropic Receptors in the Malaria Vector Mosquito Anopheles gambiae Tuned to Amines and Carboxylic Acids. Sci Rep 7, 40297.

Rinker, D.C., Jones, P.L., Pitts, R.J., Rutzler, M., Camp, G., Sun, L., Xu, P., Dorset, D.C., Weaver, D., and Zwiebel, L.J. (2012). Novel high-throughput screens of Anopheles gambiae odorant receptors reveal candidate behaviour-modifying chemicals for mosquitoes. Physiological Entomology 37, 33-41.

Smallegange, R.C., Qiu, Y.T., van Loon, J.J.A., and Takken, W. (2005). Synergism between ammonia, lactic acid and carboxylic acids as kairomones in the hostseeking behaviour of the malaria mosquito Anopheles gambiae sensu stricto (Diptera: Culicidae). Chem Senses 30, 145-152. 
Steib, B.M., Geier, M., and Boeckh, J. (2001). The effect of lactic acid on odour-related host preference of yellow fever mosquitoes. Chem Senses 26, 523-528.

Zhang, Y.V., Ni, J., and Montell, C. (2013). The Molecular Basis for Attractive SaltTaste Coding in Drosophila. Science 340, 1334-1338. 
VITA

JOSHUA I. RAJI

2010

2014

2019

2019

2016-2017

2016-2018

2017-2018

2018-2019

2018-2019

2018-2019

2016

2017

2017

2017

2018

2018

2018
Bachelor of Technology, Biology

Federal University of Technology, Akure

Master of Science, Cell Biology and Genetics

University of Lagos

Certificate in University Teaching and Learning

Florida International University, Miami, Florida

Doctoral Candidate

Florida International University, Miami, Florida
Treasurer, Biology Graduate Student Association, FIU

Head Teaching Assistant, Genetics Lab (PCB3063L), FIU

Mentoring committee, First year Biology Graduate Students, FIU

Student representative, Graduate Student Advisory Board, FIU

Graduate Teaching Assistant Mentor, CAT-FIU.

Chair, Incoming Biology Graduate Students Mentoring Committee, FIU

Student Government Association Scholarship

Florida International University (FIU), Miami.

Most Promising Science, Journal of Medical Microbiology.

Biomedical, Comparative and Immunology Symposium. Miami.

Third place oral presentation in Arts, Science and Education.

Graduate Student Appreciation Week, FIU.

Second place, oral presentation competition

BioSymposium, Biscayne Bay, Florida

First place oral presentation in Arts, Science and Education. Graduate Student Appreciation Week, FIU.

Outstanding Graduate Teaching Assistant, Provost award.

Graduate Student Appreciation Week, FIU.

T. Wainwright Miller, Jr. Scholarship

Florida Mosquito Control Association, St. Petersburg, Florida. 
Travel grant

Graduate Student Organization

2019

Best 3 Minute Thesis presentation

BioSymposium, Biscayne Bay, Florida

2019

Honorable mention, Student paper competition

American Mosquito Control Association, Orlando, Florida

2019

Newsletter recognition

CDC-Centre of Excellence in Vector Borne Diseases, Florida

2019

President's prize

Entomological Society of America, Mobile, Alabama

2019

Best PhD. paper competition

Florida Entomological Society, Jupiter, Florida

2019

Dissertation Year Fellowship,

Florida International University, Miami, Florida

Publications

Raji, J. I., (2015). Genomics and Genetics of Wobalchia: A Review. South Pacific Journal of Pharma and Bio Science, 3(1), 240-246. ISSN 2310-4899

Raji, J. I and DeGennaro, M., (2017). Genetic Analysis of Mosquito Detection of Humans. Current Opinion in Insect Science 20: 34-38

Dave-Agboola, I. and Raji, J.I. (2018). Health seeking behavior of malaria patients in Nigeria. International Journal of Health Sciences and Research 8 (7), 259-264

Raji, JI., Melo, N., Castillo, J., Gonzalez, S., Saldana, V., Stensmyr, M., and DeGennaro, M. (2019). Aedes Aegypti Mosquitoes Detect Acidic Volatiles Found in Human Odor Using the IR8a Pathway. Current Biology 29, 1-10. Available at SSRN 3280246

Raji, JI., Gonzalez, S., and DeGennaro, M. (2019). Aedes aegypti Ir8a mutant female mosquitoes show increased attraction to standing water. Journal of Communicative and Integrative Biology, https://doi.org/10.1080/19420889.2019.1681063

Raji, JI., DeGennaro, M. and Theobald, J. Visuomotor reflex diversity in Aedes aegypti and Drosophila melanogaster. To be submitted to Journal of Comparative Physiology 